\title{
A Comprehensive Review on Thiophene Based Chemosensors
}

\author{
Rikitha S. Fernandes $^{1} \cdot$ Nitinkumar S. Shetty ${ }^{1}\left[\right.$ ] Priyanka Mahesha ${ }^{1} \cdot$ Santhosh L. Gaonkar ${ }^{1}$
}

Received: 5 August 2021 / Accepted: 27 September 2021 / Published online: 8 October 2021

(c) The Author(s) 2021

\begin{abstract}
The recognition and sensing of various analytes in aqueous and biological systems by using fluorometric or colorimetric chemosensors possessing high selectivity and sensitivity, low cost has gained enormous attention. Furthermore, thiophene derivatives possess exceptional photophysical properties compared to other heterocycles, and therefore they can be employed in chemosensors for analyte detection. In this review, we have tried to explore the design and detection mechanism of various thiophene-based probes, practical applicability, and their advanced models (design guides), which could be thoughtful for the synthesis of new thiophene-based probes. This review provides an insight into the reported chemosensors (2008-2020) for thiophene scaffold as effective emission and absorption-based chemosensors.
\end{abstract}

Keywords Thiophene $\cdot$ Fluorescence $\cdot$ Colorimetric probes $\cdot$ Detection $\cdot$ ICT $\cdot$ PET

\section{Introduction}

Over the years, the revolution in industrial and agricultural sectors has brought plenty of new products and services. Along with the production of useful technologies, these advancements utilize more chemicals to meet the requirements of the population. The release of such chemicals into the environment is mainly responsible for destroying the environmental and biotic systems. Many environmental pollutants such as heavy metals and other transition metals enter the environmental systems through natural and anthropogenic activities. These are detrimental to life due to their toxicity. Hence, detection of these metal ions is vital. Therefore, there is a need to develop convenient and realistic techniques for the quick detection of diverse metal ions in biological and ecological environments. The progress of selective optical signaling systems for ion detection is an emerging subject of interest in research from recent years due to the potentiality of such systems in analytical devices. Among the various available analytical tools for ion detection, fluorometric and colorimetric analysis are among the most important and most preferred optical tools that are used

Nitinkumar S. Shetty

nitin.shetty@manipal.edu

1 Department of Chemistry, Manipal Institute of Technology, Manipal Academy of Higher Education, 576104 Manipal, Karnataka, India for the detection of various ions and molecules in a particular system due to their high selectivity, fast response, better sensitivity, real-time monitoring [1], and bioimaging capability [2,3].

From this point of view, various chemosensors have been researched and reported for the discernment of ions. Chemosensors are molecules that show a slight change in their emission properties in response to their interaction with the binding ions of the surrounding environment [4]. Furthermore, it has been known that two important processes take place during the detection of the analyte. Firstly, being molecule recognition, and the second one being signal transduction. On this basis, chemosensors can be cataloged into a receptor that binds with the analyte of interest, an active unit that changes its properties upon binding to the analyte, and a spacer that can tune the electronic properties between the above two moieties [5].

As a requirement for designing chemosensors to detect specific analytes, three pivotal factors need to be taken into consideration: high selectivity, high sensitivity, and high specificity [5]. Designing an effectual chemosensor possessing both selectivity and sensitivity features for analyte detection is troublesome. Chemosensors are sensitive to changes in the environment [6] and hence they can be generally categorized according to the operating principle of the transducer (Fig. 1) [7].

Optical devices are based on the changes of optical phenomena, such as absorbance, reflectance, luminescence, 
Fig. 1 General classification of chemosensors

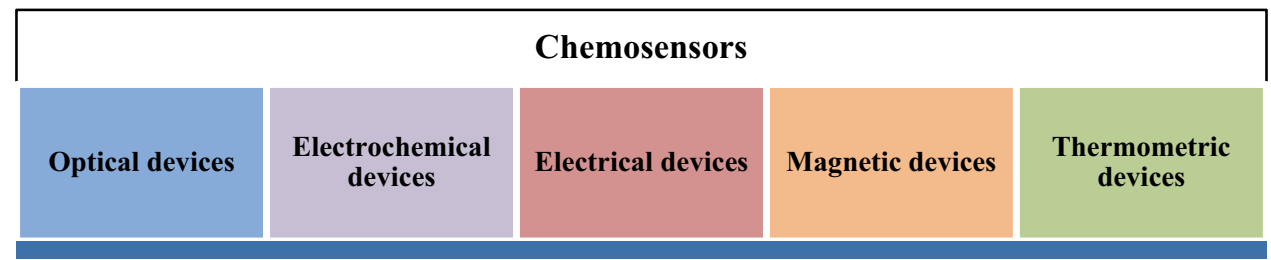

flourescence which is the outcome of an interaction of the analyte with the receptor of the sensor. Electrochemical devices transform the changes of the electrochemical interaction analyte - electrode into a signal which include voltammetric sensors, potentiometric sensors. Electrical devices sense the change in the electrical properties of the analyte without any electrochemical processes. Few examples are electrolytic conductivity sensors, electric permittivity sensors. Further, magnetic devices rely on the change of paramagnetic properties of a gas which is being analysed. Lastly, thermometric devices are based on the measurement of the heat effects of a specific chemical reaction or adsorption that involves the analyte.

Nevertheless, the detection of analytes or ions through chemosensors is usually attained by the selective coordination to the target analyte resulting in the change in the intensity of fluorescence of the fluorophore with the concentration change of ions [8], via photo-physical mechanisms such as chelation induced enhanced fluorescence (CHEF) [9], photoinduced electron transfer (PET) [10], intramolecular charge transfer (ICT) [11], Foster Resonance Energy Transfer (FRET) $[12,13]$ and various other approaches. These chemosensors provide a highly sensitive, inexpensive, reliable alternative along with simple visualization of analytes without sophisticated instruments [14].

One of the extensively used chemosensors is thiophenebased (thiophene derivatives), and they have been employed as a fluorescence signaling promoter to organic acids, metal ions, and cations [15]. Thiophene is one of the most studied five-membered heterocyclic compounds. It has been observed that five-membered heterocyclic compounds often show strong photoluminescence properties, such as long emission and absorption wavelengths, vast absorption co-efficient, and more fluorescence quantum yield, it is widely used in light-emitting materials [16] and therefore, the thiophene moiety can be employed as a functional group as a part of the chemosensor. Because of its high potential of structural variation, along with the high polarizability of sulfur atoms in the ring results in a stabilization of the conjugated chain, thereby having magnificent electronic and charge-transfer properties [17]. Oligo and polythiophenes have fluorescence frequencies that are tunable over a broad visible range and possess high absorbencies and high fluorescence efficiencies [18] and therefore, they are being employed as fluorometric and colorimetric chemosensors for the detection of proteins.

The main objective of this review is to focus light on the recent progress in the development of thiophene-based chemosensors that have been employed for the detection of cations $\left(\mathrm{Al}^{3+}, \mathrm{In}^{3+}, \mathrm{Hg}^{2+}, \mathrm{Pb}^{2+}, \mathrm{Cr}^{3+}, \mathrm{Zn}^{2+}\right.$, etc.) and anions $\left(\mathrm{CN}^{-}, \mathrm{F}^{-}, \mathrm{I}^{-}\right.$etc.). The chemical and physical interactions of these sensors with the analytes resulting in changes in the emission intensity and probe color are explored. The practical applications of these probes in the real world are also summarised.

\section{Thiophene Based Chemosensors for Detection of Cations}

Thiophene-based chemosensors provide a novel approach with an easy synthetic route and cost-effective technique for selective and quantitative detection of metal ions in biological and environmental systems. The coordination of a cation to a fluorescent chemosensor might enhance the fluorescence emission, called as Chelation Enhanced Fluorescence Effect (CHEF), or quench the fluorescence emission, called as Chelation Enhancement Quenching Effect (CHEQ). These changes in the emission intensity are employed for analyte detection.

\section{Aluminium}

Aluminium is the most abundant non-ferrous metal in the earth's crust. Most of the foods and antiperspirants contain aluminium compounds, and hence we are exposed to them daily. However, excessive exposure to $\mathrm{Al}^{3+}$ to the human body can cause awful illnesses like Parkinson's and Alzheimer's disease [19], threatens aquatic species by clogging the gills due to aluminium accumulation [20], and also affects plant growth and development. Therefore, there is a necessity for the development of chemosensors for the recognition of aluminium ions.

Considering the harmful effects, Jeong et al. designed a multifunctional fluorescent 'turn-on' chemosensor 1 using the thiophene moiety along with the diethyl aminophenol moiety (electron-donor) for the recognition of $\mathrm{Al}^{3+}$ in a nearperfect aqueous solution. The UV-Vis titration in bis-tris buffer ( $\mathrm{pH}$ 7.0) revealed that, upon the addition of $\mathrm{Al}^{3+}$, the 


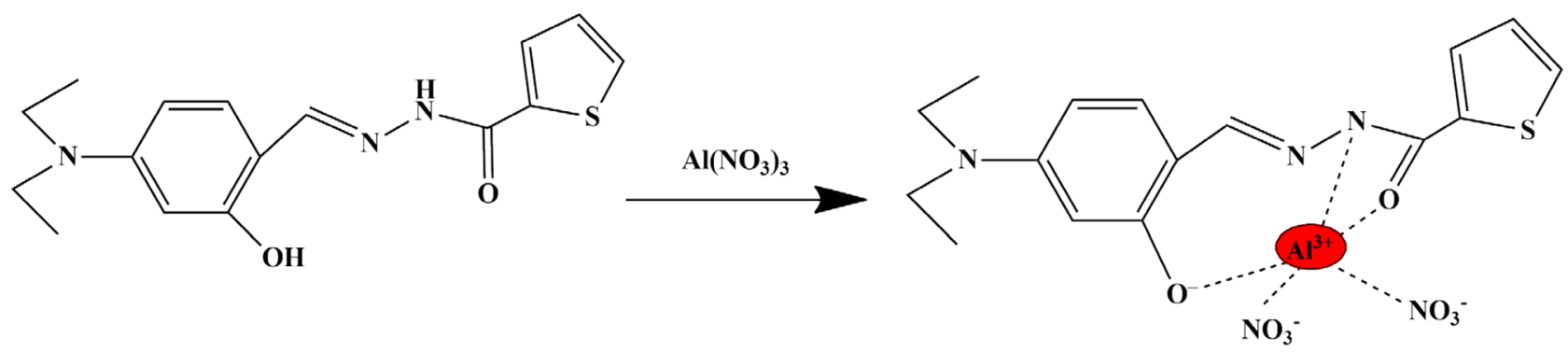

Scheme 1 Proposed mechanism of sensor 1 with $\mathrm{Al}^{3+}$

absorption intensity of the peak at $370 \mathrm{~nm}$ lessened and the absorption intensity at $420 \mathrm{~nm}$ increased, therefore showing high selectivity towards $\mathrm{Al}^{3+}$ ions. It was also found that the fluorescence intensity of the chemosensor escalated only in the presence of $\mathrm{Al}^{3+}$ ions. Job's plot analysis showed that there was a 1:1 stoichiometric ratio between $\mathrm{Al}^{3+}$ and chemosensor, and the better selectivity of the fluorescent chemosensor towards $\mathrm{Al}^{3+}$ (hard acid) is attributable to the presence of two oxygen atoms (hard base). Furthermore, the binding constant of chemosensor 1 calculated from BenesiHildebrand was found to be $7.56 \times 10^{2}$, and the LOD (Limit of Detection) was observed to be $0.41 \mu \mathrm{M}$.

Furthermore, evaluation of the feasibility of chemosensor 1 for $\mathrm{Al}^{3+}$ detection biological systems was carried out by in vitro cell imaging experiments using HeLa cells, and it was found that the fluorescence intensity augmented with the increase of $\mathrm{Al}^{3+}$ ion concentration in the cells, thereby indicating that the fluorescent chemosensor could be employed as a biocompatible detector in the determination of $\mathrm{Al}^{3+}$ ions in biological systems. The proposed sensing mechanism for $\mathrm{Al}^{3+}$ detection was ICT and deprotonation by hydrogen bonding (Scheme 1), as supported by TD-DFT and DFT studies [15].

Manjunath et al. synthesized thiophene appended pyrazoline based 'Turn-off' fluorescent chemosensor $\mathbf{2}$ and evaluated its sensing properties in HEPES buffer solution at $\mathrm{pH}$
7.2. The UV-Vis absorption band at $358 \mathrm{~nm}$ exhibited by the free 2 sensor shifted to $349 \mathrm{~nm}$ thereby exhibiting decreased intensity upon the addition of $\mathrm{Al}^{3+}$ ions only due to the coordination of sensor 2 with $\mathrm{Al}^{3+}$ ion (Scheme 2). Furthermore, the free sensor $\mathbf{2}$ showed deep blue fluorescence emission at $447 \mathrm{~nm}$, which was further quenched only in the presence of $\mathrm{Al}^{3+}$. The association constant for the binding of $\mathrm{Al}^{3+}$ ion in 2 was determined to be $1.84 \times 10^{4} \mathrm{M}^{-1}$ with $1: 1$ stoichiometry [21] and the LOD for $\mathrm{Al}^{3+}$ was $8.92 \times 10^{-8} \mathrm{M}$, which was sufficiently lower than the permissible levels of $\mathrm{Al}^{3+}$ in drinking water as set up by $\mathrm{WHO}$, thereby showing potential to examine drinking water quality.

\section{Indium}

Indium is used in biological and diagnostic disciplines, such as in treating cancer or other radiopharmaceuticals, owing to its less toxicity. But compounds of Indium, namely Indium phosphate (IP) and Indium tin oxide (ITO), have been recognized to have potential risk for respiratory diseases. Hence, detecting indium selectively is in high demand. Significantly, few fluorescent chemosensors have been developed to detect indium since inhibition from $\mathrm{Al}^{3+}$ and $\mathrm{Ga}^{3+}$ (belonging to the same group of metal ions) occurs. Thus, there is a need to develop selective chemosensors by fluorescent 'turn on' method for differentiating $\mathrm{In}^{3+}$ from $\mathrm{Al}^{3+}$ and $\mathrm{Ga}^{3+}$ ions.
Scheme 2 Sensing mechanism of chemosensor 2 to $\mathrm{Al}^{3+}$ ions

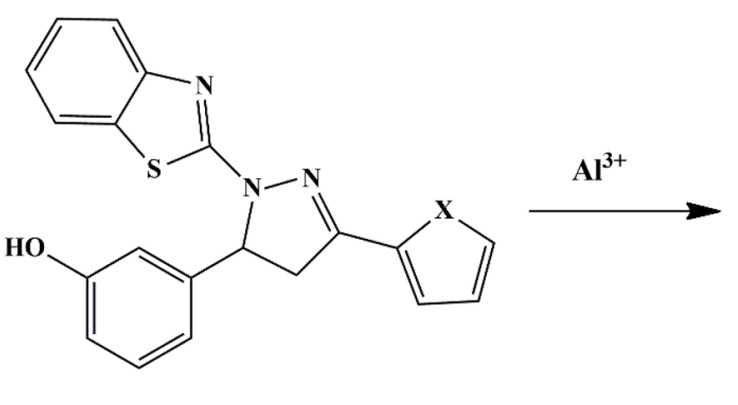

2

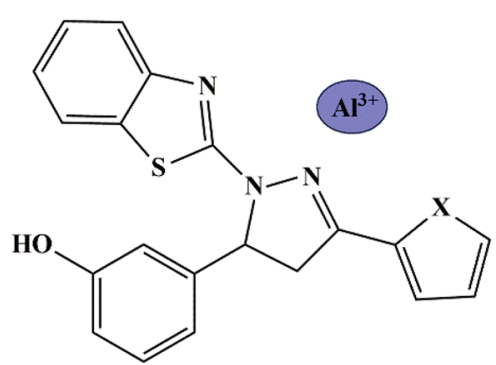

$2-\mathbf{A l}^{3+}$ 
<smiles>O=C(N/N=C/c1ccccn1)c1cccs1</smiles>

Scheme 3 Sensing mechanism of chemosensor 3 towards $\operatorname{In}^{3+}$

In this regard, Hanna Cho designed the synthesis of 'Turn-on' chemosensor 3 [(Z)-N'-(pyridine-2-ylmethylene)thiophene-2carbohydrazide] by integrating thiophene-2-carbohydrazide with picolinaldehyde. When $\mathrm{Cd}^{2+}, \mathrm{Al}^{3+}, \mathrm{Cu}^{2+}$, etc., were added to the chemosensor TP in $\mathrm{EtOH}$, there was no significant fluorescent response, except for $\operatorname{In}^{3+}$, which showed a fluorescence emission at $460 \mathrm{~nm}$ [22] due to the CHEF effect. The distinctive selectivity of probe $\mathbf{3}$ towards $\mathrm{In}^{3+}$ is assigned to the size effect and the hard-soft principle, indicating that it could effectively distinguish $\mathrm{In}^{3+}$ from $\mathrm{Al}^{3+}$ and $\mathrm{Ga}^{3+}$ because of their alike properties [23] (Scheme 3). UV-Vis titration showed that the absorption band (exhibited by the free sensor) gradually decreased at $310 \mathrm{~nm}$ and a new band at $379 \mathrm{~nm}$ emerged due to the presence of $\mathrm{In}^{3+}$. The association constant for the 2. (3) $-\mathrm{In}^{3+}$ complex was determined by Li's equation to be $8.1 \times 10^{4} \mathrm{M}^{-2}$. The LOD was estimated to be $0.61 \mu \mathrm{M}$, which was sufficiently lowest amid all the formerly reported chemosensors for $\mathrm{In}^{3+}$ detection.

\section{Mercury}

For decades, heavy metal pollution of the environment has been a significant issue due to its threat to biotic life [24, 25].
One of the most hazardous and commonly occurring heavy metal [26] pollution in the aqueous system is mercury pollution since $\mathrm{Hg}^{2+}$ ions can remain persistent in the aqueous environment and even a minute amount of $\mathrm{Hg}^{2+}$ ions cause health issues such as respiratory damage, gastrointestinal problems, Minamata disease, and prenatal brain damage. Mercury ion is spectroscopically and magnetically silent $\left(\mathrm{d}^{10}\right)$ [27] and therefore cannot be rapidly detected by the available detection techniques such as NMR and EPR. Thus, there is an essential need for new chemosensors to detect $\mathrm{Hg}^{2+}$ ions in the aqueous system.

In this regard, Zhang et al. developed a thiophene-based ratiometric fluorescent chemosensor $\mathbf{4}$ possessing triphenylamine and benzothiadiazole moieties, since thiophene can outstretch the $\pi$ conjugation and also stabilize the quinoid structure and contribute in tuning the energy gap of the $\mathrm{D}-\pi-\mathrm{A}-\pi-\mathrm{D}$ type of chromophore, and the presence of the $\pi$ bridge of thiophene could increase the fluorescence resonance wavelength up to $80 \mathrm{~nm}$. UV-Vis absorbance spectra of probe 4 revealed that only $\mathrm{Hg}^{2+}$ promoted a redshift from $489 \mathrm{~nm}$ to $535 \mathrm{~nm}$, accompanied by red to violet color change. Probe 4 exhibited a drop in the fluorescent intensity band centered at $656 \mathrm{~nm}$ and an increase in the band<smiles>CCSC(SCC)c1cc(-c2ccc(-c3cccc(N(c4ccccc4)c4cccc(C(C)C)c4)c3)s2)c2nsnc2c1-c1cccc(N(c2ccccc2)c2cccc(N(c3ccccc3)c3cccc(-c4ccc(-c5cc(C=O)c(-c6ccc(C7=CC=Cc8ccccccc7n8-c7ccccc7)s6)c6nsnc56)s4)c3)c2)c1</smiles>

Scheme 4 Sensing mechanism of chemosensor 4 with $\mathrm{Hg}^{2+}$ 
<smiles>CC(C)(C)c1cc(NCCOc2cccc3cccnc23)cc(-c2ccc(-c3ccc(-c4ccc(C(C)(C)C)s4)c4nsnc34)s2)c1</smiles>

5

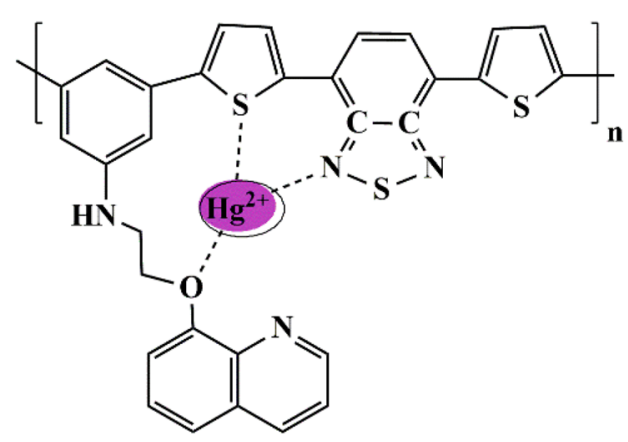

$5-\mathrm{Hg}^{2+}$

Scheme 5 Plausible sensing mechanism of probe 5 towards $\mathrm{Hg}^{2+}$

centered at $723 \mathrm{~nm}$ [28], only in the presence of the $\mathrm{Hg}^{2+}$ without interference from other competing metal ions. The LOD was determined to be $0.36 \mu \mathrm{M}$ for $\mathrm{Hg}^{2+}$ ions. Furthermore, the sensing mechanism was found to be due to the Mercury-promoted desulfurization reaction (Scheme 4).

Over the last few years, the $\pi$-conjugated polymer has gained increased attention due to its excellent optical properties and signal amplification because of repeating units. Based on these properties, Liheng et al. synthesized a redemitting 'Turn-on' polymer fluorescent probe 5 occupying thiophene, benzothiazole, and quinoline groups for specific sensing of $\mathrm{Hg}^{2+}$ ions and evaluated its potential in practical applications (in cosmetics). It was noticeable that only $\mathrm{Hg}^{2+}$ ions could enhance the fluorescence intensity of the probe in DMSO, which was evident by the color change from blue to red (under UV light) and could be explained based on the PET process [29] (Scheme 5). The binding of probe 5 and $\mathrm{Hg}^{2+}$ was found to be in a 1:1 stoichiometric ratio, and the response time was quick, being less than $10 \mathrm{~s}$. It was observed that similar fluorescence changes of probe $\mathbf{5}$ could also be observed with the increase of $\mathrm{Hg}^{2+}$ ions in cosmetics, thereby making it a valuable tool for the monitoring of $\mathrm{Hg}^{2+}$ in practical applications.

Nanostructured materials possess unique physical and chemical properties and possess potential applications in catalysis, sensors, and magnetic devices. Considering these into account, Chatteikaewtong et al. synthesized a terthiophene functionalized rhodamine fluorescence resonance energy transfer (FRET)-based chemosensor $\mathbf{6}$ and probe 6-gold nanocomposite based-chemosensor 7 for $\mathrm{Hg}^{2+}$ recognition. It was observed that the fluorescence spectra and UV-Vis spectra of probe 6 exhibited a high-fluorescence band at $578 \mathrm{~nm}$ and an absorbance intensity of $555 \mathrm{~nm}$, respectively, upon the addition of $\mathrm{Hg}^{2+}$ ions only, owing to the $\mathrm{Hg}^{2+}$ induced ring-opening of the spirolactam Rhodamine form (Scheme 6). The absorption spectra of probe 7 exhibited a significant redshift, with the color change from colorless to black, and were credibly due to the aggregation

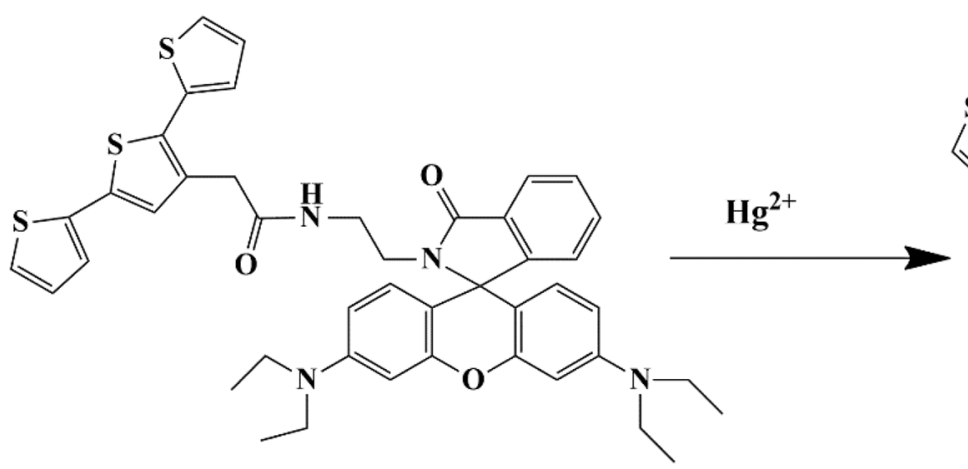

6

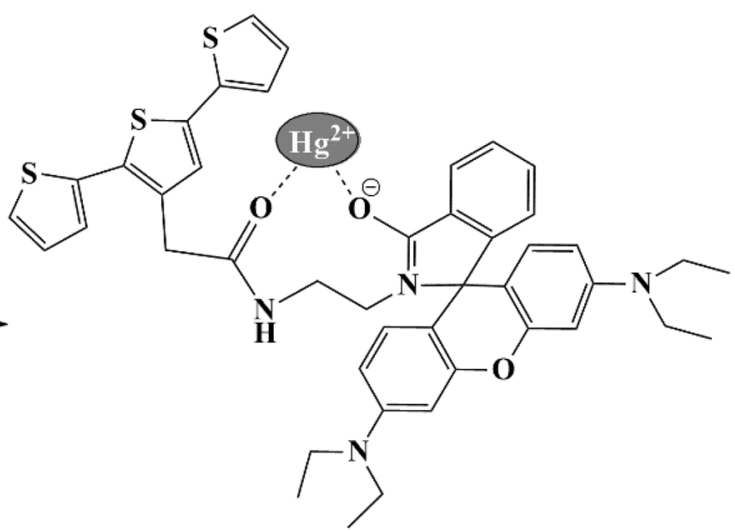

$6-\mathrm{Hg}^{2+}$

Scheme 6 A suggested mechanism for sensor 6 towards $\mathrm{Hg}^{2+}$ 


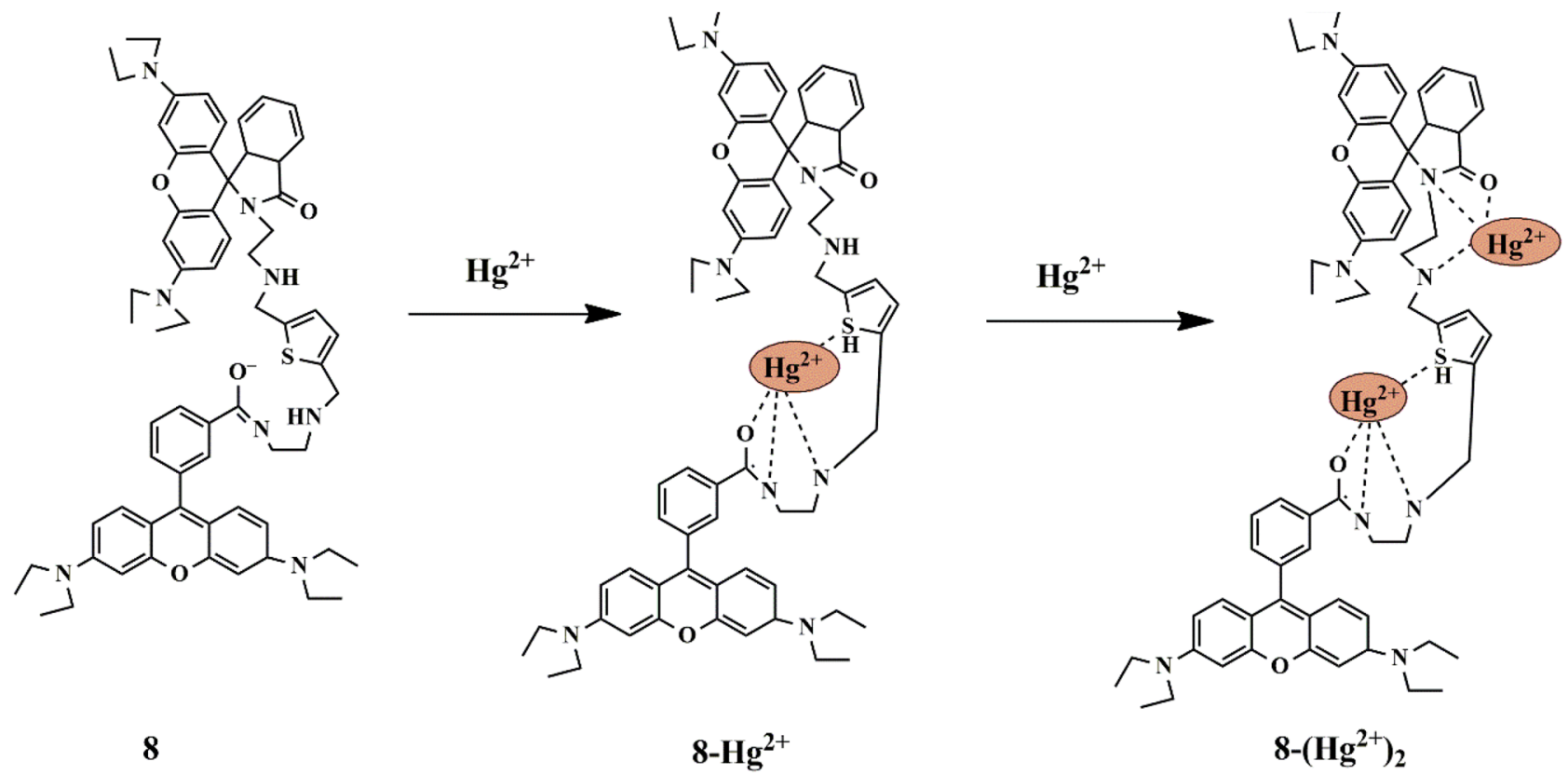

Scheme 7 Sequential complexation of $\mathrm{Hg}^{2+}$ ions to sensor 8

of gold nanoparticles by $\mathrm{Hg}^{2+}$ chelation, and was evident by TEM images. A 2:1 binding ratio for the probe $6-\mathrm{Hg}^{2+}$ and probe $7-\mathrm{Hg}^{2+}$ complex was concluded, and the LOD of probe 7 was calculated to be $0.32 \mu \mathrm{M}$ which was relatively lower [30] compared to that of probe $6(\mathrm{LOD}=1.34 \mu \mathrm{M})$, and the detection time was less than $30 \mathrm{~s}$, thereby exhibiting a high sensitivity towards $\mathrm{Hg}^{2+}$ ions.

Considering the photophysical properties of thiophene and rhodamine, Ajoy Pal et al. synthesized a thiophene derivatized rhodamine chemosensor 8 [thiophene-2,5-di(methyl-amino-ethyl rhodamine)] for $\mathrm{Hg}^{2+}$ detection. The sensor in $\mathrm{CH}_{3} \mathrm{CN}$ exhibited a maximum absorption peak at $557 \mathrm{~nm}$ and an ensuing color change to pink in the presence of $\mathrm{Hg}^{2+}$ only. Further, UV-Vis spectral studies and fluorescence studies were carried out in $\mathrm{CH}_{3} \mathrm{CN} / \mathrm{H}_{2} \mathrm{O}$ mixture to confirm the sensing property of sensor $\mathbf{8}$ towards $\mathrm{Hg}^{2+}$, and it was evident that only $\mathrm{Hg}^{2+}$ ions imparted an immediate color change from colorless to pink with maximum fluorescence. However, the other tested metal ions exhibited negligible fluorescence enhancement. The absorbance and fluorescence changes could be assigned to the metal ioninduced spiro-ring opening of rhodamine moiety. The LOD and metal ion/ligand binding stoichiometry was $2.2 \times 10^{-8} \mathrm{M}$ and 1:2 respectively. The interaction between sensor 8 and $\mathrm{Hg}^{2+}$ was evidenced from ESI-MS analysis, which suggested that sensor 8 selectively binds to the first $\mathrm{Hg}^{2+}$ ion via one of its 'amino-ethyl-amido' units along with its central sulphur atom, which then promotes a spatial reorientation of the ligand and results in a faster binding of the second $\mathrm{Hg}^{2+}$ ion (Scheme 7). To examine its reusability, $\mathrm{CO}_{3}{ }^{2-} / \mathrm{HCO}_{3}{ }^{-}$and

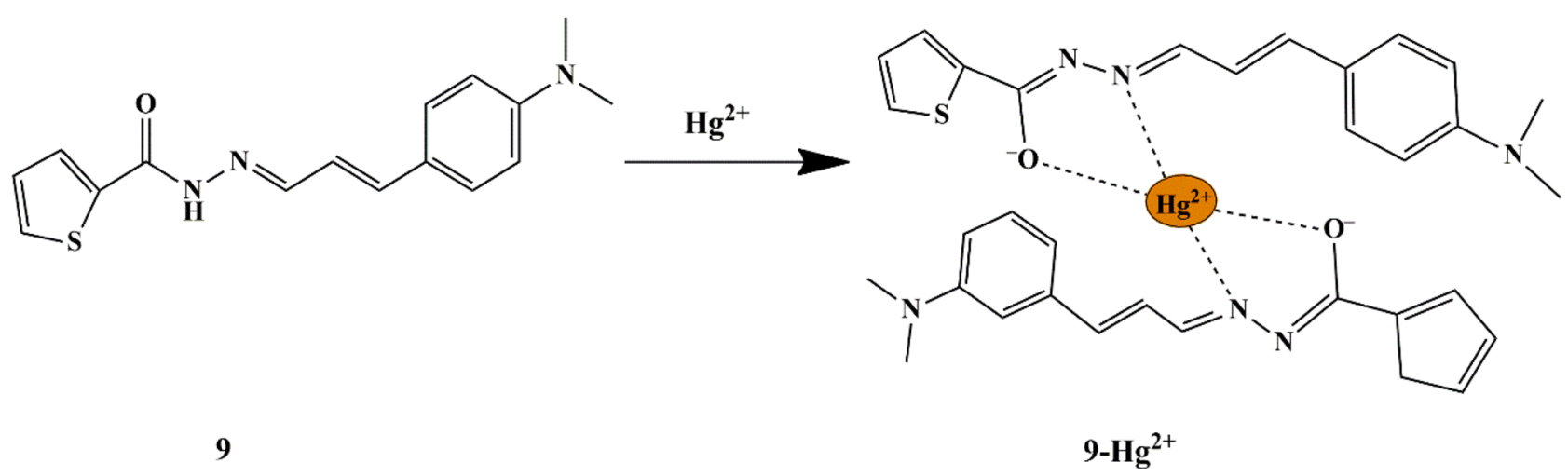

Scheme 8 Possible sensing mechanism of sensor 9 towards $\mathrm{Hg}^{2+}$ 


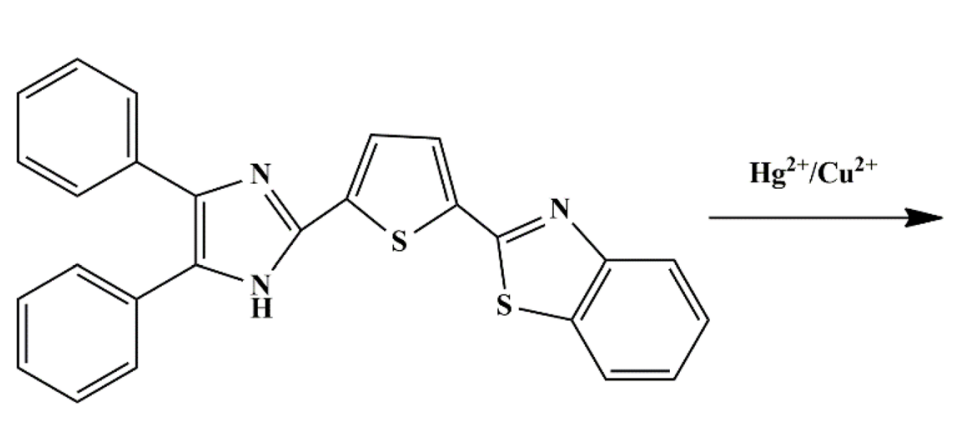

10

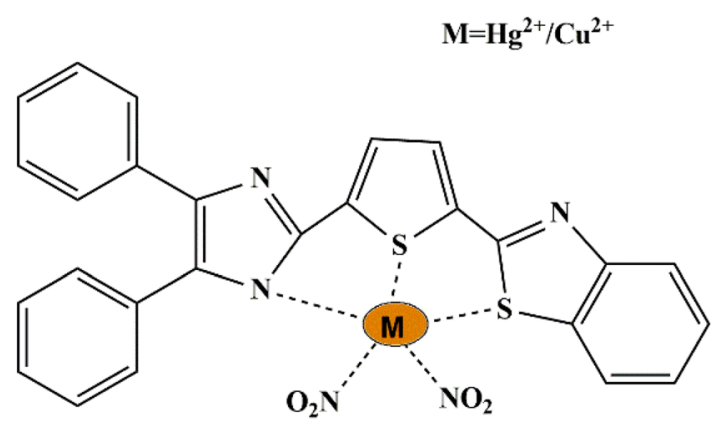

$10-\mathrm{M}^{2+}$

Scheme 9 Plausible sensing mechanism of probe $\mathbf{1 0}$ towards $\mathrm{Hg}^{2+} / \mathrm{Cu}^{2+}$

$\mathrm{CH}_{3} \mathrm{COO}^{-}$have been found to induce the reversibility in sensor $8-\mathrm{Hg}^{2+}$ complexation and the structural transformation of Rhodamine [31], thereby rendering a reversible dualchannel signaling pattern.

Hanna et al. synthesized cinnamaldehyde-based colorimetric chemosensor 9 and the thiophene derivative (with hydrazide) was introduced to overcome the drawback of the less solubility of cinnamaldehyde in water. It was observed that the absorption band of $390 \mathrm{~nm}$, exhibited by free sensor 9 in bis-tris buffer had a noticeable decrease, and a new broad absorption band of $518 \mathrm{~nm}$ emerged with the color change from pale yellow to orange, only upon the inclusion of $\mathrm{Hg}^{2+}$ ions due to the probe $9-\mathrm{Hg}^{2+}$ complex. The spectral response of 9 was noted in a broad $\mathrm{pH}$ range of $6-9$. The binding constant was determined to be $2 \times 10^{9} \mathrm{M}^{-2}$ with $2: 1$ stoichiometry. The LOD was calculated to be $0.01 \mu \mathrm{M}$ for $\mathrm{Hg}^{2+}$ and the sensing properties could be attributed to the ICT mechanism (Scheme 8), supported by DFT calculations [32].

Recently, plenty of chemosensors have been designed to separately detect $\mathrm{Hg}^{2+}$ and $\mathrm{Cu}^{2+}$ ions, since $\mathrm{Cu}^{2+}$ ion interferes with the detection of $\mathrm{Hg}^{2+}$ ions. Influenced by the difficulties in the selective sensing of $\mathrm{Hg}^{2+}$ and $\mathrm{Cu}^{2+}$ ions, Syed et al. developed a thiophene-based probe $\mathbf{1 0}$ for multiple metal-ion recognition, past distinct output signals. The naked-eye experiment revealed that the fluorescent green color of the free probe in HEPES buffer switched to blue with $\mathrm{Hg}^{2+}$ and non-fluorescent with $\mathrm{Cu}^{2+}$ ions respectively under UV light. The absorption spectra of the free probe $\mathbf{1 0}$ displayed a low energy charge transfer at $395 \mathrm{~nm}$ and a high energy band at $328 \mathrm{~nm}$, which raised and shrunk only with $\mathrm{Hg}^{2+}$ and $\mathrm{Cu}^{2+}$ ions, respectively. Moreover, upon interaction with $\mathrm{Hg}^{2+}$, a negligible drop in the relative fluorescence intensity was spotted and upon interaction with $\mathrm{Cu}^{2+}$, significant fluorescence quenching was notable, which could be attributed to the CHEF and CHEQ mechanisms, respectively (Scheme 9). By the results, it is noticeable that the fluorescence intensity of the probe $\mathbf{1 0}-\mathrm{Hg}^{2+}$ complex was uninfluenced upon interaction with $\mathrm{Cu}^{2+}$ ions. Likewise, the quenched fluorescence emission of the probe $10-\mathrm{Cu}^{2+}$ complex does not get enhanced upon interaction with $\mathrm{Hg}^{2+}$, thereby providing a means to detect both ions with higher selectivity and distinct output emission signals. Furthermore, the reversibility studies were performed using EDTA, which suggested a reversible complexation mode between probe 10 and metal ions. The binding constants were $3.1 \times 10^{5}$ for $\mathrm{Hg}^{2+}$ and $1.6 \times 10^{5}$ for $\mathrm{Cu}^{2+}$, and the binding of the probe to $\mathrm{Hg}^{2+} / \mathrm{Cu}^{2+}$ was found to be in a $1: 1$ stoichiometric ratio. Furthermore, the LOD to detect $\mathrm{Hg}^{2+}$ and $\mathrm{Cu}^{2+}$ ions were ascertained to be $28 \mu \mathrm{M}$ and $7.5 \mu \mathrm{M}$ respectively [33]. Probe $\mathbf{1 0}$ has been reported to have good cell permeability to detect $\mathrm{Hg}^{2+}$ and $\mathrm{Cu}^{2+}$ in live cells and protein medium, thereby proving its potential to discern metal ions in the biological system. Besides, a molecular logic gate was also constructed and the probe has been explored as a coding/decoding fluorescent blue ink.

Divya Singhal synthesized a chromogenic and fluorogenic thiophene-based schiff base probe 11 [2-((3-methylthiophen2-yl)methyleneamino)benzenethiol], for selective recognition of $\mathrm{Hg}^{2+}$ ions. It was seen that the probe showed an immediate color change from light yellow to yellowishorange only for $\mathrm{Hg}^{2+}$ ions. Furthermore, UV-Vis absorbance and fluorescence studies were investigated in $\mathrm{CH}_{3} \mathrm{OH} / \mathrm{H}_{2} \mathrm{O}$ ( $\mathrm{v} / \mathrm{v} 8: 2$ ), which revealed that the addition of $\mathrm{Hg}^{2+}$ displayed a new band at $430 \mathrm{~nm}$ in addition to $287 \mathrm{~nm}$ and $355 \mathrm{~nm}$ absorption bands of the probe, due to the ICT mechanism. The turn-on fluorescence emission, exhibited by probe $\mathbf{1 1}$ in response to $\mathrm{Hg}^{2+}$ ions was seen at $503 \mathrm{~nm}$, which was due to the CHEF mechanism [34] and the probe was free from interference from other tested ions, thereby clearly indicating the selective sensing of $\mathrm{Hg}^{2+}$ ions and the binding interaction was further confirmed by NMR, Mass spectra, DFT studies, and electrochemical behavior (Scheme 10). The reversibility studies of the sensing mechanism were performed using EDTA, which showed a fluorescence quenching and disappearance of the color of probe 11, in 
Scheme 10 Possible mode of binding interaction of probe $\mathbf{1 1}$ with $\mathrm{Hg}^{2+}$

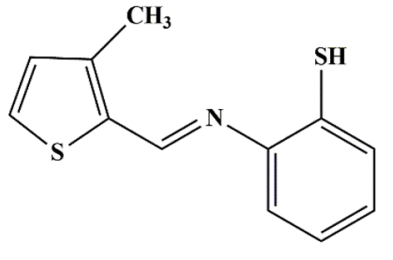

11

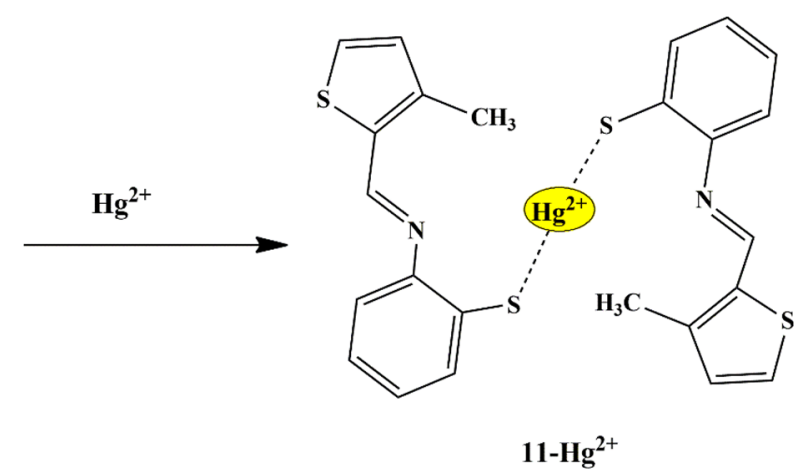

contrast to that of probe $\mathbf{1 1}-\mathrm{Hg}^{2+}$ sensing mechanism. A 2:1 stoichiometry for probe $\mathbf{1 1}$ and $\mathrm{Hg}^{2+}$ and a detection limit of $20 \mu \mathrm{M}$ was noted.

\section{Lead}

Lead is one of the noxious heavy metals, and its accumulation can result in lead poisoning, consequently leading to retarded brain development and nervous system disorders [35], convulsions, muscle paralysis [36], coma, and death. Very few fluorescent chemosensors have been reported for detecting $\mathrm{Pb}$ (II) due to their undesirable property of quenching the fluorescence emission through electron transfer [37] or spin-orbital coupling [38], which is highly disadvantageous for analytical purposes.

Jing Cao et al. synthesized a novel water-soluble thiophene functionalized chemosensor $\mathbf{1 2}$ bearing benzo[d]thiazole-2-thio unit for $\mathrm{Pb}^{2+}$ detection. It was observed that in the HEPES buffer, the probe exhibited an exceptional fluorescence intensity accompanied by a bathochromic shift in the absorption maxima, only in the presence of $\mathrm{Pb}$ (II), without any interference from other ions. This could be attributed to the binding pocket (Scheme 11) formed within probe 12, which could be a probable binding site for $\mathrm{Pb}$ (II) [39], having a 1:1 binding stoichiometry ratio.

\section{Chromium}

Chromium is one of the heavy metals and is widely used in metallurgy and pigments. It plays a role in regulating blood glucose levels [40] and the metabolism of proteins, carbohydrates, and fats in the body. However, chromium is carcinogenic, and its toxicity can result in Haemolysis and kidney failure.

Considering the above issues, Erman synthesized an anthracene appended-thiophene fluorescent probe 13 which possessed a low detection limit and a faster response time for $\mathrm{Cr}^{3+}$. It was observed that the free probe in $\mathrm{CH}_{3} \mathrm{CN} / \mathrm{H}_{2} \mathrm{O}$ (v/v 6:4) had diminished fluorescence because of the PET process. However, a new strong emission peak appeared at $500 \mathrm{~nm}$ upon the addition of $\mathrm{Cr}^{3+}$. The LOD of the probe was calculated to be $0.4 \mu \mathrm{M}$, and it had a response time of less than $1 \mathrm{~min}$. Reversibility studies were carried out by employing an excess of EDTA and it was observed that the sensing mechanism was irreversible. Moreover, the sensing mechanism is attributable to the concurrent coordination of $\mathrm{Cr}^{3+}$ ions with $\mathrm{N}$ atom on $\mathrm{C}=\mathrm{N}$ moiety and $\mathrm{S}$ atom in thiophene, which induced the attack of water resulting in the formation of 2-aminoanthracene. To investigate the potential of probe 13 in practical applications, probe $(10 \mu \mathrm{M})$ in $\mathrm{CH}_{3} \mathrm{CN} / \mathrm{HEPES}$ solution (v/v 6:4) at $\mathrm{pH} 7$ was introduced
Scheme 11 Binding pocket of probe 12 for $\mathrm{Pb}^{2+}$

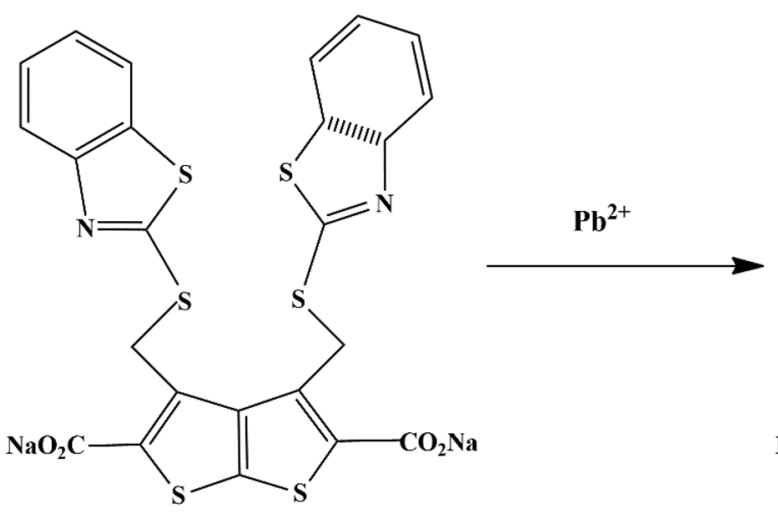

12

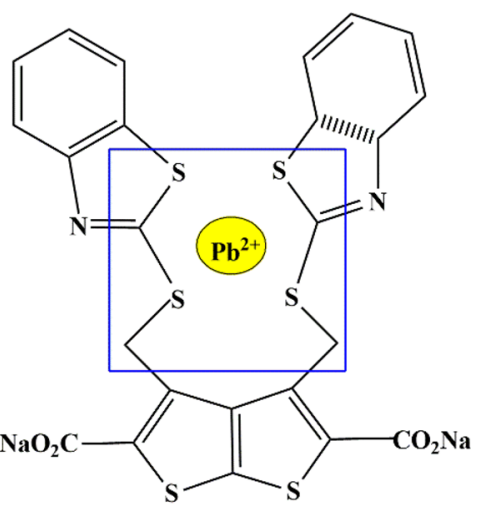

Binding pocket of 12 
onto circular test papers. They did not exhibit emission at $366 \mathrm{~nm}$ under UV light in the absence of metal ions, while only $\mathrm{Cr}^{3+}$ ions exhibited a green emission [41] by a "turnon" response (Scheme 12), thereby making it an efficient tool for $\mathrm{Cr}^{3+}$ detection.

Conjugated polymers have acquired increased attention, owing to their high sensitivity and ease of measurement and, are therefore used as fluorescent sensors. Previously developed chemosensors have certain limitations, such as low water solubility and low sensitivity. To overcome this drawback, water-soluble $\pi-\pi$ conjugated polymers could be employed to produce fluorescence, which is more remarkable compared to that of classic fluorophores. Considering these properties, Marco Laurenti et al. synthesized a watersoluble polythiophene-based fluorescent chemosensor probe 14 [Poly(3-ethoxythiophene-2,5-diyldimercaptosuccinic acid)] possessing chelating properties for the recognition of $\mathrm{Pb}^{2+}$ and $\mathrm{Hg}^{2+}$. The recognition properties of the probe were evaluated by UV-Vis and photoluminescence spectra of an aqueous solution of the probe. Initially, probe $\mathbf{1 4}$ exhibits an absorption maximum at $405 \mathrm{~nm}$ and $530 \mathrm{~nm}$ in the absorption and emission spectra, respectively. However, upon the addition of $\mathrm{Pb}^{2+}$ and $\mathrm{Hg}^{2+}$, fluorescence quenching was noticed. This could be accredited to the conformational change in probe $\mathbf{1 4}$, due to the complex formed between the metal ions and the chelating DMSA moiety of the polymer [42].

It has been known that schiff bases easily isomerize in the excited state but incline to display weak fluorescence. To overcome this drawback, thiophene moieties can be incorporated since thiophene exhibits significant optoelectronic properties. One such approach was made by Feyza et al. who designed a thiophene-based schiff base sensor $\mathbf{1 5}$ for $\mathrm{Cr}^{3+}$ detection ions in an aqueous solution. The probe displayed an enhancement in fluorescence intensity with a color change from yellow to Saxon blue upon binding to $\mathrm{Cr}^{3+}$, which is accredited to the chelation between $\mathrm{Cr}^{3+}, \mathrm{S}$, and $\mathrm{N}$ atoms (Scheme 13), thereby impeding the PET process. Besides that, the $\mathrm{pH}$ effect showed that there was enhanced fluorescence intensity upon increasing the $\mathrm{pH}$, which attained a maximum (at $\mathrm{pH} 8$ ) and then decreased, since $\mathrm{Cr}(\mathrm{OH})_{3}$ formation prevented further probe $15-\mathrm{Cr}^{3+}$ complex formation. Fluorescence studies showed that the fluorescence intensity of the probe improved with the increase in the amount of

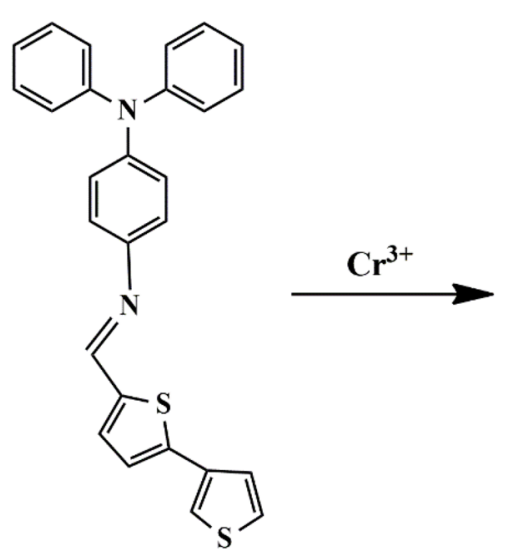

15

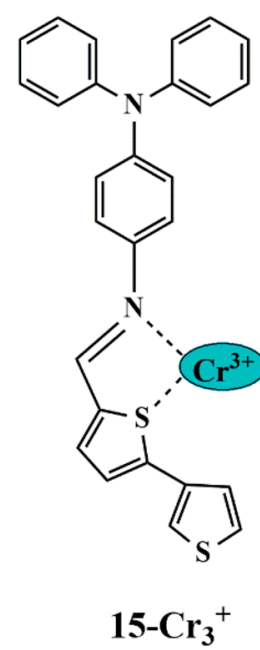

Scheme 13 Proposed sensing mechanism of probe 15 to $\mathrm{Cr}^{3+}$

$\mathrm{Cr}^{3+}\left(\lambda_{\text {excitation }}=320 \mathrm{~nm}\right)$ and Job's plot analysis revealed that probe 15 and $\mathrm{Cr}^{3+}$ showed 2:1 binding stoichiometry. The association constant was calculated to be $2.8 \times 10^{4} \mathrm{M}^{-1}$ and the LOD [43] was found to be $1.5 \times 10^{-6} \mathrm{M}$, and th optical behaviour of the probe was beneficial for $\mathrm{Cr}^{3+}$ detection in waste water.

Recently, a handful of chemosensors have been delineated for the simultaneous detection of both $\mathrm{Cr}^{3+}$ and $\mathrm{Cu}^{2+}$ ions. Hence, a novel approach was made by Natarajan et al. who synthesized a triple-action probe $\mathbf{1 6}$ [thiophenedicarboxaldehyde-rhodamine-B]. Probe in $\mathrm{CH}_{3} \mathrm{CN} / \mathrm{H}_{2} \mathrm{O}$ (v/v 4:1) displayed a significant color change from light yellow to pink with $\mathrm{Cr}^{3+}$ and $\mathrm{Cu}^{2+}$ ions, while the remaining ions did not exhibit any color change, indicating that probe $\mathbf{1 6}$ was insensitive towards anions. But only $\mathrm{CN}^{-}$ions displayed a color change when introduced to the probe $16-\mathrm{Cu}^{2+}$ solution, and a cascade recognition study confirmed the detection. The sensing property of probe $\mathbf{1 6}$ towards $\mathrm{Cu}^{2+}, \mathrm{Cr}^{3+}$, and $\mathrm{CN}^{-}$could be due to the spirolactam ring-opening and spirolactam ring-closing of the rhodamine moiety, respectively (Scheme 14). However, it was concluded that $\mathrm{Cr}^{3+}$ shows excellent enhancement in fluorescence intensity of probe 16 with 1:2 stoichiometry, due to the spirolactam ring opening [44] of the probe, whereas $\mathrm{Cu}^{2+}$ with 1:1 stoichiometry shows fluorescence quenching due to its paramagnetic nature. Moreover, the detection limits for $\mathrm{Cr}^{3+}$,
Scheme 12 Proposed detection mechanism of probe $\mathbf{1 3}$ for $\mathrm{Cr}^{3+}$

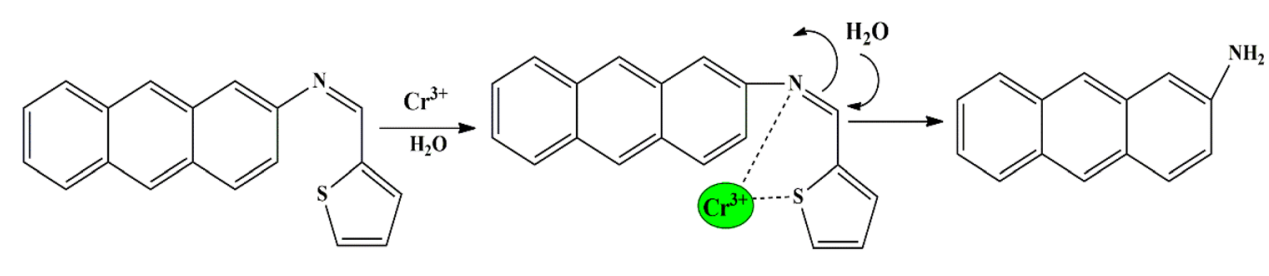

13
13- $\mathrm{Cr}^{3+}$ 


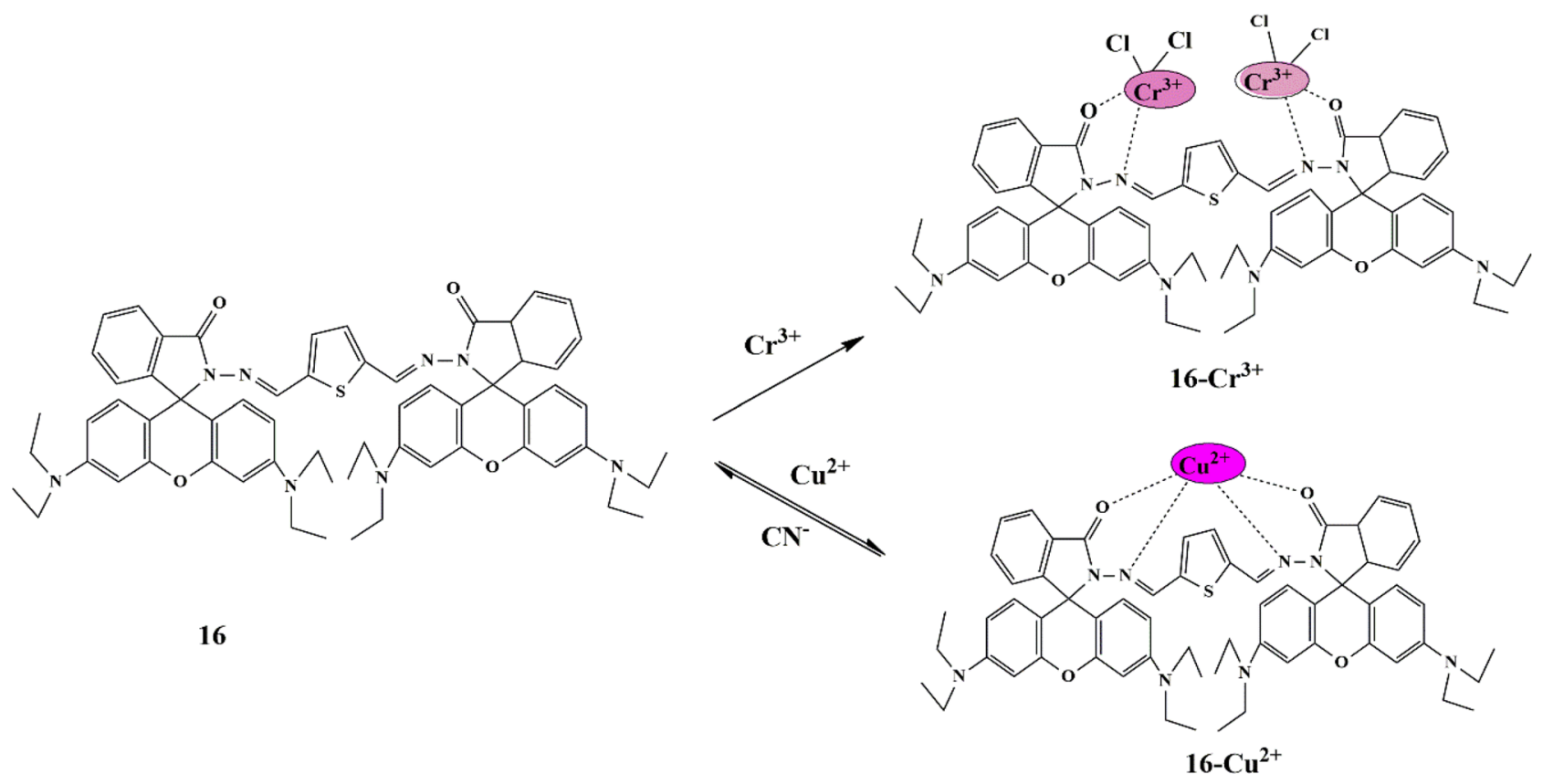

Scheme 14 Proposed sensing mechanism of probe $\mathbf{1 6}$ for $^{3+}$ and $\mathrm{Cu}^{2+}$

$\mathrm{Cu}^{2+}$, and $\mathrm{CN}^{-}$ions were $2.6 \times 10^{-6} \mathrm{M}, 1.01 \times 10^{-6} \mathrm{M}$, and $9.3 \times 10^{-7} \mathrm{M}$ respectively. The reversibility of the probe was performed by introducing a $\mathrm{CN}^{-}$into the probe $16-\mathrm{Cu}^{2+}$ complex, and good reversibility of $\mathrm{Cu}^{2+}$ detection sensing was observed.

\section{Zinc}

Zinc is the third most abundant transition metal found in specific tissues of the body [45, 46]. It is responsible for the catalytic activity of few enzymes as well [47, 48]. But, excess zinc can lead to its toxicity in the body resulting in the damage of the pancreas and metabolism disturbance, consequently leading to neurodegenerative disorders and arteriosclerosis.

Several chemosensors have been reported to detect $\mathrm{Zn}^{2+}$ ions, such as 6-methoxy-8-quinolyl-para-toluenesulfonamide
(TSQ), Zinquin, but they have limited activity because of their poor selectivity for $\mathrm{Zn}^{2+}$ ions. Motivated by the demand for low-cost and simple molecules for the selective recognition of $\mathrm{Zn}^{2+}$ ions, Dulal musib and his colleagues synthesized a novel 'turn-on' thiophene-based fluorescent probe 17 (Schiff-base of 2-aminophenol, thieno[2,3-b] thiophene-2,5-7,5 dicarbaldehyde). The probe showed enhanced fluorescence intensity in the presence of $\mathrm{Zn}^{2+}$, due to the aggregation-induced emission of probe 17 and $\mathrm{Zn}^{2+}$, whose luminescence was reduced by EDTA. Based on the outcomes, a logic gate was formulated for the selective detection of $\mathrm{Zn}^{2+}$ ions.

Luminescence behavior in $\mathrm{CH}_{3} \mathrm{CN}$ at room temperature revealed that only $\mathrm{Zn}^{2+}$ ions exhibited changes in the luminescent properties of the probe, which suggested the Metalto-Ligand charge transfer (MLCT) along with Aggregation induced emission (AIEE) $[49,50]$ (Scheme 15). The AIEE

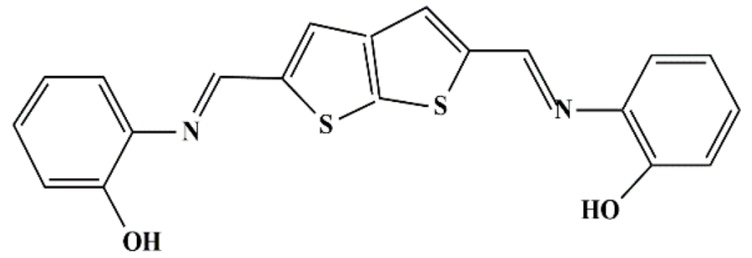

17

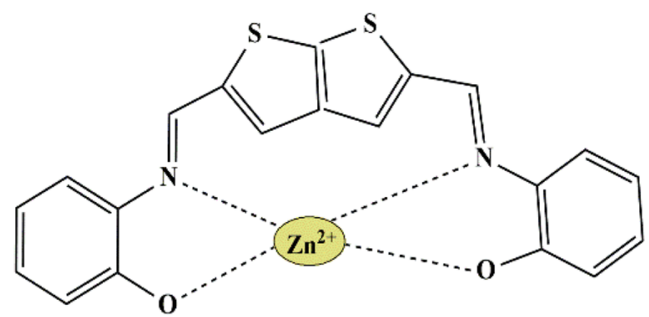

$17-\mathrm{Zn}^{2+}$

Scheme 15 Detection mechanism of the fluorescent probe 17 towards $\mathrm{Zn}^{2+}$ 


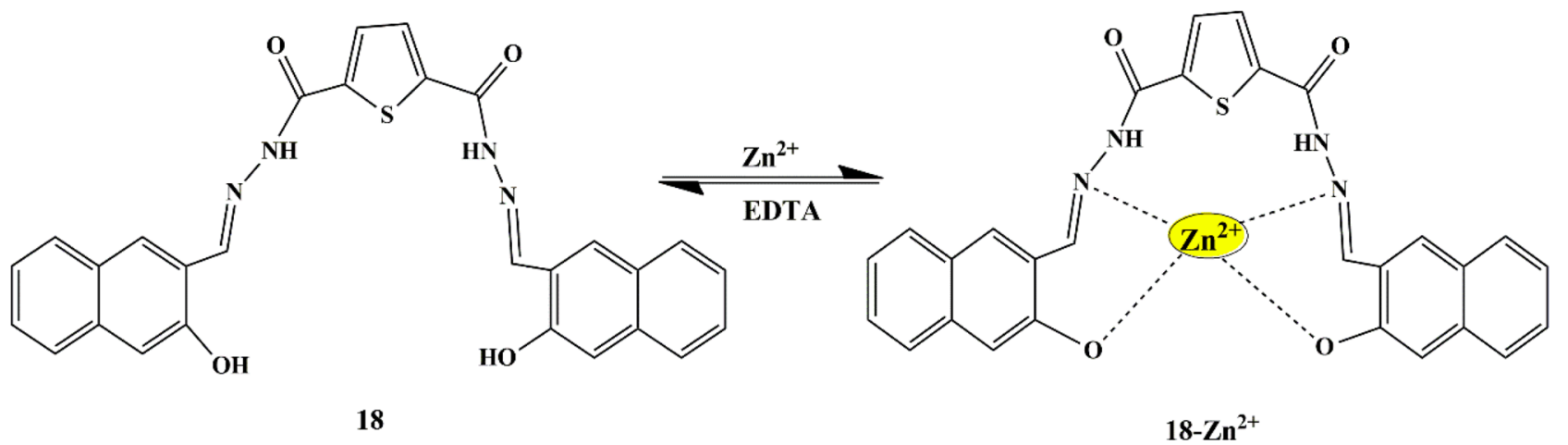

Scheme 16 Possible mechanism of sensing of $\mathrm{Zn}^{2+}$ by probe 18

property could be visualized by the appearance of deep yellow from colorless with the increase in $\mathrm{H}_{2} \mathrm{O}$ concentration. It was observed that the addition of EDTA results in a 'turnoff' fluorescence by the formation of a strong $\mathrm{Zn}^{2+}-\mathrm{EDTA}$ complex [8]. Furthermore, fluorescent titrations showed that, upon the addition of $\mathrm{Zn}^{2+}$ ions, the fluorescence emission band of probe $\mathbf{1 7}$ exhibited a redshift of $27 \mathrm{~nm}$ and a binding ratio of $1: 1$ was proposed.

Merlin Mary and Anandaram designed thiopheneappended carbohydrazide probe $\mathbf{1 8}$ as a 'turn-on' chemosensor for the detection of $\mathrm{Zn}^{2+}$ ions. The free probe displayed two distinct absorption peaks at $330 \mathrm{~nm}$ and $412 \mathrm{~nm}$ in the UV-Vis spectra due to Intra ligand charge transition (ILCT) $[51,52]$. While, upon the addition of $\mathrm{Zn}^{2+}$ to the probe in the DMSO/ $\mathrm{H}_{2} \mathrm{O}$ mixture (v/v 6:4), a new peak at $445 \mathrm{~nm}$ was observed, which proved probe $18-\mathrm{Zn}^{2+}$ complex formation (Scheme 16) and was further confirmed by FT-IR studies.
Absorption spectral titration experiments revealed that the redshift could be observed for the probe $18-\mathrm{Zn}^{2+}$ complex with $1: 1$ binding stoichiometry and the LOD was found to be $1.51 \times 10^{-7} \mathrm{M}$. Moreover, significant color changes (light yellow to fluorescent yellow) were observed with fluorescence emission occurring at $1890 \mathrm{~nm}$, due to the coordination bond formed between probe 18 and $\mathrm{Zn}^{2+}$, and the fluorescence enhancement could be attributed to the CHEF effect of the complex formed [53].

Although many probes have been synthesized for $\mathrm{Zn}^{2+}$ and $\mathrm{Hg}^{2+}$ ion recognition, thiophene-carbazole-based probes are utilized rarely. Hence, as a new approach, Ajit et al. incorporated thiophene moieties into the carbazole-based ratiometric probe 19. Distinct UV-Vis spectral behaviors were observed upon sensing of $\mathrm{Zn}^{2+}$ and $\mathrm{Hg}^{2+}$ in HEPES buffer. The probe displayed a weak band at $385 \mathrm{~nm}$ upon the addition of $\mathrm{Zn}^{2+}$ ions, whereas it exhibited new strong
Scheme 17 Possible mechanism of sensing of $\mathrm{Hg}^{2+} / \mathrm{Zn}^{2+}$ by probe 19

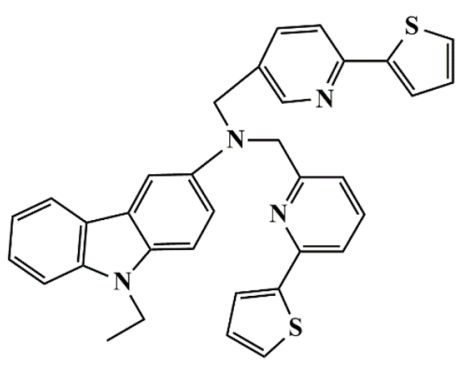

19

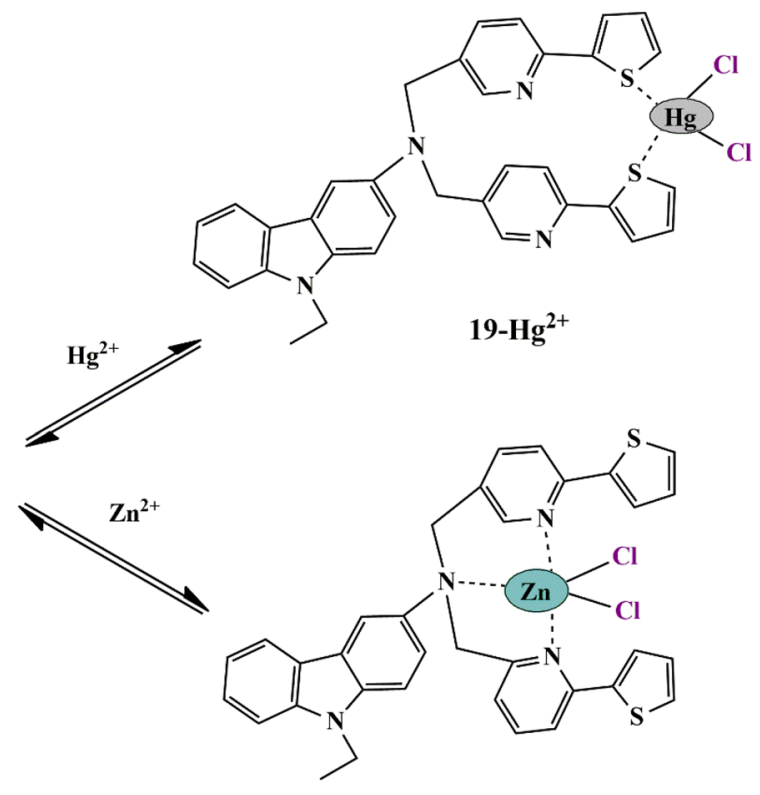

19- $\mathrm{Zn}^{2+}$ 
Scheme 18 Suggested sensing mechanism of $\mathbf{2 0}$ towards $\mathrm{Zn}^{2+}$

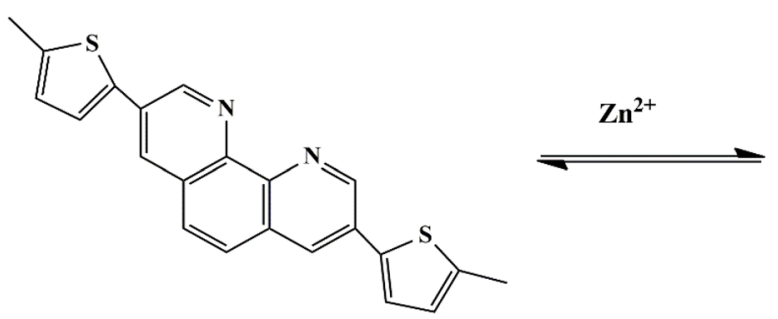

20

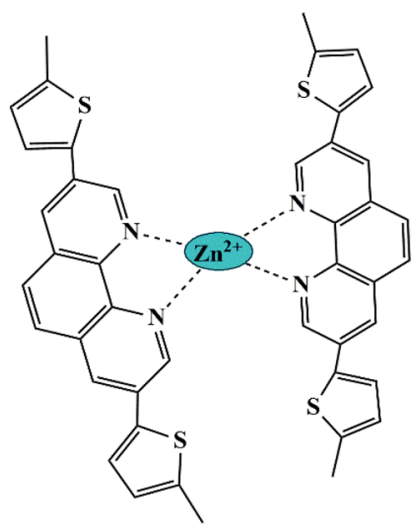

$20-\mathrm{Zn}^{2+}$ redshift absorption bands followed by a naked eye visible color change from colorless to pale yellow upon the introduction of $\mathrm{Hg}^{2+}$ ions. Job's plot indicated the 1:1 stoichiometry of probe $19-\mathrm{Zn}^{2+} / \mathrm{Hg}^{2+}$ complex (Scheme 17), and $\mathrm{Zn}^{2+}$ binds to probe 19 by at least 1.17 -fold stronger than that of $\mathrm{Hg}^{2+}$ as confirmed by emission studies [54]. For increasing concentrations of $\mathrm{Zn}^{2+}$ and $\mathrm{Hg}^{2+}$, the band at $418 \mathrm{~nm}$ gradually decreased and a new band at $520 \mathrm{~nm}$ is seen only for $\mathrm{Hg}^{2+}$ along with a visual fluorescent color change. At the same time, the probe responds to $\mathrm{Zn}^{2+}$ with distinct emission color change. The LOD for $\mathrm{Zn}^{2+}$ and $\mathrm{Hg}^{2+}$ was found to be $3.7 \mu \mathrm{M}$ and $4.8 \mu \mathrm{M}$, respectively. Probe 19 demonstrated fluorescence bioimaging of raw cells, which was evident by the green fluorescence image of the raw cells in the presence of $\mathrm{Zn}^{2+}$ ions. Therefore, the probe could be used as an intracellular bio probe for dual sensing of ions.

Phenanthroline-based chemosensors, having strong chelating abilities and robust conjugated $\pi$-systems, have received enormous attention in recent years. Zhang et al. synthesized a novel phenanthroline-thiophene based chemosensor 20 for $\mathrm{Zn}^{2+}$ detection. The free sensor in Ethanol/ water (v/v 9:1) exhibits an absorbance band at $282 \mathrm{~nm}, 359$ $\mathrm{nm}$, and $375 \mathrm{~nm}$ due to the ICT mechanism. Nevertheless, in the presence of $\mathrm{Zn}^{2+}$ ions, a new band is observed at 405 $\mathrm{nm}$, accompanied by a red shift band, which is ascribed to
LMCT between $\mathrm{Zn}^{2+}$ and probe $\mathbf{2 0}$ and enhanced ICT process, respectively. The fluorescence spectra of the free probe displayed weak fluorescence at $422 \mathrm{~nm}$, whereas this emission band showed a bathochromic shift of $461 \mathrm{~nm}$ with an exceptional fluorescence upon the addition of $\mathrm{Zn}^{2+}$, which could be attributed to the CHEF effect due to the complexation of the two 5-methylthiophene groups at the $3 \& 8$ positions of phenanthroline with $\mathrm{Zn}^{2+}$ (Scheme 18). The binding mode of probe $\mathbf{2 0}-\mathrm{Zn}^{2+}$ was proposed to be 1:2 stoichiometry, confirmed by ESI-MS spectra. The probe $\mathbf{2 0}$ could also sense $\mathrm{ClO}_{4}{ }^{-}$to a certain extent because of competitive coordination to $\mathrm{Zn}^{2+}$, thereby showing anionic interference, as evidenced by fluorescence quenching emission. Moreover, the probe could be employed in a broad $\mathrm{pH}$ range $2-10$, evident by $\mathrm{pH}$-dependent fluorescent [55] changes. Because of good cell permeability and reversible $\mathrm{Zn}^{2+}$ sensing property of the probe, it could be employed for practical applications such as biosensing of $\mathrm{Zn}^{2+}$ in living cells.

\section{Copper}

Copper is a trace element required by the body for various activities, such as behaving as a catalytic cofactor for diverse metalloenzymes. The deficiency of copper in the body can lead to anemia, impaired organ function, and Menkes disease

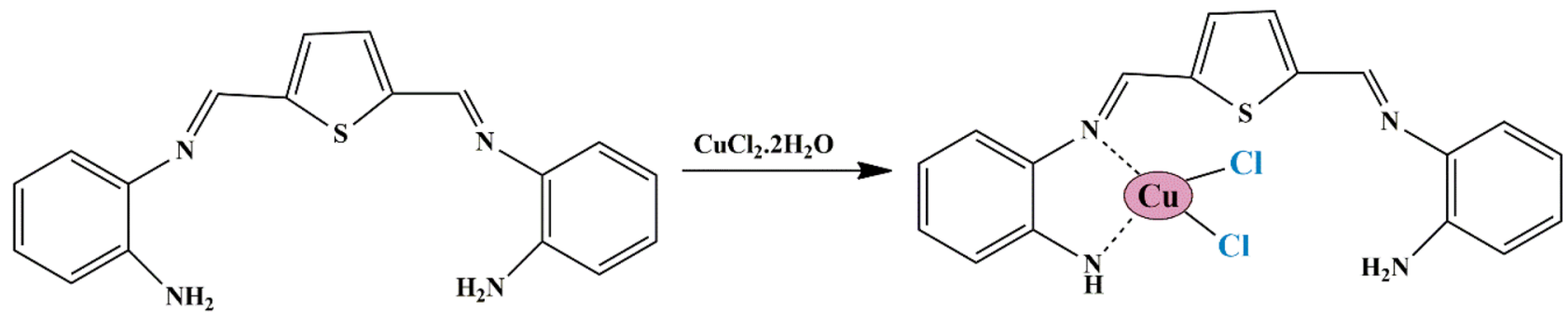


Scheme 20 Plausible detection mechanism of probe $\mathbf{2 2}$ towards $\mathrm{Cu}^{2+}$

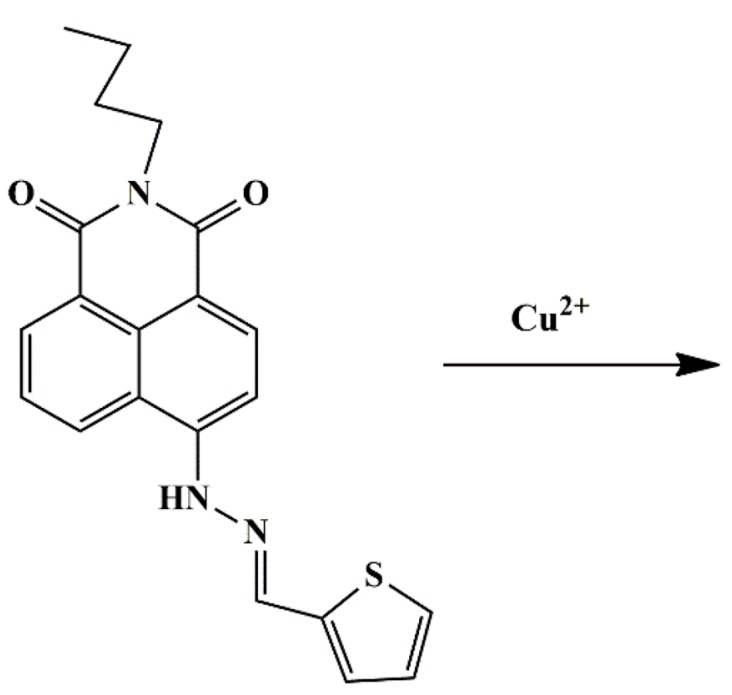

22

[56]. Contrarily, an increase in copper concentration beyond a limit can cause diarrhea, dyslexia, vomiting, headache, Wilson's disease, Alzheimer's, and Parkinson's disease [57-59].

Encouraged by sorting out the above problems, Sivalingam et al. synthesized a 'turn-on' thiophene-based schiff base (receptor 21). They evaluated its cation sensing properties in aqueous and biological samples since schiff base-type compounds are effectual metal chelators and could be utilized in fluorescent chemosensors. Receptor 21 could selectively detect $\mathrm{Cu}^{2+}$ in aqueous samples in the presence of other ions, as evidenced by the color change in the colorimetric analysis and an effective fluorescence response. The UV-Vis absorbance spectra revealed that a new band was obtained at $370 \mathrm{~nm}$ with $\mathrm{Cu}^{2+}$ ions (with the decrease in the band at $448 \mathrm{~nm}$ exhibited by the receptor). The color and optical changes could be assigned to the coordination bond formed between receptor 21 and $\mathrm{Cu}^{2+}$ ion by transferring lone pair of electrons of amine and

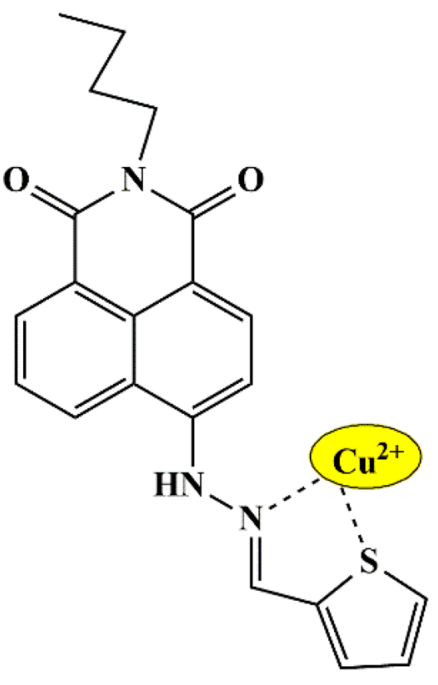

$22-\mathrm{Cu}^{2+}$ imine into the empty $\mathrm{Cu}^{2+}$ orbital (Scheme 19). Evaluation of potential applications of the receptor as a bio-probe for $\mathrm{Cu}^{2+}$ detection in bio-imaging and bio-labeling research was achieved by demonstration of $\mathrm{Cu}^{2+}$ recognition in living cells, by using $E$. coli. It was found that receptor $\mathbf{2 1}$ could behave as a nanomolar $(0.423 \mathrm{nM}) \mathrm{Cu}^{2+}$ sensor [57] with the binding constant of $4.23 \times 10^{5}$, which closely matched with the results of DFT calculations.

Using the same design guide, Guangijie et al. synthesized a new fluorescent schiff base probe $\mathbf{2 2}$ based on naphthalimide and thiophene moiety. The UV-Vis absorbance spectra displayed a drop in the absorption peak at $465 \mathrm{~nm}$ upon the addition of $\mathrm{Cu}^{2+}$ ions to the probe in $\mathrm{CH}_{3} \mathrm{CN} / \mathrm{HEPES}(\mathrm{v} / \mathrm{v}$ 3:2) solution. The binding stoichiometry was determined to be in a 1:1 ratio, supported by ESI-MS spectra and Job's plot. The probe was found to be effective in broad $\mathrm{pH}$ range, confirmed by $\mathrm{pH}$-dependent studies. Fluorescence spectroscopic studies showed that probe $\mathbf{2 2}$ exhibited a strong fluorescence emission intensity at $575 \mathrm{~nm}$, which quenched<smiles>CCOC(=O)C1=C(c2cccs2)NC(=O)/C1=N/Nc1ccc([N+](=O)[O-])cc1O</smiles>

Scheme 21 Possible mechanism for copper ion binding to probe $\mathbf{2 3}$ 
Scheme 22 Suggested binding mode of sensor $\mathbf{2 4}$ to $\mathrm{Cu}^{2+}$ ions

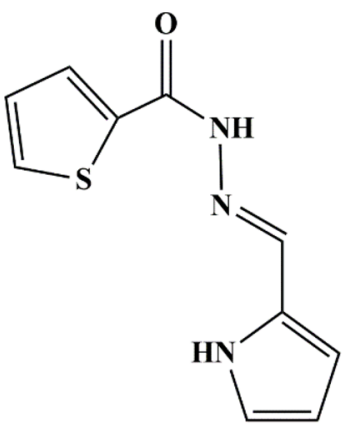

24

significantly only upon the inclusion of $\mathrm{Cu}^{2+}$ ions, which could be due to its paramagnetic nature (Scheme 20). The LOD was determined to be $1.8 \mu \mathrm{M}$, and the probe showed an irreversible sensing mechanism upon EDTA addition as it failed to recover its fluorescent intensity. Furthermore, probe 22 could also be employed to detect $\mathrm{Cu}^{2+}$ ions in live cells [60], evidenced by the significant quenching of the green fluorescence, thereby demonstrating that the probe had the ability of fluorescence imaging in vivo.

Another novel approach was put forward by Ayesha et al., who synthesized a novel pyrrolinone ester derivative-based hydrazone dye $\mathbf{2 3}$ and employed it as a multi-functional probe. The fluorescence emission spectra of the probe in $\mathrm{EtOH} /$ water (v/v 1:1) displayed a significant quenching only for $\mathrm{Cu}^{2+}$ ions, thereby showing a 'turn-off' response due to probe 23-Cu interaction [61]. Furthermore, the UV-Vis spectra provided a new characteristic absorbance band at $542 \mathrm{~nm}$ with a color change to purple that corresponds to the probe 23- $\mathrm{Cu}^{2+}$ complex (Scheme 21), and the absorbance band at $485 \mathrm{~nm}$ (of Free probe) vanished. The detection limit was $0.85 \mu \mathrm{M}$, the association constant was reckoned to be $1.67 \times 10^{4} \mathrm{M}^{-1}$, with 1:1 stoichiometry. Reversibility studies were performed using EDTA, which suggested that the binding mode was reversible.
24- $\mathrm{Cu}^{2+}$

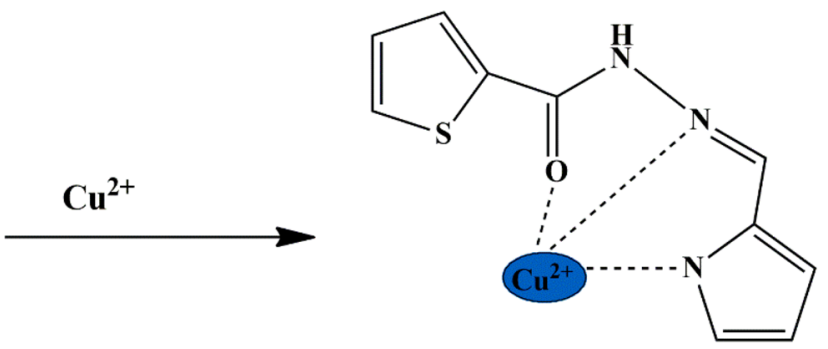

Tekuri and Trivedi synthesized a series of thiophene2-carboxylic acid hydrazide-based chemosensors, among which 24 (Thiophene-2-carboxylic acid (1 H-pyrrol-2ylmethylene)-hydrazide), and 25 (Thiophene-2-carboxylic acid isoquinolin-1-ylmethylene-hydrazide) responded for the detection of $\mathrm{Cu}^{2+}$ and $\mathrm{Cd}^{2+}$ ions. Chemosensor $\mathbf{2 4}$ displayed a striking yellow color only in the presence of $\mathrm{Cu}^{2+}$ ions, and chemosensor $\mathbf{2 5}$ exhibited a yellow appearance only in the presence of $\mathrm{Cd}^{2+}$, as evidenced by the UV-Vis titration study which showed a decrease in the absorbance intensity of $\mathbf{2 4}$ at $335 \mathrm{~nm}$ and 25 at $320 \mathrm{~nm}$, and a new absorbance band at $402 \mathrm{~nm}$ (in 24), $425 \mathrm{~nm}$ (in 25) upon titration with $\mathrm{Cu}^{2+}$ and $\mathrm{Cd}^{2+}$ ions, respectively. These changes are attributable to the change in structural conformation of chemosensors upon interaction with $\mathrm{Cu}^{2+}$ and $\mathrm{Cd}^{2+}$, thereby demonstrating a coordinative interaction between the oxygen of carbonyl group and imine nitrogen in probe $\mathbf{2 4}$, whereas Sulphur and nitrogen in probe $\mathbf{2 5}$ respectively (Scheme 22 and 23). It was found that probe $\mathbf{2 4}$ and probe $\mathbf{2 5}$ exhibited a dynamic linear absorption response range, from 0 to $50 \mu \mathrm{M}$ for $\mathrm{Cu}^{2+}$ ions and 0-30 $\mu \mathrm{M}$ for $\mathrm{Cd}^{2+}$ ions, with the LOD calculated to be $2.8 \times 10^{-6} \mathrm{M}$ and $2.0 \times 10^{-7} \mathrm{M}$ for $\mathrm{Cu}^{2+}$ and $\mathrm{Cd}^{2+}$ ions respectively [62]. The association constant was determined to be $7.8 \times 10^{3} \mathrm{M}^{-1}$ for probe $24-\mathrm{Cu}^{2+}$ and $3.7 \times 10^{4} \mathrm{M}^{-1}$ for
Scheme 23 Suggested binding mode of sensor 25 to $\mathrm{Cd}^{2+}$

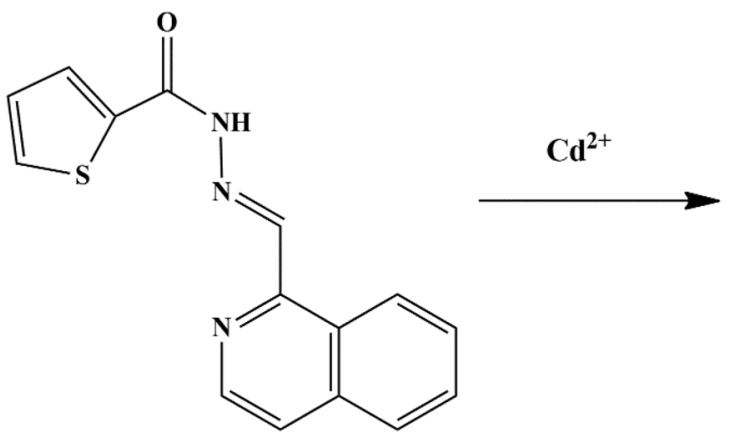

25<smiles></smiles>

25-C $\mathbf{C d}^{2+}$ 
<smiles>O=C(N/C=N/c1ccccc1O)C1=CC=CC1</smiles>

26

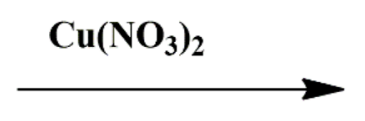

26- $\mathrm{Cu}^{2+}$

Scheme 24 Sensing mechanism of probe 26 towards $\mathrm{Cu}^{2+}$

probe $25-\mathrm{Cd}^{2+}$, and the respective binding was found to be in 1:1 stoichiometry.

To detect copper in the aqueous system, Penchang et al. synthesized a thiophene-based colorimetric sensor 26. From the UV-Vis absorption spectra results, it was evident that only $\mathrm{Cu}^{2+}$ increased the absorption band of the probe by 10 folds and displayed a prominent change in color from colorless to yellow in $\mathrm{DMSO} / \mathrm{H}_{2} \mathrm{O}(\mathrm{v} / \mathrm{v}$ 1:1) solution due to the probe 26- $\mathrm{Cu}^{2+}$ complex formation; whereas fluorescence quenching was observed due to the paramagnetic nature of $\mathrm{Cu}^{2+}$ ions. The probe also exhibited anti-interference ability for the detection of $\mathrm{Cu}^{2+}$, and the working of the probe was found to be in a broad $\mathrm{pH}$ range (6-10). The binding constant was determined to be $6.55 \times 10^{4} \mathrm{M}^{-1}$ with $1: 1$ stoichiometry of probe 26- $\mathrm{Cu}^{2+}$ complex (Scheme 24) and the LOD was determined to be $0.217 \mu \mathrm{M}$. Furthermore, to scrutinize the practical applications of the probe, the TLC-based strip tests were executed by employing $\mathrm{Cu}^{2+}$ solution in water. After introducing $\mathrm{Cu}^{2+}$ on the TLC plate (immersed in probe in DMSO/ $\mathrm{H}_{2} \mathrm{O}$ ), color change from colorless to yellow [63] was noticed under sunlight, implying that probe $\mathbf{2 6}$ could function as a suitable tool for selective detection of $\mathrm{Cu}^{2+}$ ions.
Thuy et al. synthesized thiophene appended anthracenebased fluorescent probe $\mathbf{2 7}$ for the detection of $\mathrm{CuCl}_{2}$. The probe was able to explicitly identify $\mathrm{CuCl}_{2}$ from other metals since other metals exhibited intense blue fluorescence emission in the UV-Vis spectra. The fluorescence intensity at $460 \mathrm{~nm}$ decreased upon the introduction of $1 \mathrm{mM} \mathrm{CuCl}_{2}$ in DMSO solution, and complete quenching could be observed at $30 \mathrm{mM} \mathrm{CuCl}$, which could be attributed to the overlapping of the fluorescence wavelength of probe 27 and the absorption wavelength of $\mathrm{CuCl}_{2}$ (Scheme 25). The binding between $\mathrm{CuCl}_{2}$ and probe $\mathbf{2 7}$ was found to be in 1:2 stoichiometry [64] and the binding constant was found to be 0.0895 $\mathrm{mM}^{-2}$.

\section{Silver}

Silver has been valued as a precious metal and has gained immense significance due to its potential applications in medicine, electronics and photography, catalysis, and nanochemistry [65]. Due to its widespread use, it possesses various entry routes into the body, primarily through ingestion [66], inhalation [67], and skin contact. Excessive silver ions<smiles>OCc1ccc(-c2c3ccccc3c(-c3ccc(CO)s3)c3ccccc23)s1</smiles>

Scheme 25 Photo-sensing mechanism of probe 27 towards $\mathrm{Cu}^{2+}$ 
<smiles>COC(=O)N/N=C/c1ccc([N+](=O)[O-])s1</smiles>

Scheme 26 Proposed binding mechanism of probe 28 to $\mathrm{Ag}^{+}$

can integrate with amine, imidazole, and carboxyl moieties of different metabolites in the cytosol, consequently leading to undesirable effects on humans. Long-term exposure to silver can cause Argyrosis and Argyria [68].

Bhuvanesh et al. synthesized thiophene-based probe 28, which could detect $\mathrm{Ag}^{+}$in aqueous media. There was a substantial fluorescence enhancement of probe in $\mathrm{CH}_{3} \mathrm{OH} /$ $\mathrm{H}_{2} \mathrm{O}$ (v/v 1:1) solution, indicating the possibility of ICT mechanism due to the coordination of $\mathrm{Ag}^{+}$with probe 28 in 1:1 binding stoichiometry. The $\mathrm{pH}$ and time response studies revealed the effectiveness of the probe over a broad $\mathrm{pH}$ range and a rapid response time, suggesting that it could be employed for $\mathrm{Ag}^{+}$detection in environmental and biological samples. The interaction is possible through ICT aided by the restricted torsional rotation between the $\mathrm{C}-\mathrm{C}$ single bond of the probe (Scheme 26), which was confirmed by mass spectra and the LOD was estimated to be $1.28 \times 10^{-7} \mathrm{M}$.

Moreover, to test and evaluate the potentiality of the probe in the detection of $\mathrm{Ag}^{+}$in biological applications, microscopic images of $E$. coli cells in the absence and presence of probe 28 and $\mathrm{Ag}^{+}$were compared; and observed that in the presence of $\mathrm{Ag}^{+}$, the probe displayed highly intense red fluorescence due to the probe $\left[28-\mathrm{Ag}^{+}\right]$complex inside the cells, thereby enhancing the fluorescence intensity and it

Scheme 27 Possible sensing mechanism of probe $\mathbf{2 9}$ towards $\mathrm{Ag}^{+}$ was hereby concluded that the probe could be employed in live-cell fluorescence imaging [69] for $\mathrm{Ag}^{+}$detection. Additionally, it was observed that the probe could also be used for monitoring $\mathrm{Ag}^{+}$ions in natural water samples, thereby paving a way for $\mathrm{Ag}^{+}$detection in both Aqueous and biological samples.

A successful novel approach was made by Xeong et al. who developed a thiophene-functionalized imidazophenazine based self-assembled supramolecular sensor 29 to evaluate the recognition towards $\mathrm{Ag}^{+}$. The sensor reacted with a color change from yellow to light purple upon introducing $\mathrm{Ag}^{+}$ions in DMSO/Water solution, accompanied by a redshift to $376 \mathrm{~nm}$. Moreover from the fluorescence emission spectra, it was also noticed that the fluorescence intensity of the peak at $547 \mathrm{~nm}$ abruptly decreased with the addition of the $\mathrm{Ag}^{+}$to the solution, confirming the selective sensing and detection of $\mathrm{Ag}^{+}$ ions over other interfering metal ions [70] (Scheme 27). Moreover, the 'on-off' mechanism was evaluated by the addition of $\mathrm{I}^{-}$ions to test the reversibility of the sensing mechanism, and was observed that the sensor could be considered an excellent on-off fluorescence sensor, which was evident by the alternating reviving and quenching processes in the fluorescence emission of the sensor 29$\mathrm{Ag}^{+}$solution with 2:1 binding stoichiometry.

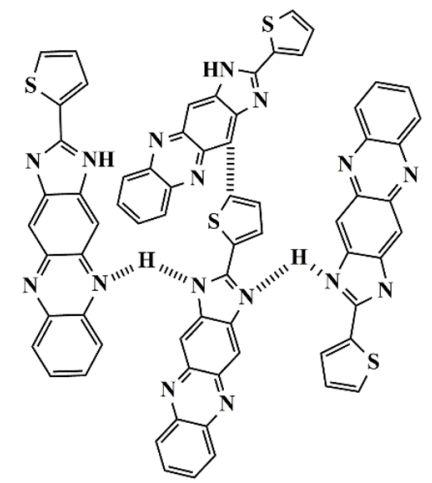

29

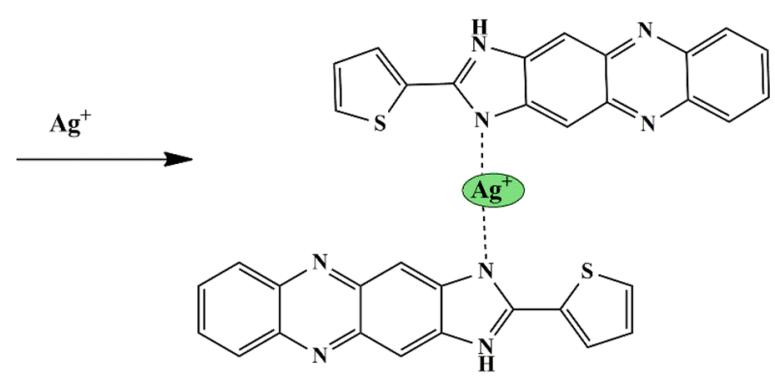

29- $\mathbf{A g}^{+}$ 
Scheme 28 Binding of $\mathrm{Ca}^{2+}$ to sensor 30/31

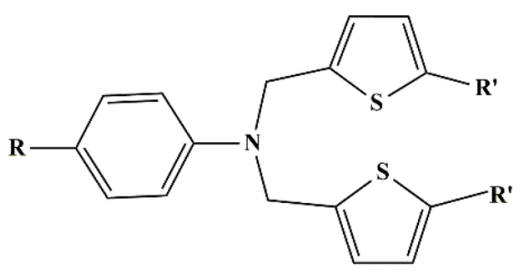

$30 / 31$

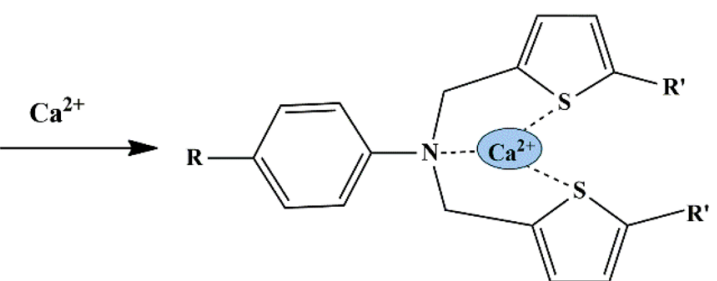

$30 / 31-\mathrm{Ca}^{2+}$
The LOD was found to be $8.18 \times 10^{-9} \mathrm{M}$, which was much lower in comparison to the previously reported chemosensors.

\section{Calcium}

Calcium is the fifth most abundant element in the human body and is a significant component of the bone, where it is stored as calcium phosphate. Calcium ions partake in the biochemical and physiological processes of the cells. In contrast to its benefits, excess calcium in the biological system can result in hypercalcemia, leading to abdominal pain, bone weakening, muscle cramps, and other neurological symptoms.

To achieve chemosensors for the selective binding of calcium ions, Rihab et al. synthesized two electroactive tetraalkylated p-phenylenediamine chemosensors (30 and 31) relying on thiophene ligands. The cyclic voltammetry studies revealed that both chemosensors were selectively able to bind $\mathrm{Ca}^{2+}$ ions over $\mathrm{Zn}^{2+}$ ions. The free ligand exhibited two peaks, but only one peak was observed at a higher potential upon adding $\mathrm{Ca}^{2+}$ ions. This could be ascribed to the oxidation of the Calcium complex, which is formed between
$\mathrm{Ca}^{2+}$ and two thiophenyl moieties and the nitrogen atom (Scheme 28). Furthermore, the calcium chelation resulted in a significant change in the transducer by larger anodic potential shifts, and the metal to ligand ratio [71] was found to be $1: 2$ suggesting a $\left[\mathrm{Ca}(\mathrm{L})_{2}\right]^{2+}$ complex formation. Chemosensor 30, having the replacement of the dimethylamino group with the piperidinyl group, showed high selectivity towards $\mathrm{Ca}^{2+}$ detection, evidenced by electrochemical studies.

\section{Zirconium}

Zirconium is widely used in ceramics, metal alloys, foundry equipment, the chemical processing industry, and electronic devices. Although, their regular use can produce high levels of residual zirconium ions, which consequently results in soil and water contamination. Inhaling zirconium compounds can give rise to pulmonary granulomas, skin and lung granulomas. Accordingly, it is crucial to develop chemosensors having high sensitivity and selectivity for the instantaneous detection of $\mathrm{Zr}^{4+}$ ions in environmental and biological samples.

In this regard, Ajit et al. synthesized a novel pyridinethiophene appended rhodamine-based probe 32, and the recognition properties of the probe towards different
Scheme 29 Proposed sensing mechanism of probe $\mathbf{3 2}$ towards $\mathrm{Zr}^{4+}$<smiles>CCN(CC)c1ccc2c(c1)Oc1cc(N(CC)CC)ccc1C21c2ccccc2C(=O)N1/N=C/c1cccc(-c2cccs2)n1</smiles> 
<smiles>c1ccc(-c2nc(-c3ccc(-c4nc(-c5ccccc5)c5ccccc5n4)s3)nc3ccccc23)cc1</smiles>

33

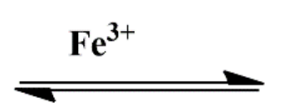

$33-\mathrm{Fe}^{3+}$

Scheme 30 A suggested possible mechanism for sensing of $\mathrm{Fe}^{3+}$

metal ions were evaluated by spectroscopic studies using $\mathrm{CH}_{3} \mathrm{OH} / \mathrm{H}_{2} \mathrm{O}$ (v/v 4:1) mixture. In the absence of metal ions, the solution of the probe was weakly fluorescent and colorless because of the ring-closed spirolactam, which then turned into deep orange upon introduction of $\mathrm{Zr}^{4+}$, due to the spirolactam-ring opening and generation of the delocalized xanthene moiety (Scheme 29). Emission and absorption titrations of probe $\mathbf{3 2}$ display fragile spectral characteristics in the emission spectrum, whereas the introduction of $\mathrm{Zr}^{4+}$ ions enhanced the fluorescence intensity significantly with an intense orange fluorescent emission band at $582 \mathrm{~nm}$. Moreover, the sensing mechanism was reversible upon adding EDTA due to the disappearance of the formed complex, and the LOD was calculated to be $16.99 \mu \mathrm{M}$.

Additionally, to demonstrate the practical bio-sensing capability of the probe, fluorescence imaging experiments were carried out in vivo in $C$. albicans cells. Fluorescence imaging was evaluated, which showed that probe $\mathbf{3 2}$ alone was non-emissive, but pollen cells loaded with $\mathrm{Zr}^{4+}$ exhibited red fluorescence from the intracellular area. The evidence of the viability of cells (after loading with probe and $\mathrm{Zr}^{4+}$ ) throughout the imaging experiment was confirmed by Bright field microscopy [72], indicating that the probe could be used for examining intracellular $\mathrm{Zr}^{4+}$ in living cells.

\section{Iron}

Iron is the most necessary microelement responsible for the proper functioning of physiological processes in living organisms. Iron is an essential constituent of hemoglobin and myoglobin and is also required for growth, neurological development, cellular functioning, and synthesis of some hormones. However, excess Iron can cause Iron poisoning, whose symptoms include diarrhea, vomiting, abdominal pain, and other ill effects on humans.

To develop fluorescent chemosensors to detect $\mathrm{Fe}^{3+}$, Kannikanthi et al. synthesized a fluorescent chemosensor 33 [2,5-bis(4-phenylquinazolin-2-yl)thiophene]. The free<smiles>c1cc(-c2ccc(-c3nnc(-c4ccc(-c5ccsc5)s4)s3)cc2)cs1</smiles>

34

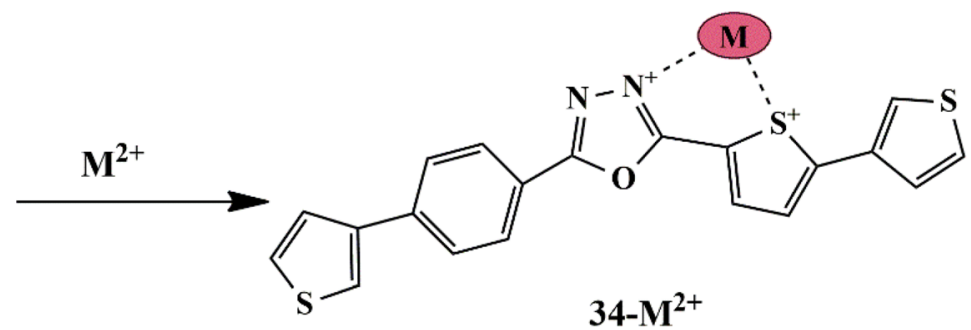

\section{$\mathrm{M}=\mathrm{Fe}$ \\ $\mathrm{Cu}$ \\ Ni}

Scheme 31 A proposed binding mechanism for 34 towards $\mathrm{Fe}^{2+} / \mathrm{Ni}^{2+} / \mathrm{Cu}^{2+}$ 


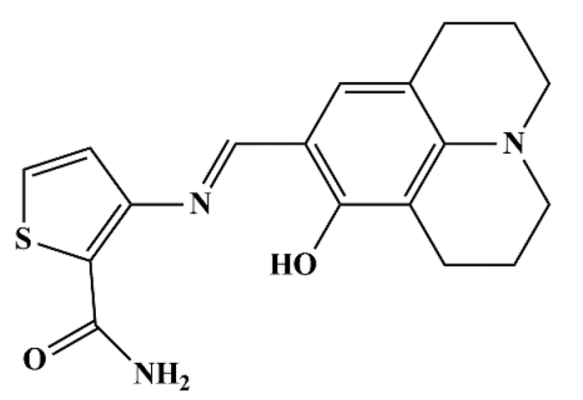

35

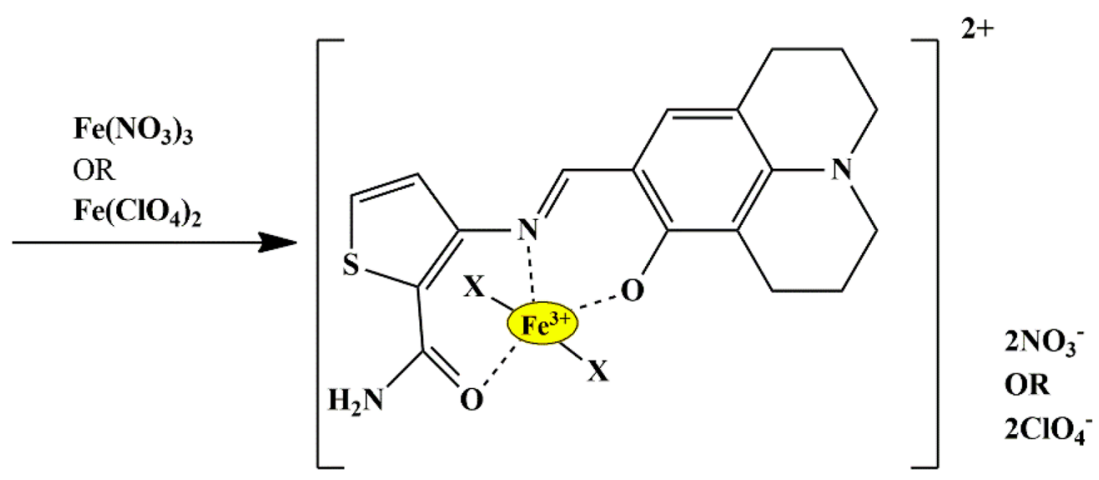

$35-\mathrm{Fe}^{3+}$

Scheme 32 Proposed binding mechanism of sensor $\mathbf{3 5}$ to $\mathrm{Fe}^{3+}$

sensor in $\mathrm{CH}_{3} \mathrm{CN}$ displayed an absorption band at $362 \mathrm{~nm}$, and it exhibited a color change from colorless to greenishyellow, and an occurrence of a new band at $419 \mathrm{~nm}$, only in the presence of $\mathrm{Fe}^{3+}$ ion. Fluorescence quenching at 427 $\mathrm{nm}$ upon the addition of $\mathrm{Fe}^{3+}$ ions, which could be attributed to the ICT between thiophene and phenylquinazoline units along with the MLCT (Scheme 30) between the sensor and $\mathrm{Fe}^{3+}$ ion in 1:1 binding mode. The LOD was calculated to be $1.6 \times 10^{-8} \mathrm{M}$. Reversibility equips the reusability of the chemosensor in practical applications, and hence reversibility studies were evaluated using EDTA. Upon addition of EDTA to the sensor $33-\mathrm{Fe}^{3+}$ complex, the fluorescence of sensor $\mathbf{3 3}$ is reimposed, thereby implying that the probe could be employed as a reversible sensor for $\mathrm{Fe}^{3+}$ ions. Furthermore, to investigate its applications in nanoscale computations, the probe could also be employed to construct an inhibit-type logic function with $\mathrm{Fe}^{3+}$ and EDTA being the chemical inputs and fluorescence emission [73] outputs at $533 \mathrm{~nm}$.

Considering high photoluminescence properties of 1,3,4-oxadiazole moiety, Lohit Naik et al. synthesized a turn-off fluorescent chemosensor based on thiophene substituted 1,3,4-oxadiazole derivative $\mathbf{3 4}$, for the detection of multiple metal ions. The sensitivity of probe 34 in $_{2} \mathrm{H}_{5} \mathrm{OH} /$ water, $\mathrm{CH}_{3} \mathrm{OH} /$ water, and $\mathrm{CH}_{3} \mathrm{CN} / \mathrm{H}_{2} \mathrm{O}$ mixture (v/v 1:1) at $\mathrm{pH} 7.2$, was investigated by UV-Vis absorbance spectroscopy. It was observed that, in all three mixtures, the absorbance peak and fluorescence emission peak of the probe were seen at $275 \mathrm{~nm}$ at $405 \mathrm{~nm}$, respectively. It was observed that in the $\mathrm{C}_{2} \mathrm{H}_{5} \mathrm{OH} / \mathrm{H}_{2} \mathrm{O}$ mixture, the fluorescence emission quenched to a greater amount upon the addition of $\mathrm{Fe}^{2+}$, owing to the paramagnetic nature of $\mathrm{Fe}^{3+}$ and could be ascribed to the CHEQ mechanism. In $\mathrm{CH}_{3} \mathrm{CN} / \mathrm{H}_{2} \mathrm{O}$ and $\mathrm{CH}_{3} \mathrm{OH} / \mathrm{H}_{2} \mathrm{O}$ mixture, the absorbance peak accounted maximum for $\mathrm{Cu}^{2+}$ at $225 \mathrm{~nm}$ and $\mathrm{Ni}^{2+}$ at $400 \mathrm{~nm}$, respectively, due to the CHEF mechanism (Scheme 31). The binding of probe and metal ions was in 1:1 stoichiometry and the detection limit for $\mathrm{Fe}^{2+}, \mathrm{Ni}^{2+}$, and $\mathrm{Cu}^{2+}$ was calculated to be $2.977 \times 10^{-6} \mathrm{M}, 0.895 \times 10^{-6} \mathrm{M}, 0.593 \times 10^{-6} \mathrm{M}$, respectively. The detection time was quick [74] $(<6.5 \mathrm{~min})$ signifying that probe $\mathbf{3 4}$ can be implemented for the rapid detection of multiple metal ions.<smiles>CCN(CC)c1ccc2c(c1)Oc1cc(N(CC)CC)ccc1C21c2ccccc2C(=O)N1N(C(=O)c1cccs1)C(=O)c1cccs1</smiles>

36

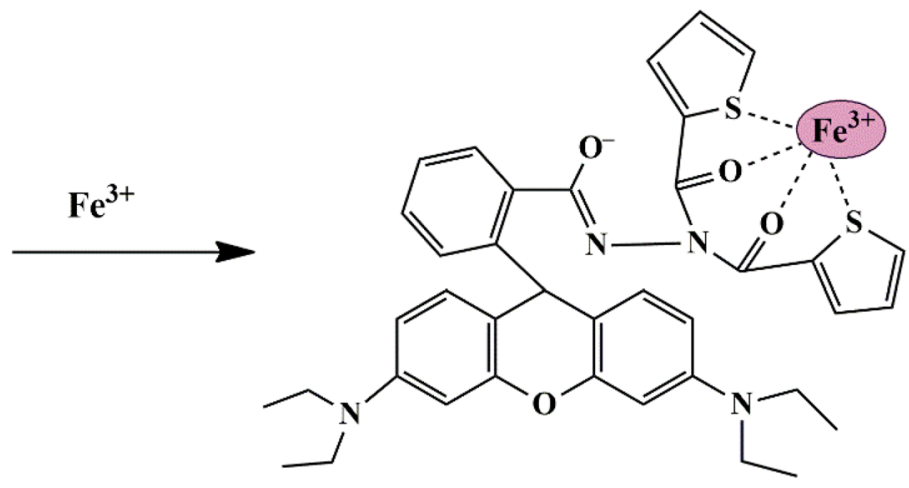

$36-\mathrm{Fe}^{3+}$

Scheme 33 Proposed binding mechanism of probe 36 to $\mathrm{Fe}^{3+}$ 
Scheme 34 Detection mechanism of probe 37 for $\mathrm{Fe}^{3+} / \mathrm{Hg}^{2+}$ ions

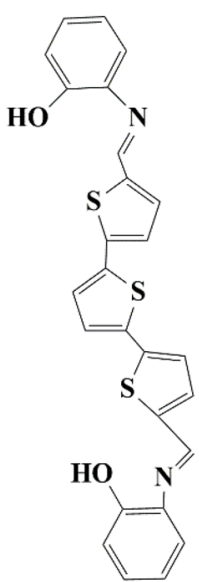

37

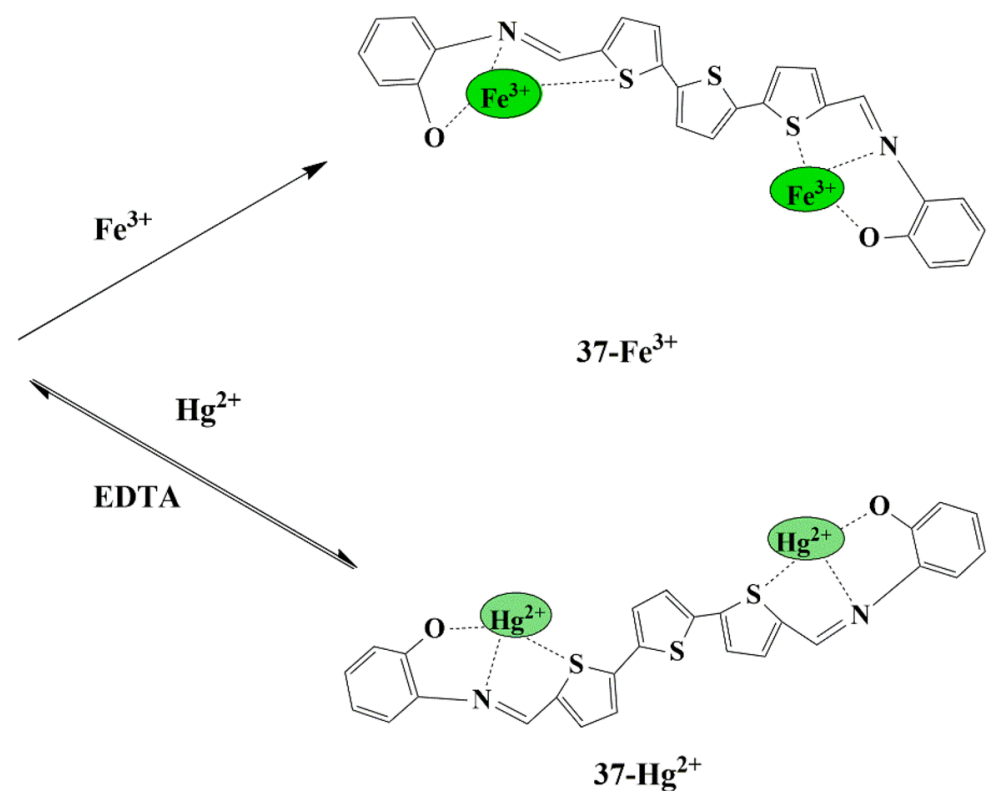

Owing to the paramagnetic nature of $\mathrm{Fe}^{3+}$, earlier reported fluorescent chemosensors functioned through fluorescence quenching mechanism, which was a considerable drawback in case in-situ monitoring and in vivo imaging [75]. As an out-turn, fluorescent and colorimetric probes operating by 'turn-on' response gained an enormous amount of attention. One such representative was the thiophenebased colorimetric sensor 35, developed by Jung et al. for the sequential detection of $\mathrm{Fe}^{3+} /^{2+}$ in a near-perfect aqueous solution. The sensor in bis-tris buffer showed distinct visual color changes from yellow to brown only upon the addition of $\mathrm{Fe}^{3+} /^{2+}$, with significant spectral changes due to MLCT mechanism (Scheme 32) and a 1:1 metal ion/ligand complexation was proposed. The sensor could sense $\mathrm{Fe}^{3+}$ at $\mathrm{pH}$ range $4-8$, which was confirmed by $\mathrm{pH}-$ dependent studies, and could be employed as a recyclable sensor to detect $\mathrm{Fe}^{3+}$ as evidenced by the reversibility studies using EDTA [76]. The LOD for $\mathrm{Fe}^{3+}$ and $\mathrm{Fe}^{2+}$ was determined to be $0.51 \mu \mathrm{M}$ and $1.51 \mu \mathrm{M}$, respectively, which was lower than the EPA (Environmental Protection Agency) guideline for drinking water, indicating that sensor $\mathbf{3 5}$ could be employed in the real-time monitoring of $\mathrm{Fe}^{3+}$ in drinking water.

As an innovative approach, Lieu et al. designed an N,Ndithenoyl-rhodamine based probe $\mathbf{3 6}$, for $\mathrm{Fe}^{3+}$ recognition. All the tested cations except $\mathrm{Fe}^{3+}$ didn't display any change in fluorescence spectra of the probe solution $\left(\mathrm{CH}_{3} \mathrm{OH} / \mathrm{H}_{2} \mathrm{O}\right.$ $\mathrm{v} / \mathrm{v} 1: 1)$ due to the closed conformation of the rhodamine spirolactam, whereas $\mathrm{Fe}^{3+}$ ions showed a strong fluorescence band complemented by an immediate color change from colorless to pink, due to the ring-opening reaction of rhodamine spirolactam (Scheme 33). The fluorescence titration revealed that increasing $\mathrm{Fe}^{3+}$ amount results in an

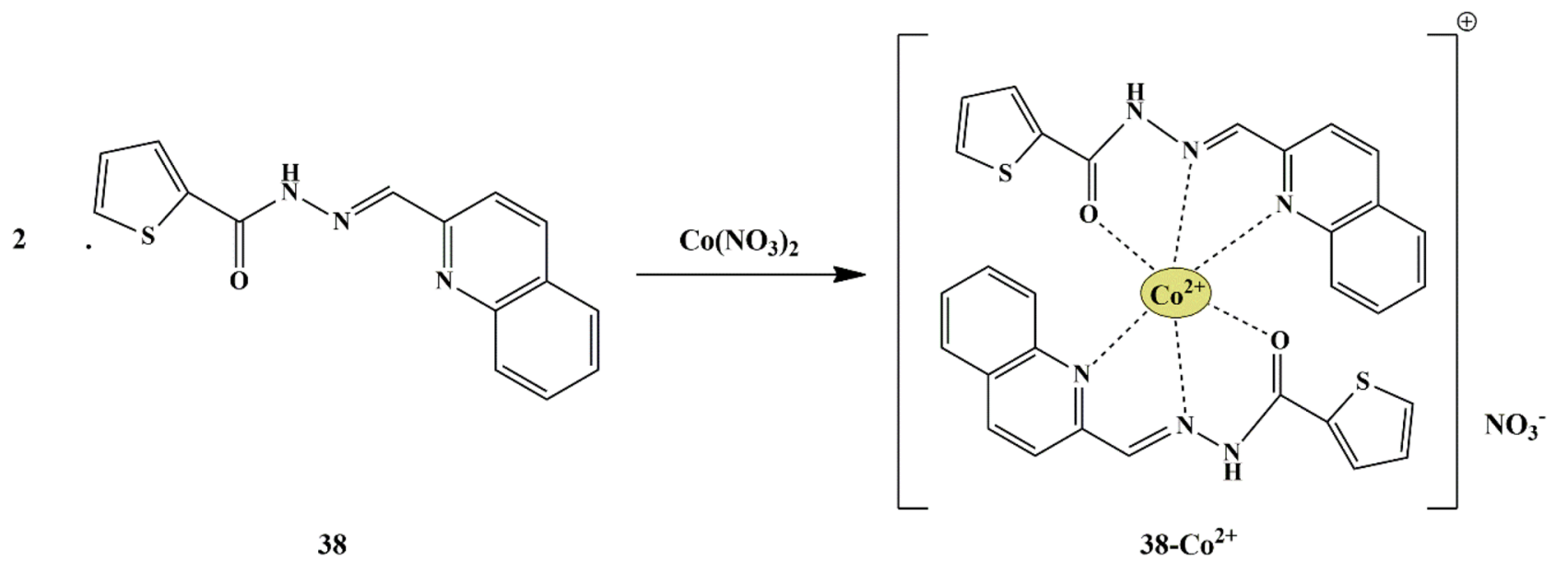

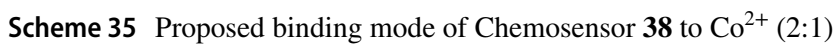




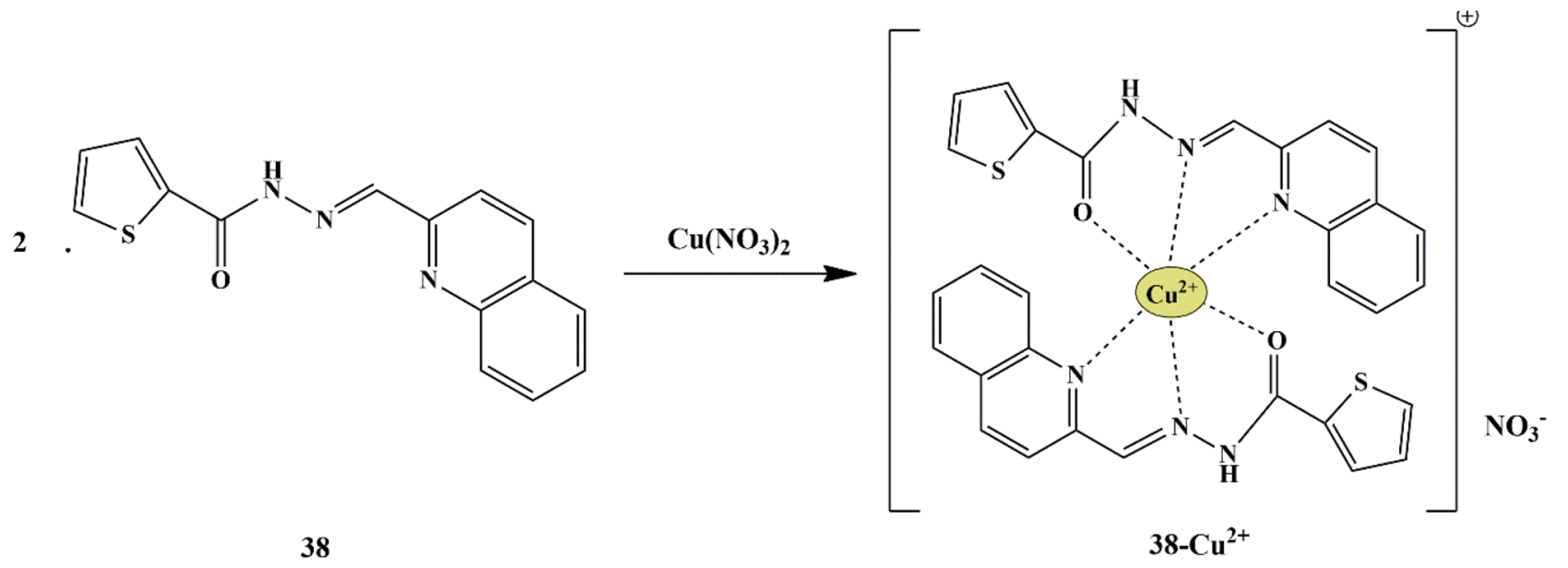

Scheme 36 Proposed binding mechanism of Chemosensor 38 to $\mathrm{Cu}^{2+}$

apparent peak at $588 \mathrm{~nm}$, which further increased along with the color change from colorless to pink, suggesting the ring-opening of the rhodamine spirolactam [77] and the increased coordination interactions between $\mathrm{Fe}^{3+}$ ions and Oxygen and Sulphur on the three amides and thiophene of probe 36 respectively, as confirmed by H-NMR analysis. It was found that the LOD was $3.74 \mu \mathrm{mol} / \mathrm{L}$, and the binding stoichiometry between the probe $36-\mathrm{Fe}^{3+}$ complex was $1: 1$ ratio. Additionally, the probe could effectively detect $\mathrm{Fe}^{3+}$ ions in living cells with good membrane permeability and less toxicity.

Very few multifunctional or dual-mode fluorescent chemosensors have been designed for the detection of $\mathrm{Fe}^{3+}$ and $\mathrm{Hg}^{2+}$ in aqueous media, and hence in this regard, Tau Sun and his colleagues synthesized an oligothiophene- Schiff based chemosensor 37, which could detect both $\mathrm{Hg}^{2+}$ and $\mathrm{Fe}^{3+}$ simultaneously. The fluorescence spectral studies were performed in $\mathrm{CH}_{3} \mathrm{CN} / \mathrm{H}_{2} \mathrm{O}$ (v/v 4:6) since it was found that the probe was partially water-soluble. The usage of organic phase guarantees higher availability of sensor molecules in the medium. The free sensor exhibited weak fluorescence, which could be imputed to the PET process [78]. However, the addition of $\mathrm{Fe}^{3+} / \mathrm{Hg}^{2+}$ ions to the sensor solution displayed an exceptional fluorescence enhancement at 520 $\mathrm{nm}$ due to the CHEF effect, and the fluorescence intensity increased with an increase in the amount of $\mathrm{Fe}^{3+} / \mathrm{Hg}^{2+}$ ions, which could be attributed to the reduced PET process as a result of the complexation of sensor 37 with $\mathrm{Fe}^{3+} / \mathrm{Hg}^{2+}$ (Scheme 34). The results obtained from the fluorescence spectra were in conformity with the results of the naked-eye experiment, which displayed the color change from light yellow to fluorescent green in the presence of $\mathrm{Fe}^{3+}$ and $\mathrm{Hg}^{2+}$ ions. The LOD for $\mathrm{Fe}^{3+} / \mathrm{Hg}^{2+}$ was estimated to be as $3.52 \times 10^{-8} \mathrm{M}$ and $5.0 \times 10^{-8} \mathrm{M}$. Besides, binding interactions studied by NMR, FT-IR spectral analysis, indicated a 1:2 metal/ligand binding stoichiometry and evidenced that phenol Oxygen, aldimine Nitrogen, and thiophene Sulphur of sensor 37 was entailed in the complex formation with $\mathrm{Fe}^{3+} / \mathrm{Hg}^{2+}$. Reversibility studies in EDTA indicated the irreversible binding interaction between the chemosensor and $\mathrm{Fe}^{3+}$ and reversible interaction with $\mathrm{Hg}^{2+}$. Furthermore, the fluorescence intensity of the sensor $37-\mathrm{Fe}^{3+} / \mathrm{Hg}^{2+}$ complex exhibits a 'turn-on' emission in a $\mathrm{pH}$ range (4-12) and persists in the 'turn-off' emission in acidic $\mathrm{pH}(\mathrm{pH}<4)$, suggesting that the sensor could be employed in a wide $\mathrm{pH}$ range, by exhibiting distinct 'on-off' responses.
Scheme 37 Plausible sensing mechanism of sensor 39 towards $\mathrm{Co}^{3+}$

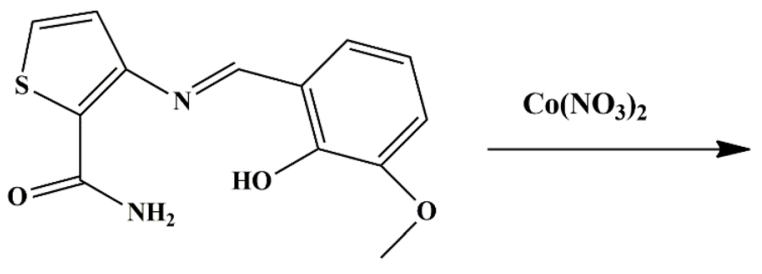


Scheme 38 Detection mechanism of $\mathbf{4 0}$ and $\mathbf{4 1}$ for $\mathrm{Pd}^{2+}$ ion<smiles>[X]c1cc(-c2cccs2)c2c(c1C#N)CCCN2</smiles>

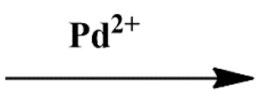<smiles></smiles>

$40 / 41-\mathrm{Pd}^{2+}$

\section{$41=\mathrm{X}=\mathrm{SMe}$}

\section{Cobalt}

Cobalt is an ultra-trace element in the biological system and is a key constituent of cobalamin, better known as Vitamin $\mathrm{B}_{12}$, and is required for the proper metabolism of iron, and plays a crucial role in the hemoglobin synthesis [79]. Nevertheless, high or long-term exposure to cobalt can result in cancer, respiratory disorders, skin problems such as dermatitis, reduced cardiac output.

In this regard, Jung et al. synthesized thiophene-2carbohydrazide based chemosensor $\mathbf{3 8}$ and evaluated its sensing properties in aqueous media. The colorimetric detection of the sensor was investigated towards different metal ions at $400 \mathrm{~nm}$ in tris-buffer/DMSO (v/v 95:5) mixture. Amidst the tested metal ions, only $\mathrm{Co}^{2+}$ and $\mathrm{Cu}^{2+}$ exhibited immediate color change from colorless to yellow, in addition to distinct spectral changes. The UV-Vis titration revealed that the absorption band of chemosensor at $325 \mathrm{~nm}$ decreased remarkably, with the appearance of a new band at $400 \mathrm{~nm}$, only for $\mathrm{Co}^{2+}$ which can be attributed to the co-ordination of chemosensor with $\mathrm{Co}^{2+}$ in 2:1 stoichiometry, further promoting Ligand to Metal charge transfer (LMCT) (Scheme 35 and 36). The LOD for $\mathrm{Co}^{2+}$ was calculated to be $0.19 \mu \mathrm{M}$ and the binding of chemosensor $\mathbf{3 8}$ with $\mathrm{Co}^{2+}$ and $\mathrm{Cu}^{2+}$ was found to be reversible with a chelating agent such as EDTA. Besides, the $\mathrm{Co}^{2+}-2$. ( sensor 38 ) complex can be employed as a colorimetric sensor for $\mathrm{CN}^{-}$, which was evident from a color change of yellow to colorless [80] in the aqueous solution.

Chang et al. developed a thiophene-carboxamide-based colorimetric chemosensor 39 for detecting $\mathrm{Cu}^{2+}$ and $\mathrm{Co}^{2+}$ in a near-perfect aqueous solution. The sensor could selectively respond to $\mathrm{Cu}^{2+}$ and $\mathrm{Co}^{2+}$ ions by a color change from colorless to yellow at $417 \mathrm{~nm}$. Furthermore, the binding properties of the sensor with $\mathrm{Cu}^{2+}$ and $\mathrm{Co}^{2+}$ ions were investigated through UV-Vis titrations, which revealed that the sensor 39-cation complex had 1:1 binding stoichiometry. There was no interference from other ions except $\mathrm{Cu}^{2+}$, during $\mathrm{Co}^{2+}$ detection since $\mathrm{Cu}^{2+}$ was tightly bonded to the sensor and this interference could be eliminated by adding excessive $\mathrm{F}^{-}$ions, which could be used to distinguish between probe 39- $\mathrm{Cu}^{2+}$ and probe $39-\mathrm{Co}^{2+}$ complex by color change. The LOD for $\mathrm{Cu}^{2+}$ and $\mathrm{Co}^{2+}$ was found to be $0.14 \mu \mathrm{M}$ and 0.88 $\mu \mathrm{M}$, respectively. The possible mechanism for detecting $\mathrm{Co}^{3+}$ (oxidation of $\mathrm{Co}^{2+}$ to $\mathrm{Co}^{3+}$ by $\mathrm{O}_{2}$ molecules, based on ESI mass result) and $\mathrm{Cu}^{2+}$ could be attributed to the ICT and LMCT mechanism (Scheme 37). Furthermore, the binding modes of the sensor to $\mathrm{Cu}^{2+}$ and $\mathrm{Co}^{2+}$ were found to be a 1:1 binding stoichiometry [81].

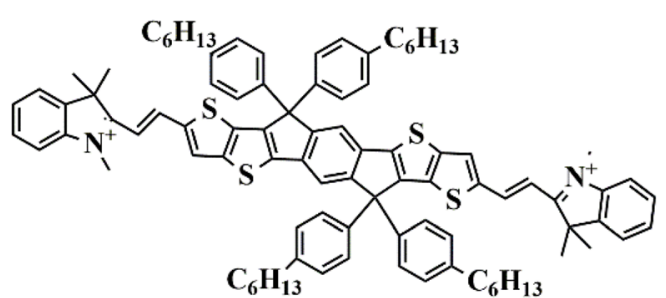

42

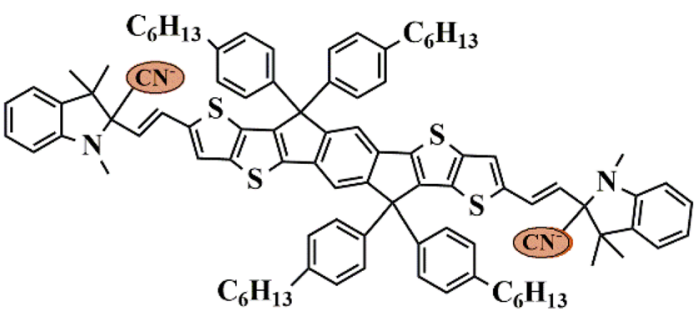

42- $\mathrm{CN}^{-}$

Scheme 39 Detection mechanism of sensor $\mathbf{4 2}$ towards $\mathrm{CN}^{-}$ 
Scheme 40 Recognition mechanism of probe $\mathbf{4 3}$ for $\mathrm{CN}^{-}$ions

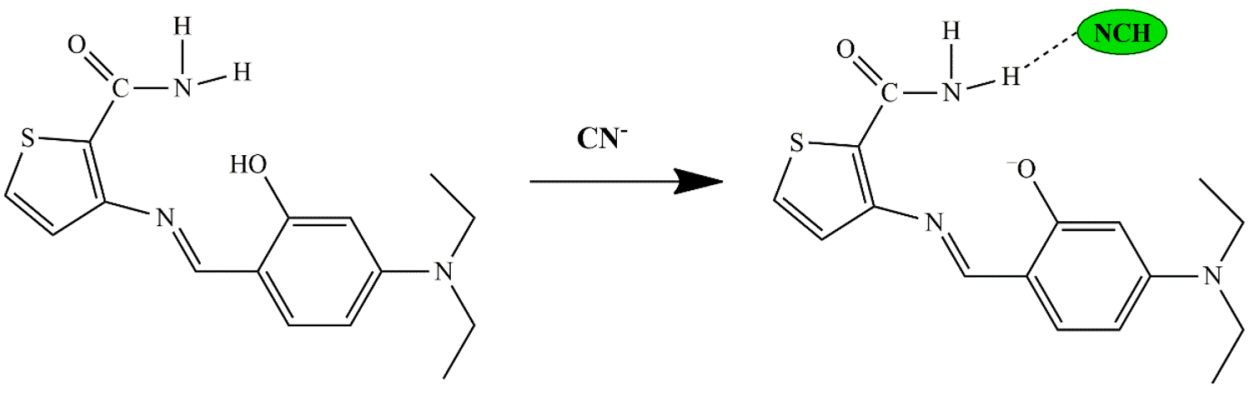

43

43- $\mathrm{CN}^{-}$

\section{Palladium}

Palladium is widely used in industrial processes due to its role as a catalyst in many organic synthesis reactions such as Suzuki coupling, Heck reaction, Wacker process. Although the toxicity of palladium is believed to be low, it coordinates with nucleic acids, proteins, and other macromolecules such as $\mathrm{VitB}_{\mathbf{6}}$, thereby impeding many cellular functions if accumulated in the body.

Palladium ion has an open-shell electronic configuration and hence could behave as a fluorescence quencher and considering this aspect, Shally et al. designed thiophene appended tetrahydroquinoline-based 'turn-off' chemosensors 40 (with morpholino group) and 41 (with methylthio group). The UV-Vis spectrum shows the absorption peak at $390 \mathrm{~nm}$ and $378 \mathrm{~nm}$ for free $\mathbf{4 0}$ and $\mathbf{4 1}$ sensors respectively, but the peak at $390 \mathrm{~nm}$ faded and a new peak appeared at $325 \mathrm{~nm}$ for $\mathbf{4 0}$ whereas, the absorption peak of probe 41 at $378 \mathrm{~nm}$ vanished and a new peak was generated at $430 \mathrm{~nm}$, upon the addition of $\mathrm{Pd}^{2+}$ ions, as evidenced by the color change to yellow from colorless in probe 41 only. In the presence of $\mathrm{Pd}^{2+}$ ions, both the fluorescence emission intensities of both sensors were significantly quenched, with probe $\mathbf{4 1}$ experiencing a more substantial quenching compared to 40. Job's plot suggested stoichiometry binding of both sensors with $\mathrm{Pd}^{2+}$ ion is in 1:1 ratio. Besides, both were found to behave as bidentate ligands [82], by binding through Sulphur of thiophene and hydroquinoline $\mathrm{N}$-atom to $\mathrm{Pd}^{2+}$ (Scheme 38 ), as confirmed by HRMS spectra, NMR spectra, and DFT studies. The LOD of probes 40 and 41 was calculated to be $49 \times 10^{-9} \mathrm{M}$ and $44 \times 10^{-9} \mathrm{M}$. These chemosensors illustrated better efficiency and promising results with a lower LOD.

It has also been observed that thiophene units as spacers in combination with crown ethers exhibit modulatory sensory behavior to obtain selective cationic $\left(\mathrm{Hg}^{2+}, \mathrm{Pb}^{2+}\right.$, $\mathrm{Cu}^{2+}, \mathrm{Pd}^{2+}$ ) chemosensors [83]. One such novel approach was made by Rosa et al. and wherein they synthesized new (oligo) thiophene bipendant-armed ligands and were assessed as chemosensors in the presence of $\mathrm{Na}^{+}, \mathrm{Ag}^{+}$, $\mathrm{Pd}^{2+}$ and $\mathrm{Hg}^{2+}$ in methane-sulfonic acid by spectrofluorimetric titrations. Compounds bearing bithiophene moiety were found to behave as a palladium chemosensor since enhanced fluorescence intensity was noticed. Subsequent additions of $\mathrm{Na}^{+}$and $\mathrm{Pd}^{2+}$ gradually enhanced the emission band intensity, which could be attributed to the fact that complexation of $\mathrm{Na}^{+}$at the crown ether occurs, followed by interaction of $\mathrm{Pd}^{2+}$ with sulphur atoms [84] of the bithiophene unit.

\section{Thiophene Based Chemosensors for the Detection of Anions}

Anions comprise an indispensable component of various clinical, industrial processes. Due to their beneficial and detrimental role in the living systems, there is a scope for anion
Scheme 43 Plausible sensing mechanism of probe $\mathbf{4 6}$ for $\mathrm{CN}^{-}$ions

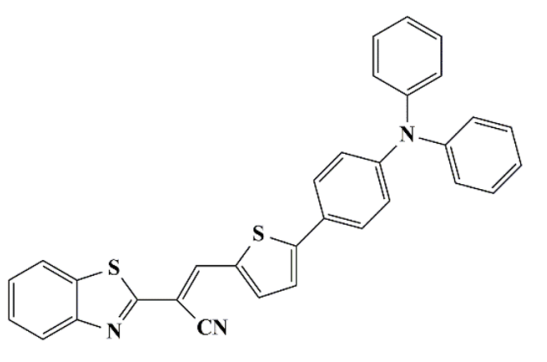

46

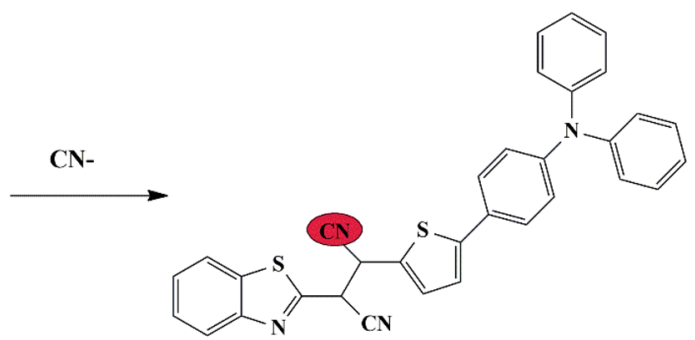

46- $\mathrm{CN}^{-}$ 
<smiles>CCCCc1ccc2cc(-c3csc(/N=C/c4ccc([O-])cc4[O-])c3C#N)c(=O)oc2c1</smiles>

Scheme 41 Turn-on Di-deprotonated chemosensor 44

recognition in the future employing fluorescent chemosensors, thereby quantifying and detecting the anions relatively inexpensive and easier. Few receptors assimilated with transition metal ions such as copper, nickel, zinc, and ruthenium normally respond to an analyte by manifesting perceptible color or optical changes through metal-anion interactions in a solution under neutral conditions. Some of the common anions are cyanide $\left(\mathrm{CN}^{-}\right)$, bisulfite $\left(\mathrm{HSO}_{3}{ }^{-}\right)$, Fluoride $\left(\mathrm{F}^{-}\right)$, Chloride $\left(\mathrm{Cl}^{-}\right)$, Bromide $\left(\mathrm{Br}^{-}\right)$, Iodide $\left(\mathrm{I}^{-}\right)$, Acetate $\left(\mathrm{AcO}^{-}\right)$, Perchlorate $\left(\mathrm{ClO}_{4}^{-}\right)$.

\section{Cyanide}

Cyanide ions are one of the most toxic ions because of their excellent binding ability with ferric $\left(\mathrm{Fe}^{3+}\right)$ ions in heme, which obstructs binding with reduced divalent ferrous $\left(\mathrm{Fe}^{2+}\right)$ ion and interrupts the electron transfer biological oxidation, causing internal asphyxia. The brain will be first damaged due to the condition of hypoxia, which consequently leads to respiratory problems and death [85]. Cyanide toxicity also induces convulsions, loss of consciousness. Because of its wide application in diverse sectors, developing a simple, quick method for detecting $\mathrm{CN}^{-}$ions is reasonably necessary.

Dan Wen synthesized a novel chemosensor $\mathbf{4 2}$ for quick detection of cyanide $\left(\mathrm{CN}^{-}\right)$ions. UV-Vis spectral studies confirmed that the absorbance band of $625 \mathrm{~nm}$, exhibited by the sensor in $\mathrm{CH}_{3} \mathrm{CN} / \mathrm{H}_{2} \mathrm{O}$ (v/v 1:1) gradually reduced, and new absorbance bands at $430 \mathrm{~nm}$ and $458 \mathrm{~nm}$ occurred, with a color change from blue to yellow only for $\mathrm{CN}^{-}$ions, which is attributable to the blocking of ICT between the hemicyanin moiety and sensor $\mathbf{4 2}$ due to the nucleophilic attack of $\mathrm{CN}^{-}$to indolium group (Scheme 39). Moreover, investigating the practical applications of the probe, it was observed that sensor $\mathbf{4 2}$ filter paper could detect $\mathrm{CN}^{-}$, which is evident by the color change from blue to yellow and the LOD was noted to be $0.89 \mu \mathrm{M}$ [86], implying that the probe could be implemented for the detection of $\mathrm{CN}^{-}$ions.

Min et al. developed a new probe 43 [((E)-3-((4(diethylamino)-2-hydroxybenzylidene) amino)-2,3dihydrothiophene-2-carboxamide)] for $\mathrm{CN}^{-}$detection. UV-Vis titrations studies revealed that the peak at $430 \mathrm{~nm}$ decreased, with the occurrence of two new bands at $320 \mathrm{~nm}$ and 470 $\mathrm{nm}$ upon the addition of $\mathrm{CN}^{-}$ions to the probe solution. It was able to selectively sense $\mathrm{CN}^{-}$ions through fluorescence enhancement. ESI-MS data and job plots were analyzed, and the binding mode was in 1:1 stoichiometry. The LOD for $\mathrm{CN}^{-}$was $44.6 \mu \mathrm{M}$, and the detection process was proposed through H-NMR titrations, which showed that deprotonation of the probe could result in the ICT suppression, thereby inducing fluorescence 'turn-on' of probe 43- $\mathrm{H}^{+}$(Scheme 40). From the results, it was then confirmed that the probe [87] could be utilized for the selective detection of $\mathrm{CN}^{-}$by the fluorescent turn-on method in aqueous systems.

Various chemosensors have been established for the $\mathrm{CN}^{-}$detection that is soluble in aqueous media to mimic the real environment. But, developing a chemosensor for the selective detection of $\mathrm{CN}^{-}$ions in the presence of highly
Scheme 42 Proposed sensing mechanism of $\mathbf{4 5}$ for $\mathrm{CN}^{-}$ions

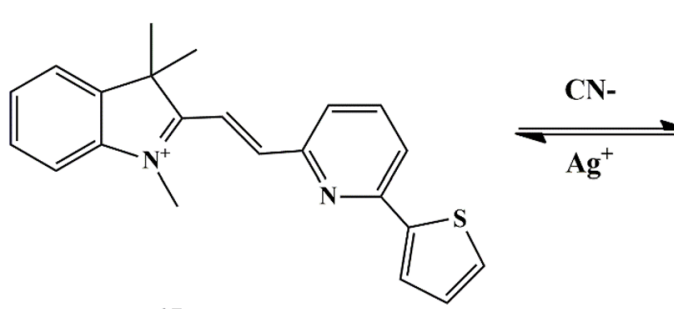

45

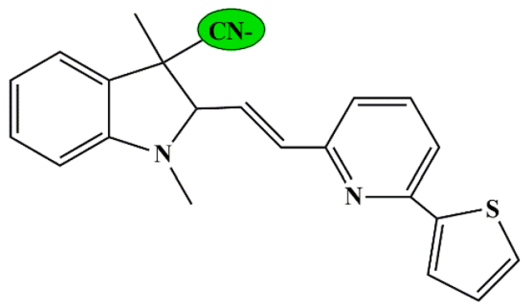

$45-\mathrm{CN}^{-}$ 
competitive ions such as $\mathrm{F}^{-}, \mathrm{I}^{-}$remains a challenge. In this regard, Meryem and his colleagues synthesized a coumarinthiophene-based schiff base chemosensor 44. The anion sensing properties were carried out in DMSO and water and further compared. The chemosensor in DMSO with only $\mathrm{F}^{-}$, $\mathrm{CN}^{-}$and $\mathrm{AcO}^{-}$ions showed few spectral changes in the UVVis titration spectra, whereas colorimetric sensing showed that only $\mathrm{F}^{-}, \mathrm{AcO}^{-}, \mathrm{CN}^{-}, \mathrm{H}_{3} \mathrm{PO}_{4}^{-}$ions exhibited a color change of the solution from yellow to orange. However, chemosensor 44 in DMSO/ $\mathrm{H}_{2} \mathrm{O}$ (v/v 1:9) exhibited selectivity only towards $\mathrm{CN}^{-}$ions with a $1: 1$ binding stoichiometric ratio, which was evident by the increased fluorescence intensity in the fluorescence spectra. H-NMR spectroscopy studies, corroborated by DFT and TD-DFT results confirmed the mechanism of the sensing process, which displayed the deprotonation [88] of hydroxyl moiety on the phenyl part of the schiff base upon reaction with $\mathrm{CN}^{-}$ions (Scheme 41). Nevertheless, the reversibility studies were carried out in TFA, and the sensing reaction was found to be reversible. The detection limit for $\mathrm{CN}^{-}$ions in an aqueous solution was $0.32 \mu \mathrm{M}$, which was relatively lower than in organic media $(\mathrm{LOD}=1.69 \mu \mathrm{M})$. The results indicated that the chemosensor could quickly detect $\mathrm{CN}^{-}$via a di-deprotonation and ICT mechanism in the aqueous solution. Furthermore, the possibility of chemosensor being used in practical applications was evaluated using tap water, and it was observed that chemosensor $\mathbf{4 4}$ showed high-intensity green fluorescence on reaction with $\mathrm{CN}^{-}$ions, thereby paving the way for real-time monitoring of anions in aqueous and environmental samples. Moreover, the probe was also explored to be DNA-detection agent due to the intercalation of $\mathbf{4 4}$ into duplex DNA.

A ratiometric probe was reported by Ajit Kumar et al. wherein an indole conjugated thiophene-pyridyl-based probe 45 was employed for $\mathrm{CN}^{-}$detection. Fluorescence Titration of the probe with $\mathrm{CN}^{-}$exhibited a blue shift along with fluorescence quenching of the band at $619 \mathrm{~nm}$ and the emergence of a new band at $504 \mathrm{~nm}$. The absorbance titrations exhibited spectral changes, with a noticeable color change from dark brown to colorless in the presence of $\mathrm{CN}^{-}$ions and could be assigned to the blocking of ICT due to the adduct formed by the nucleophilic addition of $\mathrm{CN}^{-}$to indolyl cation of probe 45 (Scheme 42); confirmed by TD-DFT calculations [89] and HRMS spectra, with 1:1 stoichiometric ratio between the probe and $\mathrm{CN}^{-}$ions. Furthermore, fluorescence competitive titrations were carried out, which revealed that the probe was highly sensitive towards $\mathrm{CN}^{-}$ions. For the practical application of the probe, the test paper strips based on probe 45 were prepared, which could detect $\mathrm{CN}^{-}$with an immediate color change. It could also be used for biomedical applications for sensing $\mathrm{CN}^{-}$at significantly lower concentrations.

Yan Zhao synthesized an off-on type fluorescent chemosensor 46, which has a triphenyl amine bearing thiophene derivative of benzothiazole as a $\mathrm{CN}^{-}$sensor. The free probe showed a broad absorbance band at $545 \mathrm{~nm}$ in PBS buffer in the UV-Vis absorption spectra, which decreased along with the emergence of a new band at $340 \mathrm{~nm}$ upon addition of $\mathrm{CN}^{-}$. It was also seen that strong 'turn-on' fluorescence enhancement is notable only for the $\mathrm{CN}^{-}$ions, without any interference by other anions. The Job's plot indicated a 1:1 binding mode between probe and $\mathrm{CN}^{-}$and the LOD for the $\mathrm{CN}^{-}$ions is $4.24 \times 10^{-8} \mathrm{M}$. The fluorescence enhancement is ascribed to the interruption of ICT of the probe [90] due to the attack of $\mathrm{CN}^{-}$ions at the cyano vinyl group (Scheme 43), as corroborated by NMR studies and DFT calculations. Furthermore, probe $\mathbf{4 6}$ could be used in real-time monitoring of $\mathrm{CN}^{-}$ions by test strips in aqueous solution, evidenced by the color change from mild violet to light yellow-green fluorescence, under UV light only in the presence of $\mathrm{CN}^{-}$and could also be implemented for fluorescence imaging of live cells.

Numerous sensing mechanisms for $\mathrm{CN}^{-}$have been proposed for fluorescent chemosensors via different mechanisms, with nucleophilic addition being the highly selective mechanism to sense $\mathrm{CN}^{-}$ions. Utilizing this sensing mechanism, $\mathrm{Zi}$ Hua et al. synthesized and evaluated the sensing properties of a novel triphenylamine thiophene-based (with dicyanovinyl moieties) probe 47 . The free probe exhibited pink non-fluorescent color due to the ICT mechanism [91], which further faded in the presence of $\mathrm{CN}^{-}$ions, accompanied by a fluorescence emission enhancement at $480 \mathrm{~nm}$.
Scheme 44 Proposed sensing mechanism of probe $\mathbf{4 7}$ for $\mathrm{CN}^{-}$ions

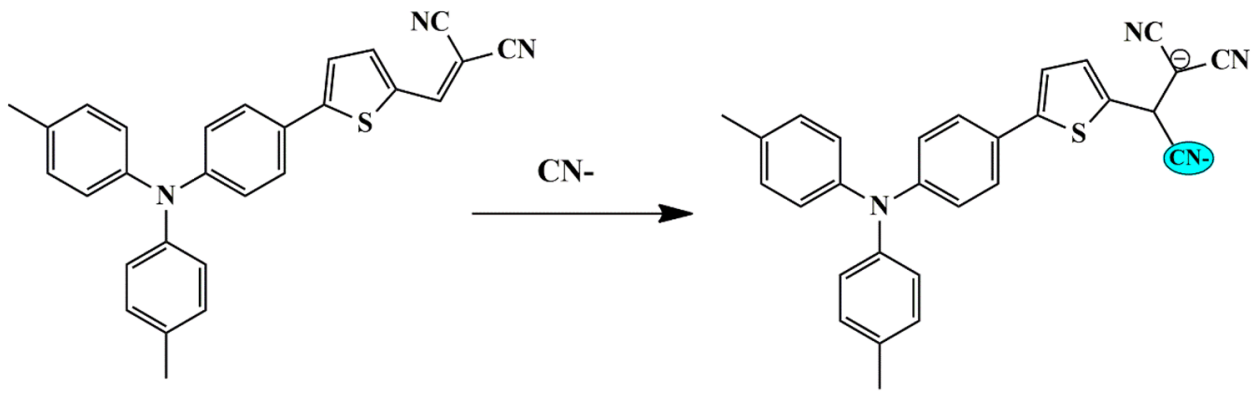

$47-\mathrm{CN}^{-}$ 
Furthermore, the UV-Vis absorbance spectra revealed that only for $\mathrm{CN}^{-}$, spectral changes and color change of light pink to colorless under naked-eye and bright blue under UV light was observed. The sensing mechanism is attributable to the nucleophilic addition reaction to form probe [47$\mathrm{CN}^{-}$] adduct (Scheme 44). Moreover, a low LOD was determined to be $51 \mathrm{nM}$, which indicates that the probe could be employed to detect low levels of $\mathrm{CN}^{-}$in drinking water, which also met the requirements of $\mathrm{WHO}$ for $\mathrm{CN}^{-}$detection. Additionally, probe $\mathbf{4 7}$ could be employed in bio-imaging to detect $\mathrm{CN}^{-}$ions in HeLa cells in a concentration-dependent manner, with lower cytotoxicity and good cell permeability.

In recent years, chemosensors relying on copper ion displacement for $\mathrm{CN}^{-}$detection have achieved significant attention. Successful examples are the coumarin-based schiff bases 48 and 49 chemosensors possessing furan and thiophene as the side groups respectively, developed by Kangnan and group. Both the chemosensors showed high affinity towards $\mathrm{Cu}^{2+}$ ions, which was evident by the spectral changes and fluorescence quenching, indicating the complex formation of $48 / 49-\mathrm{Cu}^{2+}$ and PET processes, respectively. Moreover, probe $\mathbf{4 8 / 4 9 -}-\mathrm{Cu}^{2+}$ complex could detect $\mathrm{CN}^{-}$ions, with obvious and immediate color change from red to yellow-green, which is assigned to the strong binding ability of $\mathrm{Cu}^{2+}$ towards $\mathrm{CN}^{-}$ions, consequently resulting in the $\mathrm{Cu}^{2+}$ removal from the complex and recovery of the probes, thereby showing the copper displacement mechanism [92] (Scheme 45). The detection limits of probe 48- $\mathrm{Cu}^{2+}$ and $49-\mathrm{Cu}^{2+}$ for $\mathrm{CN}^{-}$were $0.019 \mu \mathrm{M}$ and 0.02 $\mu \mathrm{M}$, respectively. The reversibility of these chemosensors was evaluated and was found to exhibit a 'turn on-off' mechanism with the introduction of $\mathrm{CN}^{-}$. Therefore, both probes could be re-used several times for $\mathrm{CN}^{-}$detection.

\section{Fluoride}

Fluoride is naturally present in the human body in bones and teeth and drinking water is the primary source of fluoride ions. However, excess fluoride is hazardous and can be detrimental to life by causing severe dental fluorosis or skeletal fluorosis [93]. It is highly beneficial to develop a highly effective chemosensor that can selectively detect $\mathrm{F}^{-}$ions with the naked eye response.

One successful approach was made by Renuga et al. who synthesized fluorescent receptor $\mathbf{5 0}$ [2,20 -(1E,10 E)-(thiophene-2,5-diylbis(methan-1-yl-1-ylidene)] for selective detection of $\mathrm{F}^{-}$ions in the presence of competing anions in $\mathrm{CH}_{3} \mathrm{CN}$. A color change was observed from fluorescent green to orange in the presence of $\mathrm{F}^{-}$ions only, which could be attributed to the $\mathrm{H}$-bonding between the $\mathrm{OH}^{-}$group of receptor $\mathbf{5 0}$ and $\mathrm{F}^{-}$ions (Scheme 46). Upon using spectrophotometric techniques, a new red-shifted absorption band centered at $520 \mathrm{~nm}$ was observed for an increase in $\mathrm{F}^{-}$ions [94], which could be explained by the Internal Charge Transfer mechanism. The binding constant was calculated as $1.3 \times 10^{3}$ and the binding between the receptor and anion was in 1:1 binding stoichiometry. Further, fluorescence spectra displayed that the receptor produced a strong emission band at $510 \mathrm{~nm}$ and $545 \mathrm{~nm}$ because of its strong fluorescent nature, manifesting that the chemosensor can be utilized to detect $\mathrm{F}^{-}$in the presence of competing anions.

Few Thiophene derivatives have also been reported for the sensing of anions, due to their optical property. For instance, Ufuk Yanar et al. synthesized novel coumarinacetamido thiophene-based colorimetric and fluorometric chemosensor $\mathbf{5 1}$ for ratiometric sensing of anions. The chemosensor exhibited visible colorimetric changes (color change from light yellow to deep yellow) and emission quenching in the presence of $\mathrm{CN}^{-}, \mathrm{F}^{-}$and $\mathrm{AcO}^{-}$in DMSO. Nevertheless, the probe was more sensitive to $\mathrm{CN}^{-}$than $\mathrm{F}^{-}$and $\mathrm{AcO}^{-}$at the stoichiometric binding ratio of 1:2:5. Molecular orbital analysis was studied, which explained that the fluorescent property and the quenching property of probe 51 were because of the $\pi-\pi^{*}$ transition on coumarin and ¡charge transfer transition from donor to acceptor unit, respectively. The mechanism of fluorescence quenching was due to ICT [95] (Scheme 47), which was supported by Computational studies.<smiles></smiles> 
Scheme 46 Probable sensing mechanism of $\mathbf{5 0}$ towards $\mathrm{F}^{-}$ions

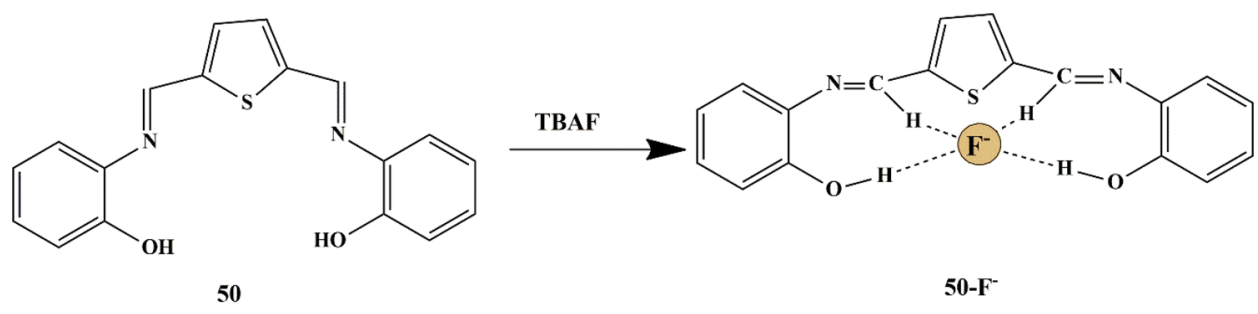

An innovative approach was made by Neeraj et al. who attempted and succeeded in controlling the selectivity of the sensor by modification of the side groups of the hydrazone Schiff bases of sensors, which were derived from 1,8-naphthalimide and substituted furan/ thiophene ring systems. All four sensors responded selectively to $\mathrm{F}^{-}$and $\mathrm{CN}^{-}$ions with an abrupt color change from yellow to blue. The fluorescent emission intensity was quenched significantly with negligible interferences from other tested anions. It was concluded that a stoichiometric binding ratio of 2:1 exists between probes $\mathbf{5 2 / 5 3}$ (having thiophene/ furan rings respectively) and $\mathrm{F}^{-}$ions, while 1:1 binding mode exists between probes $\mathbf{5 4 / 5 5}$ (having furan with $-\mathrm{NO}_{2}$ and furan with $-\mathrm{CH}_{3}$ group respectively) with $\mathrm{F}^{-}$and $\mathrm{CN}^{-}$respectively. Sensors $\mathbf{5 2}$ and $\mathbf{5 3}$ were found to exhibit the lowest detection limit of $0.04 \mathrm{ppm}$ and $0.07 \mathrm{ppm}$ for $\mathrm{F}^{-}$and $\mathrm{CN}^{-}$ions. Moreover, the mechanism of detection was due to the Hydrogen bonding succeeded by deprotonation, resulting in the ICT process. In addition, discriminative detection of anions was performed with $\mathrm{Cu}^{2+}$ ions, and it was found that sensors $\mathbf{5 4}$ and $\mathbf{5 5}$ exhibited selective recognition of $\mathrm{F}^{-}$over $\mathrm{CN}^{-}$ions; which was evident by spectral changes and the 'naked eye' color change from bright yellow to dull yellow, whereas yellow to green for sensor $\mathbf{5 4}$ and $\mathbf{5 5}$ respectively [96]. Only sensors $\mathbf{5 4}$ and $\mathbf{5 5}$ could effectively detect both $\mathrm{F}^{-}$and $\mathrm{CN}^{-}$, whereas $\mathbf{5 2 / 5 3}$ was less effective in $\mathrm{CN}^{-}$detection because of the loss of $\mathrm{CN}^{-}$fluorescence by the addition of other anions. The applicability of sensors was examined by test strip experiments, which exhibited significant color changes upon the detection of $\mathrm{F}^{-} / \mathrm{CN}^{-}$ions.

Following the same design guide, Siddarth et al. synthesized a new bis Schiff base $\mathbf{5 6}$ with dual -NH functionality for $\mathrm{F}^{-}$detection. The chromogenic response of the probe in $\mathrm{CH}_{3} \mathrm{CN}$ solution was found to be selective to $\mathrm{F}^{-}$over other anion analytes, which was evident by the naked-eye color change from colorless to red. The UV-Vis absorbance spectra of the free probe exhibited two peaks at $260 \mathrm{~nm}$ and $380 \mathrm{~nm}$, which were then subjected to red-shift along with the occurrence of a new band at 478 upon the addition of $\mathrm{F}^{-}$ions. The sensing mechanism could be assigned to the Hydrogen bonding and deprotonation [97] between probe 56 and $\mathrm{F}^{-}$ions (Scheme 48) with 1:2 stoichiometry, corroborated by H-NMR studies and DFT studies. The LOD was calculated to be $6.9 \times 10^{-7} \mathrm{M}$, with a response time of $20 \mathrm{~s}$, thereby meeting the requirements of real-time monitoring of $\mathrm{F}^{-}$ions.

Recently, various AIEE based fluorescent dyes based have been synthesized, since they could be an efficient optical tool exhibiting distinctive properties with promising results, and therefore could be employed in bioimaging,

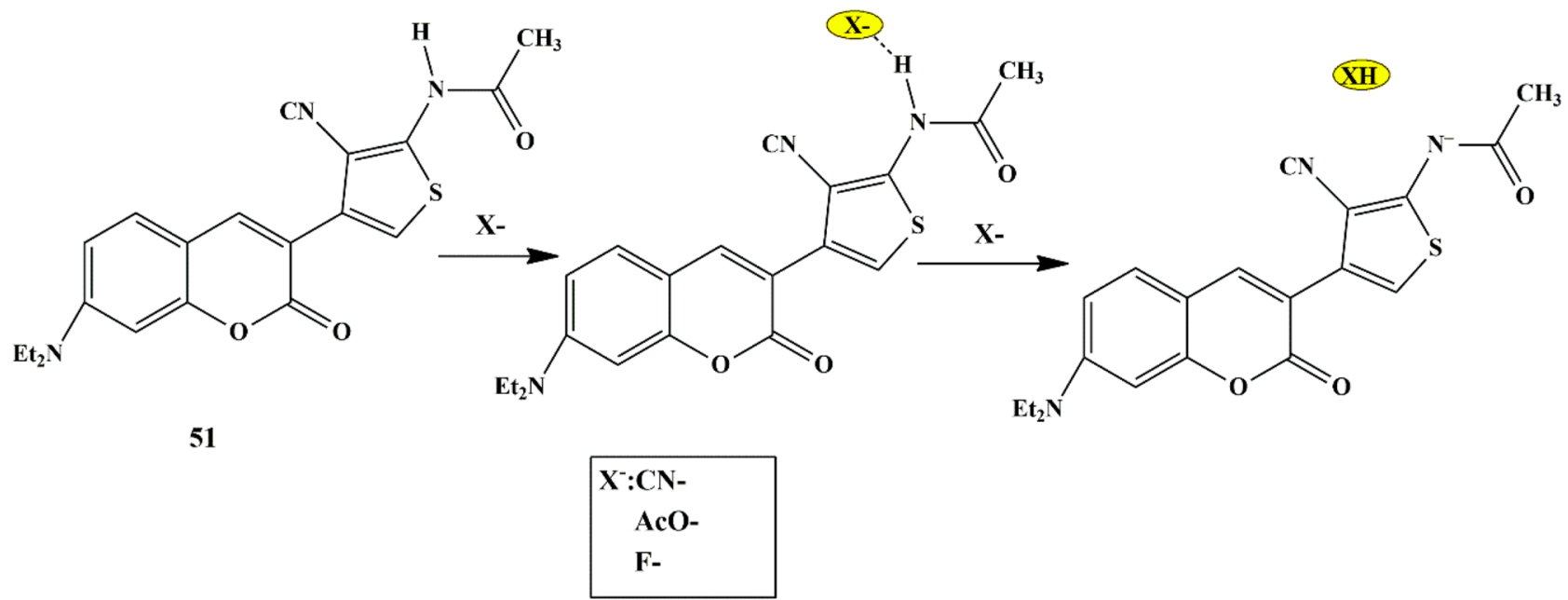

Scheme 47 A suggested mechanism for the detection of anions by $\mathbf{5 1}$ 


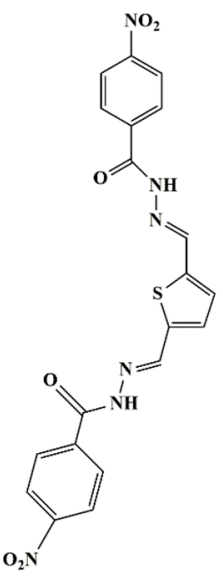

56

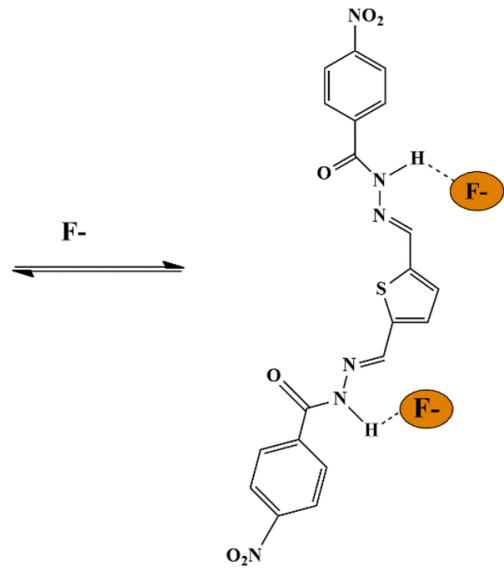

$56-\mathrm{F}^{-}$
Scheme 48 Proposed sensing mechanism of probe $\mathbf{5 6}$ for $\mathrm{F}^{-}$ions

organic light-emitting devices, and chemosensors. One such approach was made by Pranjalee et al. who synthesized a pyrene-thiophene-based probe $\mathbf{5 7}$ based on the AIEE property for $\mathrm{F}^{-}$detection. The probe exhibited a new peak at $450 \mathrm{~nm}$ with a hypochromic shift in the UV spectra, along with the visible color change from colorless to bright yellow upon interaction with $\mathrm{F}^{-}$ions, without the perturbation of detection by other anions. Furthermore, the UV-titration experiments revealed a new peak at $450 \mathrm{~nm}$, which indicates $\mathrm{H}$-bonding between $\mathrm{F}^{-}$and probe 57, thereby inducing the deprotonation of $\mathrm{NH}$ group with increasing $\mathrm{F}^{-}$ion concentration, resulting in push-pull effect, further confirmed by NMR and DFT studies. The binding mode was found to be in 1:1 stoichiometry ratio, and the LOD was estimated to be $2.02 \times 10^{-7} \mathrm{M}$. The AIEE property of probe 57 was evaluated in the $\mathrm{CH}_{3} \mathrm{CN} / \mathrm{H}_{2} \mathrm{O}$ mixture and could be attributed to the hindered intramolecular rotation and the formation of J-type aggregates [98] (Scheme 49) which suppresses the non-radiative decay of excited state. The potentiality of the sensor to sense $\mathrm{F}^{-}$was also evaluated by test strip experiments. The sensor displayed a visible color change of strips from colorless to yellow (under UV light) upon detection of $\mathrm{F}^{-}$, thereby signifying its potential application for $\mathrm{F}^{-}$recognition.

Presumably, Thienothiophene (TTs) moiety has rarely been employed as a donor group in Donor-Acceptor systems possessing excellent sensing properties. Thienothiophenes is one of the structurally derived thiophene isomers, which has an electron-rich conjugated structure, and is integrated with polymers and other small compounds to enhance their photophysical and electronic properties, thereby upgrading the device performance. In the past few years, thiophenes bearing electron-deficient borane in the main and side chains of oligomers, and polymers have gained significant importance, and representative examples are the chemosensors 58 and 59, possessing conjugated thieno[3,2-b]thiophene and cross-conjugated thieno[2,3-b]thiophene, developed by Gulsen et al. for $\mathrm{F}^{-}$detection. The vital photophysical behaviors of both sensors were due to the ICT mechanism between thienothiophenes and two bulky dimesitylboron units. Sensor 58 exhibited exceptional bathochromic shifts in both absorption and fluorescence spectra as compared to sensor 59. Furthermore, both sensors showed positive emission solvatochromism with an increase in solvent polarity owing to their quadrupolar structures. Among the two sensors, $\mathbf{5 8}$ was found to be an efficient blue emitter. The characteristic spectral changes in the absorption and emission spectra and noticeable color change were observed upon binding of only Lewis base $\mathrm{F}^{-}$to the Lewis acid organoboron group [99]. The results concluded that probe $\mathbf{5 9}$ responded through turn-on and probe $\mathbf{5 9}$ responded through 'turn-off' response, thereby possessing high sensitivity and selectivity toward $\mathrm{F}^{-}$anions without interference from other anions. The high quantum yield, good solvatochromic behavior, and intense interaction with $\mathrm{F}^{-}$anions entitle these compounds to be used as potential luminescent chemosensors.

One more similar approach was made by the same group of researchers Gulsen et al. who synthesized four novel Organoboron copolymers consisting of thienothiophene and selenothiophene analogs with thiophene $\pi$-spacer. The sensors 61 and 63 having cross-conjugated selenopheno[2,3$b]$ thiophene and thieno[2,3-b]-thiophene, respectively

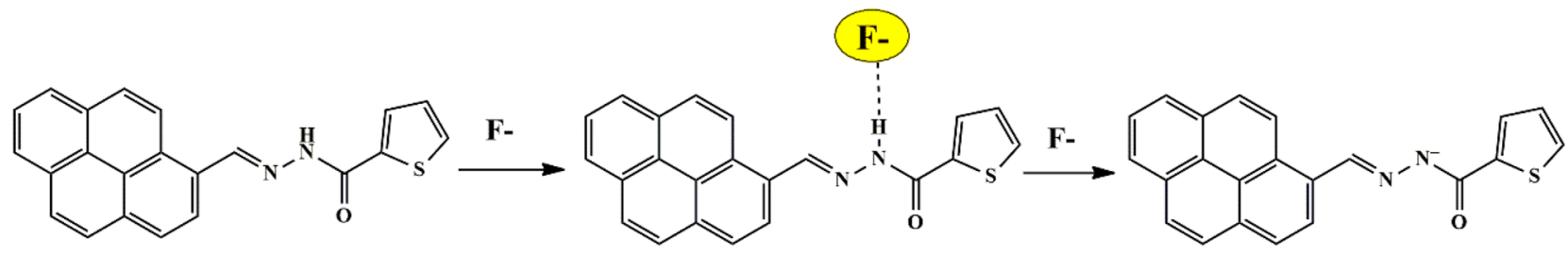

57 


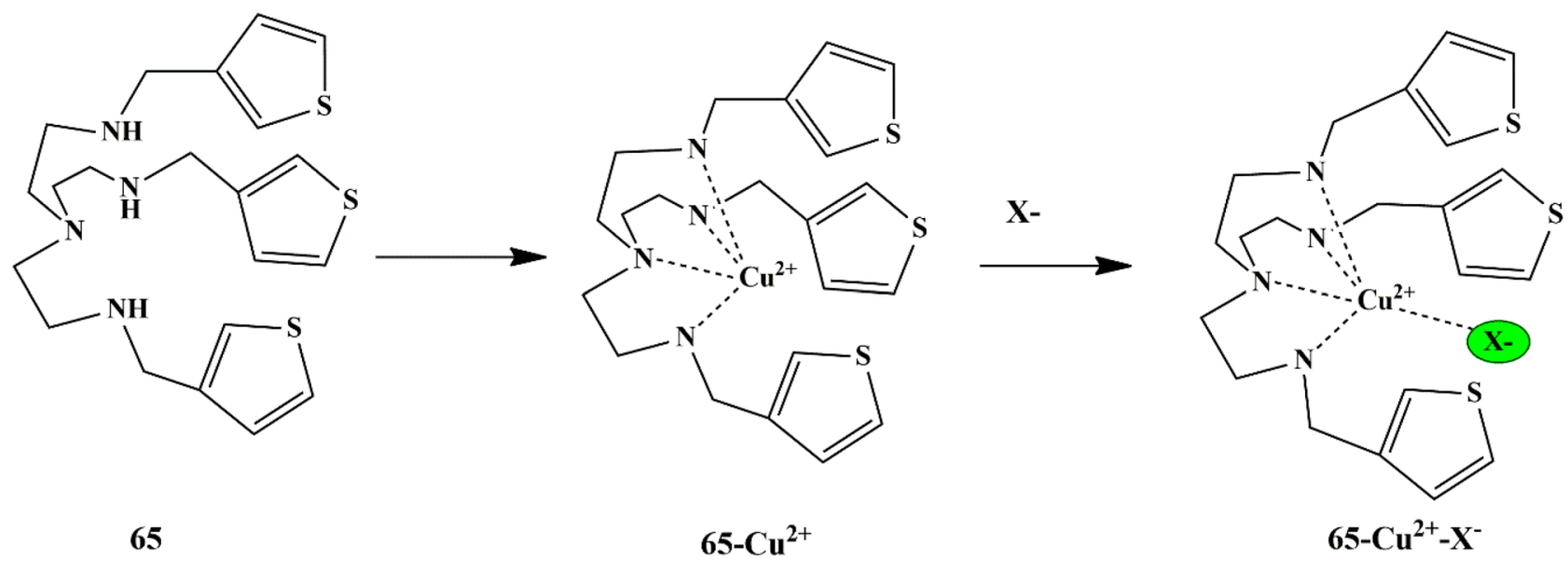

Scheme 50 Proposed halide bound complex

exhibited weak spectral changes due to the poor electronic couplings of cross-conjugated donors and mesityl boron acceptor in the polymer chain. In contrast, probes $\mathbf{6 0}$ and $\mathbf{6 2}$ exhibited strong spectral changes in the UV-Vis absorption spectra. Furthermore, it was found that probe $\mathbf{6 0}$ exhibited the lowest bandgap as compared to the other copolymers, and it also exhibited the largest stokes shift [100]. All sensors exhibited a turn-off response accompanied by a color change from yellow to colorless, among which probe $\mathbf{6 3}$ showed selective sensitivity of $\mathrm{F}^{-}$because of the presence of less polarizable sulfur atom of thiophene compared to selenium and its cross-conjugated structure. Therefore, these copolymers could be employed as promising candidates for $\mathrm{F}^{-}$detection.

\section{lodide}

Iodine is a trace element, which mainly exists in the form of iodide in the human body, and is involved in biological functions, for instance, thyroid gland function. Apart from that, elemental iodine has been exploited in diverse applications, for instance, in the manufacturing of dyes, synthesis of some organic chemicals, and medicine. On that account, it is crucial to develop sensitive chemosensors to detect $\mathrm{I}^{-}$in food, pharmaceutical products, and biological samples.
Kannikanti et al. synthesized a turn-off fluorescent chemosensor 64 [2,5-bis(4-phenylquinazolin-2-yl) thiophene] for the sensing and detection of $\mathrm{I}^{-}$ions. The recognition of probe towards anions was studied by absorption and emission spectra, which revealed that the spectra remained unaltered until $\mathrm{I}^{-}$ion was added to the $\mathrm{CH}_{3} \mathrm{CN}$ solution of the probe. The absorption of the probe was observed at $291 \mathrm{~nm}$ and $362 \mathrm{~nm}$ with a color change from colorless to yellow. Correspondingly, the fluorescence emission intensity of the probe quenches upon interaction with $\mathrm{I}^{-}$ion with $2: 1$ stoichiometry. The LOD for $\mathrm{I}^{-}$was found to be $1.7 \times 10^{-7} \mathrm{M}$ [73]. Furthermore, to evaluate its potentiality in practical applications, probe $\mathbf{6 4}$ was utilized to construct a field test kit for the qualitative analysis of $\mathrm{I}^{-}$in aqueous samples.

Syed et al. synthesized a novel thiophene-based tripodal copper (II) complex receptor $\mathbf{6 5}$ to detect halides. It showed distinct color changes in $\mathrm{CH}_{3} \mathrm{CN}$ solution from blue to aqua, lime, turquoise, and greenish-yellow in the presence of $\mathrm{F}^{-}$, $\mathrm{Cl}^{-}, \mathrm{Br}^{-}, \mathrm{I}^{-}$ions, respectively. The binding properties of the receptor were evaluated by UV-Vis titration experiments, which exhibited a 1:1 stoichiometric complex of receptor $\mathbf{6 5}$ with each halide. Furthermore, it was observed that the receptor responded distinctly to different halides concerning the intensity and absorption maximum, due to axial ligation of the respective halide to the coordinatively unsaturated
Scheme 51 Possible mechanism of probe $\mathbf{6 7}$ binding to Bisulphite

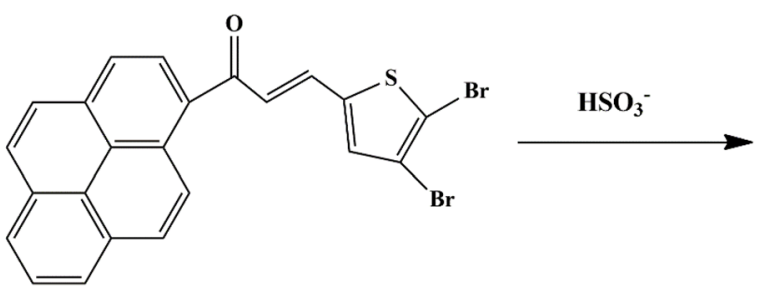

67

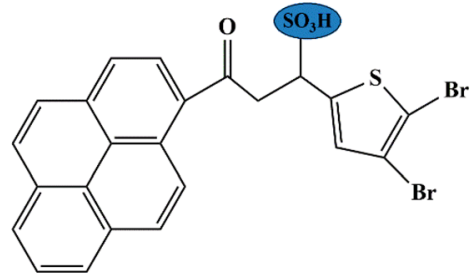

$67-\mathrm{HSO}_{3}^{-}$ 


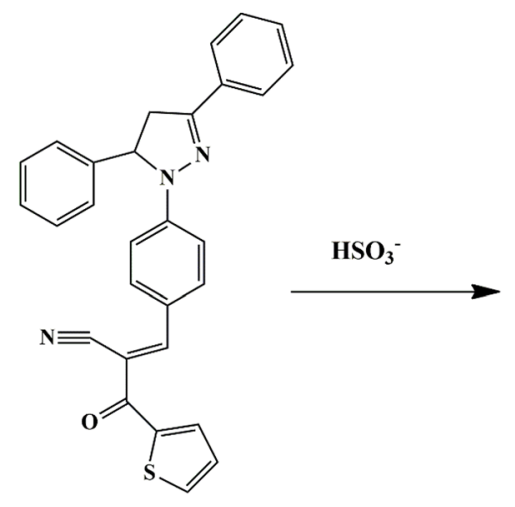

69

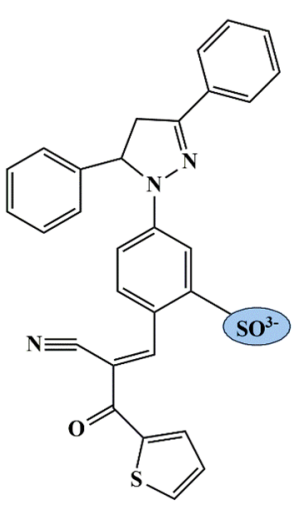

69- $\mathrm{SO}_{3}^{-}$
Scheme 52 Suggested mechanism of probe $\mathbf{6 9}$ binding to Bisulphite

copper center, resulting in the halide complex formation (Scheme 50). The order of receptor $\mathbf{6 5}$ bindings to the halides was observed in the order of $\mathrm{F}^{-}>\mathrm{Cl}^{-}>\mathrm{Br}^{-}>\mathrm{I}^{-}$, which is ascribed to the basicity of the respective halide. Along with this, the effect of solvent polarity on receptor was studied by using $\mathrm{CH}_{3} \mathrm{CN} / \mathrm{H}_{2} \mathrm{O}$ mixture in addition to $\mathrm{CH}_{3} \mathrm{CN}$, and it was found that the receptor-halide complex showed a weaker binding trend compared to the observed binding trend [101] in pure $\mathrm{CH}_{3} \mathrm{CN}$, because of increasing solvent polarity.

Conjugated polyelectrolytes have acquired significant attention for many years because of their optical properties and potential applications in optical sensors and biological imaging. They exhibit outstanding characteristics, for instance, their energy transfer which is quite useful as biomarkers by fluorescence quenching and FRET mechanism, high sensitivity, and selectivity by electrostatic binding to target analytes. Moreover, diblocked copolymers of polythiophenes (PT) and Polyflourene (PF) are valuable, versatile materials. One such representative is the conjugated $\mathrm{AB}$ diblock copolymer $\mathbf{6 6}$ [poly[9,9-bis(2-ethylhexyl)fluorene]b-poly[3-(6-trimethylammoniumhexyl) thiophene]bromide] designed by Sofia et al. for the selective sensing of anions. The absorbance spectrum of the free sensor exhibited structured emission at 400-500 nm and 520-500 nm due to the PF and PT units, respectively, along with distinct fluorescence emission resulting from incomplete energy transfer between the PF and PT units [102]. The halide sensing of probe $\mathbf{6 6}$ was evident by the decrease in fluorescence quenching of the PT unit in the presence of halides, clearly following the quenching order of $\mathrm{I}^{-}>\mathrm{Br}^{-}>\mathrm{Cl}^{-}$, which could be attributed to heavy atom effects and electron transfer. Nevertheless, the sensor could also be employed for DNA quantification by the formation of nanostructured networks.

\section{Bisulphite}

Bisulfites have various applications in wastewater treatment, in the prevention of corrosion, and in DNA sequencing. They also play an essential role in pharmaceuticals, food, and beverage industries since $\mathrm{HSO}_{3}{ }^{-}$can hinder oxidation, microbial and enzymatic reactions. However, anthropogenic activities ensue a substantial input to the atmospheric burden of sulfur compounds regionally and globally, which could be threatening to human health and the environment. Sulfur dioxide $\left(\mathrm{SO}_{2}\right)$ is one such primary air contaminant. When inhaled can be converted into bisulfites and sulfites, thereby causing asthmatic attacks, negatively influencing cardiovascular diseases and lung cancer allergic reactions if inhaled excessively. Therefore, there is a high demand for the development of chemosensors for $\mathrm{HSO}_{3}{ }^{-}$detection.

Considering the above issues, Jianbin et al. synthesized a Thiophene attached pyrene-based probe $\mathbf{6 7}$ and investigated its sensing properties towards $\mathrm{HSO}_{3}{ }^{-}$ions. From the absorption and Fluorescence spectra in $\mathrm{H}_{2} \mathrm{O}$ /ethanol solution ( $\mathrm{v} / \mathrm{v}$ 9:1), it was observed that the absorption peak of the probe at $332 \& 411 \mathrm{~nm}$ reduced gradually, while the fluorescence intensity at $530 \mathrm{~nm}$ reduced along with the simultaneous emergence of a new band at $420 \mathrm{~nm}$ upon the addition of $\mathrm{HSO}_{3}{ }^{-}$ions. Furthermore, the fluorescence spectra showed that the tested anions showed negligible fluorescence intensity except for $\mathrm{HSO}_{3}{ }^{-}$, which displayed a dramatically enhanced fluorescence intensity of the probe, and this could be attributed to the Michael addition reaction (Scheme 51) between probe 67 and $\mathrm{HSO}_{3}{ }^{-}$, confirmed by HRMS spectra.

To evaluate the potentiality of the probe in biological applications, fluorescence imaging was accomplished in
Scheme 53 Plausible detection mechanism of Probe 70- $\mathrm{Cu}^{2+}$ ensemble for $\mathrm{S}^{2-}$ ions
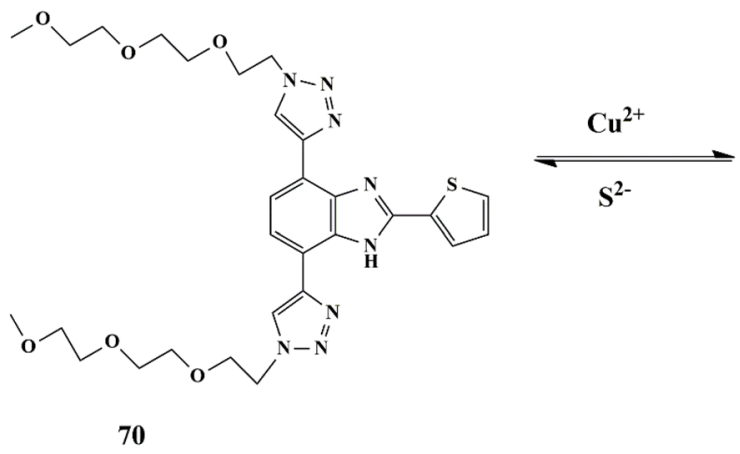
Scheme 54 Possible mechanism of probe $\mathbf{7 1}$ binding to Bisulphite

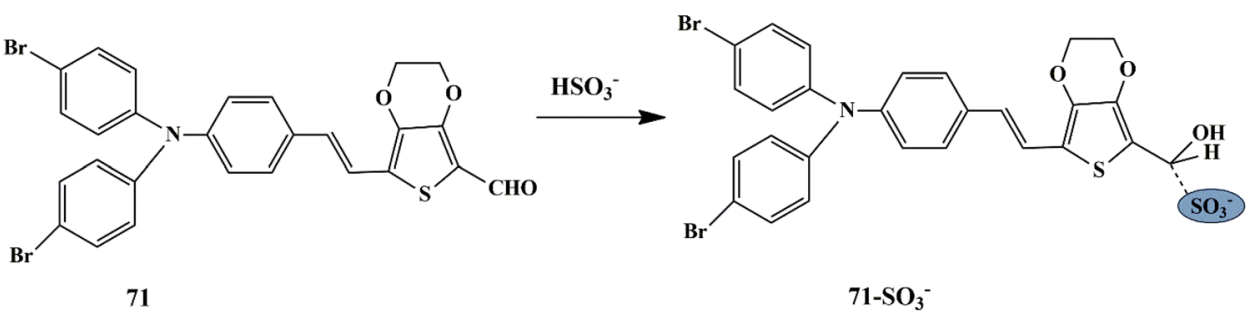

A549 cells, C. elegans, and zebrafish, which displayed a decrease of yellow fluorescence emission by the free probe and enhancement of blue fluorescence emission upon the incubation of probe 67 with $\mathrm{HSO}_{3}{ }^{-}$in the cells, which indicated that the probe possessed a good cell membrane permeability [103] and could be employed in the detection of exogenous and endogenous $\mathrm{HSO}_{3}{ }^{-}$ions in vivo.

Tomascz et al. synthesized two Off-On pyrazoline-based chemosensors 68 and 69 having two different end groups being phenyl and thiophene moieties respectively, which were capable of detecting sulphite anions. Both the probes exhibited weak ICT fluorescence, which is obstructed after the nucleophilic sulfite ion attachment to the $\alpha$, $\beta$-unsaturated ketone part of the probe, confirmed by NMR and DFT studies. Subsequently, a blue shift of the absorption and emission spectra of the probes was seen, corresponding to a visible naked eye color change from orange to colorless. Among the two probes, 69 was found to be effective in the selective detection of $\mathrm{HSO}_{3}{ }^{-}$by significant quenching due to the presence of the thiophene group (Scheme 52). Nevertheless, the practical application of the probes was illustrated by utilizing a paper test strip method for $\mathrm{HSO}_{3}{ }^{-}$detection. It was observed that the paper discolored from orange or yellow to blue [104], confirming its potentiality to detect $\mathrm{HSO}_{3}{ }^{-}$in water samples. In this study, a simple replacement of end groups by thiophene surpassed the response time by 1.2 times and the detection limit by 1.5 times.

Encouraged by the need for water-soluble fluorescent chemosensors, Chak Shing et al. synthesized a Thiophenebenzimidazole-based chemosensor $\mathbf{7 0}$ to detect $\mathrm{S}^{2-}$ ions in Water. The strong blue fluorescence of the free probe was observed to be quenched due to the formation of the probe 70- $\mathrm{Cu}^{2+}$ ensemble (Scheme 53). It restored fluorescence by the presence of $\mathrm{S}^{2-}$ anions (4 equivalents) only, exhibiting a 'turn-on' response. The LOD of 71- $\mathrm{Cu}^{2+}$ towards $\mathrm{S}^{2-}$ was found to be 354 nM. Furthermore, Cytotoxicity studies of live cells revealed that the probe showed low toxicity and could be a potent sensor for detecting $\mathrm{S}^{2-}$ intracellularly [105] with an excellent cell permeability, thereby showing potential applications in biological systems.

Although few sensors have been reported for sulfite anions, dual-channel chemosensors for the detection of hydrogen sulfite are quite limited, and hence as an emerging approach, Xiaohong et al. designed a series of compounds possessing electron-donating thiophene moieties attached to triphenylamine (TPA) with aldehyde groups. Only probe 71, having ethylene dioxy-thiophene and a thiophene group, could exhibit spectral changes in the UVVis spectra along with a notable color change from yellow to colorless for $\mathrm{HSO}_{3}{ }^{-}$ions. Furthermore, it was found that probe 71 could selectively detect $\mathrm{HSO}_{3}{ }^{-}$ions over other anions, which was evident by the color change from yellowish-green to blue, attributable to the nucleophilic addition of the aldehyde to hydrogen sulfite resulting in aldehyde-hydrogen sulfite adduct [106] (Scheme 54), thereby tuning the ICT efficiency, and this mechanism was corroborated by ESI-MS spectra. The detection limit was determined to be low as $0.9 \mu \mathrm{M}$, which was indicative of the higher sensitivity of the probe towards $\mathrm{HSO}_{3}{ }^{-}$anions.

\section{Hypochlorite}

Hypochlorite is widely being used in industries and households as an effective cleaning agent to remove stains and whiten clothes, disinfectants, and air fresheners. One of the most potent oxidizing agents is sodium hypochlorite, which is mainly used as a bactericide to treat drinking water and eliminate foul odors. The residual reactive chlorine formed during the disinfection of water can form disinfection
Scheme 55 Suggested mechanism of probe $\mathbf{7 2}$ in response to $\mathrm{ClO}^{-}$ions
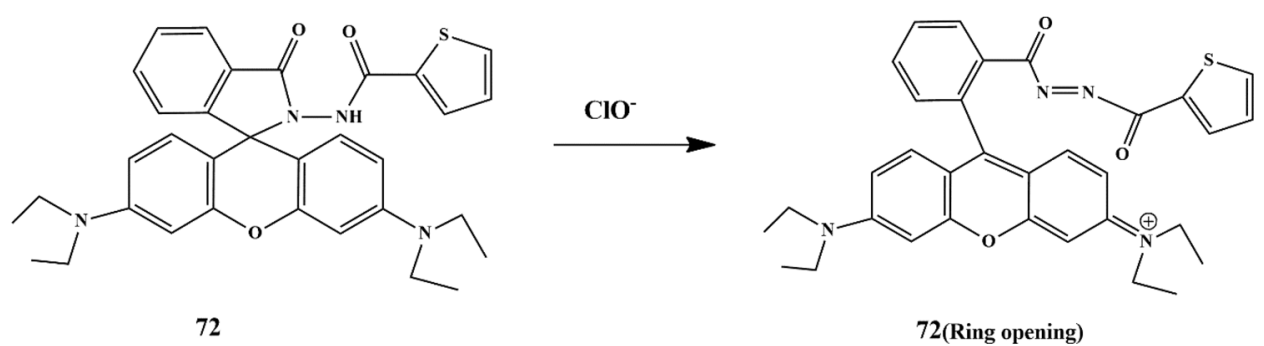
Scheme 56 Suggested mechanism of probe $\mathbf{7 4}$ in response to Acetate ions<smiles>O=[N+]([O-])c1ccc([N+](=O)[O-])c([N+](=O)[O-])c1</smiles>

74

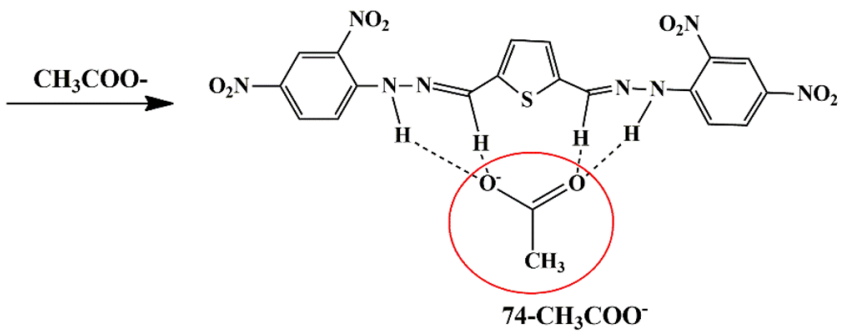

by-products such as trihalomethanes, known to be carcinogenic. Additionally, hypochlorite toxicity can induce oxidation damage of the extracellular components, consequently leading to Arthritis, respiratory disorders, cancer. Concerning the danger of $\mathrm{ClO}^{-}$ions, it is crucial to keep a track of hypochlorite ions in aqueous and biological samples.

Ying et al. designed a fluorometric and colorimetric probe 72 based on rhodamine-B fluorophore and thiophene-2carbohydrazide. An instant 'naked-eye' color change of the probe in Tris- $\mathrm{HCl}$ buffer solution, from colorless to pink, and the appearance of red fluorescence $\left(\lambda_{\text {excitation }}=365 \mathrm{~nm}\right)$ under UV light, upon the addition of $\mathrm{ClO}^{-}$ions was indicative of the ring-opening reaction of the spirolactam of rhodamine (Scheme 55). Besides, a new absorption peak and fluorescence peak at $556 \mathrm{~nm}$ and $578 \mathrm{~nm}$ emerged, which further suggested that $\mathrm{ClO}^{-}$could persuade a ring-opening reaction of rhodamine moiety, verified by HRMS spectra. Hypochlorite titration experiments were also performed, in which the probe exhibited spectral changes with increasing concentrations of $\mathrm{ClO}^{-}$ions along with deepened color change. It exhibited a fast response time of $10 \mathrm{~s}$ with a detection limit of $7 \mu \mathrm{mol} / \mathrm{L}$. Furthermore, the practical application of the probe was tested for aqueous samples by filter paper strips, which showed a color change upon detection of $\mathrm{ClO}^{-}$ions. It was also observed that probe $\mathbf{7 2}$ could be used for fluorescent bioimaging and mitochondrial targeting [107] of HeLa cells, thereby being an effective tool for monitoring $\mathrm{ClO}^{-}$ions.

\section{Thiocyanate}

Thiocyanate is pervasive and abundantly found in the extracellular fluids of mammals and enters into the body primarily from the diet. Thiocyanate serves various applications as additives or starting materials for dye synthesis, chemical tracers and finds applications in textiles and manufacturing industries. However, thiocyanate toxicity symptoms have been related to the nervous system, such as motor impairment, anxiety, thyroid gland disorders such as hypothyroidism, skin, and kidneys. Despite the prevailing circumstances, the development of chemosensors for $\mathrm{SCN}^{-}$detection is minimal.

One successful attempt was the probe 73 [4-methyl2,6-bis((thiophen-2-ylmethylimino)methyl)phenol], developed by Sudipta et al. for $\mathrm{SCN}^{-}$detection. The absorption spectrum of free probe in $\mathrm{H}_{2} \mathrm{O} / \mathrm{CH}_{3} \mathrm{OH}$ (v/v 1:4, HEPES buffer) solution exhibited two intense peaks at $350 \mathrm{~nm}$, and $450 \mathrm{~nm}$, which gradually diminished and increased respectively, upon the addition of $\mathrm{SCN}^{-}$ions and this is attributable to the $\mathrm{CH}=\mathrm{N}$ isomerization. Furthermore, the fluorescence emission intensity enhanced along with a blue shift upon $\mathrm{SCN}^{-}$addition and the detection of $\mathrm{SCN}^{-}$was not affected by other bio-relevant anions. The $\mathrm{SCN}^{-}$recognition could be ascribed to the Hydrogen bond formation [108] between probe $\mathbf{7 3}$ and $\mathrm{SCN}^{-}$ion and 1:1 stoichiometry were proposed. The probe's LOD for $\mathrm{SCN}^{-}$was found to be 0.88 $\mu \mathrm{mol} / \mathrm{L}$ with a quick response time $(<5 \mathrm{~min})$.
Scheme 57 Suggested mechanism of sensor 75/76 in response to Acetate ions
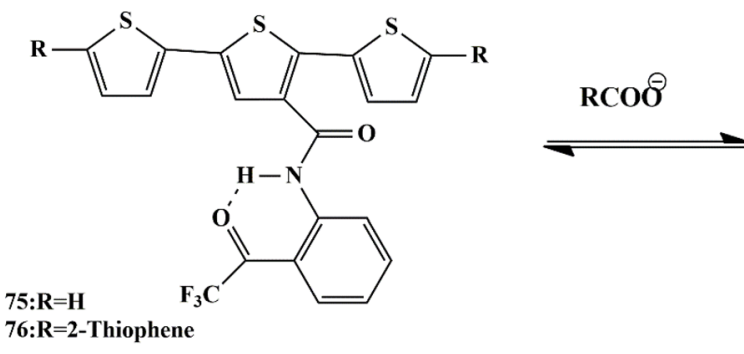

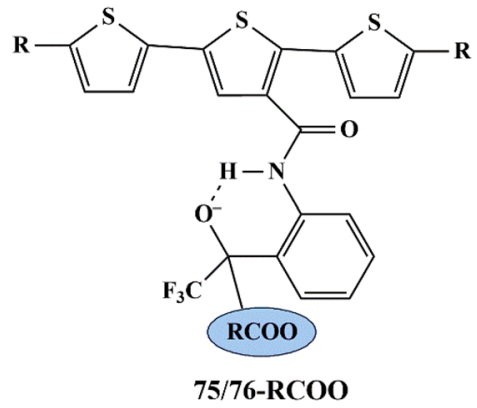


Table 1 Different chemosensors with the ions detected, detection limits and applications

\begin{tabular}{|c|c|c|c|}
\hline Chemosensors & Ions detected & LOD & Applications \\
\hline 1 & $\mathrm{Al}^{3+}$ & $0.41 \mu \mathrm{M}$ & $\begin{array}{l}\text { Used as biocompatible detector for } \mathrm{Al}^{3+} \text { in Biological systems (HeLA } \\
\text { cells) }\end{array}$ \\
\hline 2 & & $8.92 \times 10^{-8} \mathrm{M}$ & Evaluation of drinking water quality \\
\hline 3 & $\mathrm{In}^{3+}$ & $0.61 \mu \mathrm{M}$ & Sensing of $\mathrm{In}^{3+}$ \\
\hline 4 & & $0.36 \mu \mathrm{M}$ & - \\
\hline 5 & & - & Sensing of $\mathrm{Hg}^{2+}$ in Cosmetics \\
\hline 6 & $\mathrm{Hg}^{2+}$ & $1.34 \mu \mathrm{M}$ & \\
\hline 7 & & $0.32 \mu \mathrm{M}$ & - \\
\hline 8 & & $2.2 \times 10^{-8} \mathrm{M}$ & \\
\hline 9 & & $0.01 \mu \mathrm{M}$ & \\
\hline 10 & $\mathrm{Hg}^{2+}$ and $\mathrm{Cu}^{2+}$ & $28 \mu \mathrm{M}$ and $7.5 \mu \mathrm{M}$ & $\begin{array}{l}\text { Detection of } \mathrm{Hg}^{2+} \text { and } \mathrm{Cu}^{2+} \text { in protein medium (BSA), Dalton's } \\
\text { Lymphoma cells (DL), in contaminated water samples and test } \\
\text { strips and explored as coding/decoding fluorescent blue security ink } \\
\text { and construction of molecular logic gate. }\end{array}$ \\
\hline 11 & $\mathrm{Hg}^{2+}$ & $20 \mu \mathrm{M}$ & Sensing of $\mathrm{Hg}^{2+}$ in partially aqueous medium \\
\hline 12 & $\mathrm{~Pb}^{2+}$ & - & - \\
\hline 13 & $\mathrm{Cr}^{3+}$ & $0.4 \mu \mathrm{M}$ & Sensing of $\mathrm{Cr}^{3+}$ on circular test papers \\
\hline 14 & $\mathrm{~Pb}^{2+}$ and $\mathrm{Hg}^{2+}$ & - & - \\
\hline 15 & $\mathrm{Cr}^{3+}$ & $1.5 \times 10^{-6} \mathrm{M}$ & Detection of $\mathrm{Cr}^{3+}$ in wastewater samples \\
\hline \multirow[t]{3}{*}{16} & $\mathrm{Cr}^{3+}$ & $2.6 \times 10^{-6} \mathrm{M}$ & Detection of $\mathrm{Cr}^{3+}$ in live HeLa cells \\
\hline & $\mathrm{Cu}^{2+}$ & $1.01 \times 10^{-6} \mathrm{M}$ & - \\
\hline & $\mathrm{CN}^{-}$ & $9.3 \times 10^{-7} \mathrm{M}$ & - \\
\hline 17 & $\mathrm{Zn}^{2+}$ & - & $\begin{array}{l}\text { Construction of logic gate for selective potential and biological } \\
\text { sensing of } \mathrm{Zn}^{2+}\end{array}$ \\
\hline 18 & & $1.51 \times 10^{-7} \mathrm{M}$ & Designing of molecular logic operation for $\mathrm{Zn}^{2+}$ detection \\
\hline 19 & $\mathrm{Zn}^{2+}$ and $\mathrm{Hg}^{2+}$ & $3.7 \mu \mathrm{M}$ and $4.8 \mu \mathrm{M}$ & Intracellular probe for dual sensing of ions \\
\hline 20 & $\mathrm{Zn}^{2+}$ & - & Biosensing of $\mathrm{Zn}^{2+}$ in living cells. \\
\hline 21 & & $0.423 \mathrm{nM}$ & Bio-probe for $\mathrm{Cu}^{2+}$ detection in bio-imaging and bio-labeling research \\
\hline 22 & $\mathrm{Cu}^{2+}$ & $1.8 \mu \mathrm{M}$ & Detection of $\mathrm{Cu}^{2+}$-Fluorescence imaging in vivo \\
\hline 23 & & $0.85 \mu \mathrm{M}$ & Colorimetric detection of ammonia and response to $\mathrm{pH}$ effect. \\
\hline 24 & & $2.8 \times 10^{-6} \mathrm{M}$ & Detection of $\mathrm{Cu}^{2+}$ ions in environmental water samples \\
\hline 25 & $\mathrm{Cd}^{2+}$ & $2.0 \times 10^{-7} \mathrm{M}$ & Detection of $\mathrm{Cd}^{2+}$ ions in environmental water samples \\
\hline 26 & $\mathrm{Cu}^{2+}$ & $0.217 \mu \mathrm{M}$ & Quantification of $\mathrm{Cu}^{2+}$ in food and water samples \\
\hline 27 & $\mathrm{CuCl}_{2}$ & - & - \\
\hline 28 & $\mathrm{Ag}^{+}$ & $1.28 \times 10^{-7} \mathrm{M}$ & $\begin{array}{l}\text { Live-cell fluorescence imaging for } \mathrm{Ag}^{+} \text {detection and monitoring } \mathrm{Ag}^{+} \\
\text {ions in natural water samples }\end{array}$ \\
\hline 29 & & $8.18 \times 10^{-9} \mathrm{M}$ & - \\
\hline 30 and 31 & $\mathrm{Ca}^{2+}$ & - & - \\
\hline 32 & $\mathrm{Zr}^{4+}$ & $16.99 \mu \mathrm{M}$ & Live cell imaging of $\mathrm{Zr}^{4+}$ ions \\
\hline 33 & $\mathrm{Fe}^{3+}$ & $1.6 \times 10^{-8} \mathrm{M}$ & $\begin{array}{l}\text { Construction of field test kit for qualitative analysis of } \mathrm{Fe}^{3+} \text { and } \\
\text { formulation of INHIBIT gate }\end{array}$ \\
\hline 34 & $\begin{array}{l}\mathrm{Fe}^{2+} \\
\mathrm{Ni}^{2+} \\
\mathrm{Cu}^{2+}\end{array}$ & $\begin{array}{l}2.977 \times 10^{-6} \mathrm{M} \\
0.895 \times 10^{-6} \mathrm{M} \\
0.593 \times 10^{-6} \mathrm{M}\end{array}$ & Rapid detection of multiple ions \\
\hline 35 & $\mathrm{Fe}^{3+}$ and $\mathrm{Fe}^{2+}$ & $0.51 \mu \mathrm{M}$ and $1.51 \mu \mathrm{M}$ & Quantification of $\mathrm{Fe}^{3+}$ in water samples \\
\hline 36 & $\mathrm{Fe}^{3+}$ & $3.74 \mu \mathrm{mol} / \mathrm{L}$ & $\begin{array}{l}\text { Detection of } \mathrm{Fe}^{3+} \text { in living cells with good membrane permeability } \\
\text { and less toxicity }\end{array}$ \\
\hline 37 & $\mathrm{Hg}^{2+}$ and $\mathrm{Fe}^{3+}$ & $3.52 \times 10^{-8} \mathrm{M}$ and $5.0 \times 10^{-8} \mathrm{M}$ & Analytical quantification of $\mathrm{Hg}^{2+}$ and $\mathrm{Fe}^{3+}$ in water samples \\
\hline 38 & $\mathrm{Co}^{2+}$ and $\mathrm{Cu}^{2+}$ & $0.19 \mu \mathrm{M}$ for $\mathrm{Co}^{2+}$ & Determination of $\mathrm{Co}^{2+}$ and $\mathrm{Cu}^{2+}$ in drinking and tap water samples \\
\hline 39 & & $0.88 \mu \mathrm{M}$ and $0.14 \mu \mathrm{M}$ & - \\
\hline 40 and 41 & $\mathrm{Pd}^{2+}$ & $49 \times 10^{-9} \mathrm{M}$ and $44 \times 10^{-9} \mathrm{M}$ & Detection of $\mathrm{Pd}^{2+}$ using TLC strips \\
\hline
\end{tabular}


Table 1 (continued)

\begin{tabular}{|c|c|c|c|}
\hline Chemosensors & Ions detected & LOD & Applications \\
\hline 42 & & $0.89 \mu \mathrm{M}$ & $\begin{array}{l}\text { Qualitative detection of } \mathrm{CN}^{-} \text {ions in drinking and mineral water using } \\
\text { test strips }\end{array}$ \\
\hline 43 & & $44.6 \mu \mathrm{M}$ & Selective detection of $\mathrm{CN}^{-}$by fluorescent turn-on method \\
\hline 44 & & $0.32 \mu \mathrm{M}$ & $\begin{array}{l}\text { Real-time monitoring of } \mathrm{CN}^{-} \text {in aqueous media and also employed as } \\
\text { DNA-detection agent. }\end{array}$ \\
\hline 45 & $\mathrm{CN}^{-}$ & - & Biomedical applications for sensing $\mathrm{CN}^{-}$at lower concentrations. \\
\hline 46 & & $4.24 \times 10^{-8} \mathrm{M}$ & $\begin{array}{l}\text { Real-time monitoring of } \mathrm{CN}^{-} \text {ions in aqueous solution and } \\
\text { fluorescence imaging of live cells. }\end{array}$ \\
\hline 47 & & $51 \mathrm{nM}$ & $\begin{array}{l}\text { Detection of low levels of } \mathrm{CN}^{-} \text {in drinking water and bio-imaging to } \\
\text { detect these ions }\end{array}$ \\
\hline 48 and 49 & & $0.019 \mu \mathrm{M}$ and $0.02 \mu \mathrm{M}$ & - \\
\hline 50 & $\mathrm{~F}^{-}$ & - & Detection of $\mathrm{F}^{-}$in the presence of competing anions. \\
\hline 51 & $\mathrm{CN}^{-}, \mathrm{F}^{-}$and $\mathrm{AcO}^{-}$ & - & Ratiometric sensing of anions \\
\hline 52 and 53 & $\mathrm{~F}^{-}$and $\mathrm{CN}^{-}$ & $0.04 \mathrm{ppm}$ and $0.07 \mathrm{ppm}$ & Solid state detection ability of $\mathrm{F}^{-}$and $\mathrm{CN}^{-}$using test strip analysis \\
\hline 54 and 55 & $\mathrm{~F}^{-}$ & - & - \\
\hline 56 & & $6.9 \times 10^{-7} \mathrm{M}$ & $\begin{array}{l}\text { Real-time monitoring of } \mathrm{F}^{-} \text {ions by construction of logic gate and } \\
\text { molecular switches. }\end{array}$ \\
\hline 57 & & $2.02 \times 10^{-7} \mathrm{M}$ & Detection of $\mathrm{F}^{-}$by test-strip method \\
\hline 58 and 59 & & - & Potential luminescent chemosensors \\
\hline $61,62,63$ & & - & Promising candidates for $\mathrm{F}^{-}$detection \\
\hline 64 & $\mathrm{I}^{-}$ & $1.7 \times 10^{-7} \mathrm{M}$ & Qualitative analysis of $\mathrm{I}^{-}$in aqueous samples \\
\hline 65 & $\mathrm{~F}^{-}, \mathrm{Cl}^{-}, \mathrm{Br}^{-}, \mathrm{I}^{-}$ & - & - \\
\hline 66 & $\mathrm{I}^{-}$ & - & DNA quantification by the formation of nanostructured networks \\
\hline 67 & $\mathrm{HSO}_{3}^{-}$ & - & Detection of exogenous and endogenous $\mathrm{HSO}_{3}{ }^{-}$ions in vivo \\
\hline 68 and 69 & & - & Detection of $\mathrm{HSO}_{3}{ }^{-}$in water samples \\
\hline 70 & $S^{2-}$ & $354 \mathrm{nM}$ & Efficacious bio probe for detecting $\mathrm{S}^{2-}$ intracellularly \\
\hline 71 & $\mathrm{HSO}_{3}^{-}$ & $0.9 \mu \mathrm{M}$ & - \\
\hline 72 & $\mathrm{ClO}^{-}$ & $7 \mu \mathrm{mol} / \mathrm{L}$ & $\begin{array}{l}\text { Employed in fluorescent bioimaging and mitochondrial targeting of } \\
\text { HeLa cells }\end{array}$ \\
\hline 73 & $\mathrm{SCN}^{-}$ & $0.88 \mu \mathrm{mol} / \mathrm{L}$ & - \\
\hline 74 & $\begin{array}{l}\mathrm{F}^{-}, \mathrm{AcO}^{-} \text {and } \\
\mathrm{H}_{2} \mathrm{PO}_{4}^{-}\end{array}$ & - & Qualitative estimation of $\mathrm{F}^{-}$and $\mathrm{AcO}^{-}$in toothpaste and vinegar \\
\hline 75 and 76 & $\mathrm{RCOO}^{-}$ & - & $\begin{array}{l}\text { These chemosensors could be further explored in biomolecules for } \\
\text { Carboxylate anion detection. }\end{array}$ \\
\hline
\end{tabular}

Although diverse, efficient colorimetric sensors have been reported for anion detection and sensing, their applicability towards the real specimens or samples, is still limited. In this regard, Sivalingam et al. synthesized a thiophenebased dihydrazone derivative probe $\mathbf{7 4}$ to detect anions in an organic and aqueous medium. Among all anions, the probe exhibited strong affinity towards $\mathrm{F}^{-}, \mathrm{AcO}^{-}$and $\mathrm{H}_{2} \mathrm{PO}_{4}{ }^{-}$ions in DMSO/ $\mathrm{H}_{2} \mathrm{O}$ (v/v 10:0 \& v/v 9:1), evident by a visual color change from orange to violet and yellow to brown in aqueous and organic medium, respectively, along with a strong absorption band at $590 \mathrm{~nm}$. Probe 74 gains importance in sensing $\mathrm{AcO}^{-}$in any form such as TBA acetate, transition metal acetate, and sodium acetate in the aqueous medium. The sensing mechanism can be assigned to the hydrogen bond formation between $\mathrm{N}-\mathrm{H}$ and $\mathrm{AcO}^{-}$ions (Scheme 56) with a 1:1 stoichiometry binding mode [109] for all receptor-anion complex. Ultimately, the probe could qualitatively estimate $\mathrm{F}^{-}$and $\mathrm{AcO}^{-}$in real samples such as commercially available toothpaste and vinegar samples by colorimetric technique.

Oligothiophenes have excellent photophysical properties, such as their intrinsic fluorescence and simplistic polymerization properties, due to which it has received considerable attention. Despite their advantageous properties, small efforts have been put forward for the development of oligothiophene-based fluorescent chemosensors. One such great effort was put forth by Dae et al., who reported efficient turn-on oligothiophenebased fluorescent chemosensors (75 and 76) for the detection and sensing of carboxylate anions with a binding mode of 1:1 stoichiometry. Both sensors exhibited fluorescence quenching in $\mathrm{CH}_{3} \mathrm{CN}$ due to the $\mathrm{n}-\pi *$ transition of the trifluoroacetophenone group. In contrast, they exhibited remarkable fluorescence 
enhancement for $\mathrm{CN}^{-}, \mathrm{AcO}^{-}, \mathrm{F}^{-}$, and $\mathrm{H}_{2} \mathrm{PO}_{4}^{-}$, among which the selectivity of probe $\mathbf{7 5}$ was highest for $\mathrm{AcO}^{-}$, evident by a slight bathochromic shift. The fluorescence enhancement could be accounted for due to Carbonyl adduct formation, supported by H-NMR and F-NMR studies, and the sensing mechanism was through the elimination of $n-\pi^{*}$ transition and presence of intramolecular Hydrogen bonding [110] (Scheme 57) which enhances the conformational rigidity of the adduct, thereby promoting fluorescence enhancement. Therefore, these highly efficient fluorescence turn-on chemosensors could be further explored in biomolecules for Carboxylate anion detection.

Chemosensors have been a powerful tool pertaining to its ease of use, reliability and practical applicability. High selectivity and sensitivity of the chemosensors is achieved by introducing various moieties to the fluorophore core system. In the current review, we have listed out thiophene based fluorescent and colorimetric chemosensors (Table 1) along with their detection of ions, LOD and their applications.

\section{Conclusions}

There is ever-growing research on the design, synthesis, and improvement in the sensitivity and detection of the various ions in the environmental and biological systems. Thiophene-based fluorometric probes have become an essential tool in detecting anions, cations, and neutral molecules because of their significant characteristics such as extended emission and absorption wavelengths, vast absorption co-efficient, and more fluorescence quantum yield. Consideration of the reviewed data shows that thiophene moiety in combination with other heterocycles has achieved significant interest. The sensing of molecules can be done when thiophene is used as a fluorophore moiety or a signaling unit to behave as a fluorescent "Turn off" or "Turn On" chemosensor, when combined with other heterocycles, during the detection of analytes of interest. Although, the substitution needs to be carefully selected in order to obtain excellent results as well as take the benefit of the optical and chelating properties of the probe. The mechanism of sensing of various cations and anions and the reversibility of the interaction mechanism has also been reviewed.

Author Contribution Rikitha Sharyl Fernandes: Collection of data and drafting the manuscript. Nitinkumar Sudhakar Shetty: Design of the work, drafting and critical review. Priyanka Mahesha: Fine tuning and data analysis. Santhosh Laxman Gaonkar: Data interpretation and review.

Funding Open access funding provided by Manipal Academy of Higher Education, Manipal.

\section{Declarations}

Ethics Approval Not applicable.

Consent to Participate Not applicable.

Consent for Publication We will give our full consent for publication.

Conflicts of Interest/Competing Interests The authors declare that there is no conflict of interest.

Open Access This article is licensed under a Creative Commons Attribution 4.0 International License, which permits use, sharing, adaptation, distribution and reproduction in any medium or format, as long as you give appropriate credit to the original author(s) and the source, provide a link to the Creative Commons licence, and indicate if changes were made. The images or other third party material in this article are included in the article's Creative Commons licence, unless indicated otherwise in a credit line to the material. If material is not included in the article's Creative Commons licence and your intended use is not permitted by statutory regulation or exceeds the permitted use, you will need to obtain permission directly from the copyright holder. To view a copy of this licence, visit http://creativecommons.org/licenses/by/4.0/.

\section{References}

1. Pal A, Bag B (2014) A rhodamine based off-on probe for selective detection of $\mathrm{Hg}$ (II) and subsequent L-proline and 4-hydroxyproline discrimination. RSC Advances 4(20):10118-10122

2. Choi J-H et al (2019) $\mathrm{Al}^{3+}$-Morpholine-appended Anthracene Ensemble as a Dual Photonic Switch for $\mathrm{H}_{2} \mathrm{PO}_{4}{ }^{-}$and $\mathrm{CN}^{-}$ Ions and its Biological Applications. Bull Korean Chem Soc 40(2):138-145

3. Lee D, Youn N, Singh, Jang DO (2010) A benzimidazolebased single molecular multianalyte fluorescent probe for the simultaneous analysis of $\mathrm{Cu}^{2+}$ and $\mathrm{Fe}^{3+}$. Tetrahedron Lett 51(7):1103-1106

4. Gupta A, Garg S, Singh H (2020) Development of chalcone based derivatives for sensing applications. Anal Methods

5. Tigreros A, Portilla J (2020) Recent progress in chemosensors based on pyrazole derivatives. RSC Advances 10(33): 19693-19712

6. Phillips JA et al (2011) Using azobenzene incorporated DNA aptamers to probe molecular binding interactions. Bioconjug Chem 22(2):282-288

7. Hulanicki A, Glab S, Ingman FO (1991) Chemical sensors: definitions and classification. Pure Appl Chem 63(9):1247-1250

8. Musib D et al (2020) A New Thiophene-based Aggregationinduced Emission Chemosensor for Selective Detection of $\mathrm{Zn}^{2+}$ Ions and Its Turn Off. Chem Lett 49(5):473-476

9. Czarnik AW (1992) Fluorescent chemosensors for ion and molecule recognition. American Chemical Society, Washington, DC

10. Daly B, Ling J, Prasanna De Silva A (2015) Current developments in fluorescent PET (photoinduced electron transfer) sensors and switches. Chem Soc Rev 44(13):4203-4211

11. De Silva A, Prasanna et al (1997) Signaling recognition events with fluorescent sensors and switches. Chem Rev 97(5):1515-1566

12. Fan L-J et al (2009) Fluorescent conjugated polymer molecular wire chemosensors for transition metal ion recognition and signaling. Coord Chem Rev 253(3-4):410-422 
13. Formica M et al (2012) New fluorescent chemosensors for metal ions in solution. Coord Chem Rev 256(1-2):170-192

14. Qian $Y$ et al (2015) A highly selective chemosensor for nakedeye sensing of nanomolar $\mathrm{Cu}$ (II) in an aqueous medium. RSC Adv 5(95):77965-77972

15. Jeong H, Young et al (2017) Thiophene and diethylaminophenolbased turn-on fluorescence chemosensor for detection of $\mathrm{Al}^{3+}$ and $\mathrm{F}^{-}$in a near-perfect aqueous solution. Tetrahedron 73(18):2690-2697

16. Rasmussen SC, Sean J, Evenson, Casey B, McCausland (2015) Fluorescent thiophene-based materials and their outlook for emissive applications. Chem Commun 51(22):4528-4543

17. Cheng X et al (2012) Fluorescent and Colorimetric Probes for Mercury (II): Tunable Structures of Electron Donor and $\pi$-Conjugated Bridge. Chemistry-A European Journal 18(6):1691-1699

18. Barbarella G, Melucci M, Sotgiu G (2005) The versatile thiophene: an overview of recent research on thiophene-based materials. Adv Mater 17(13):1581-1593

19. Crisponi $\mathrm{G}$ et al (2012) Chelating agents for human diseases related to aluminium overload. Coord Chem Rev 256(1-2):89-104

20. Cronan CS, Walker WJ, Bloom PR (1986) Predicting aqueous aluminium concentrations in natural waters. Nature 324(6093):140-143

21. Rangasamy M, Palaninathan K (2019) Thiophene and furan appended pyrazoline based fluorescent chemosensors for detection of $\mathrm{Al}^{3+}$ ion. Inorg Chem Commun 101:177-183

22. Cho H, Chae JB, Kim C (2018) A thiophene-based bluefluorescent emitting chemosensor for detecting indium (III) ion. Inorg Chem Commun 97:171-175

23. Presti M, Lo et al (2016) Selective chromo-fluorogenic detection of trivalent cations in aqueous environments using a dehydration reaction. New J Chem 40(11):9042-9045

24. Di Natale F et al (2006) Capture of mercury ions by natural and industrial materials. J Hazard Mater 132(2-3):220-225

25. Kim H, Na et al (2012) Fluorescent and colorimetric sensors for detection of lead, cadmium, and mercury ions. Chem Soc Rev 41(8):3210-3244

26. Aragay G, Pons J, Arben, Merkoçi (2011) Recent trends in macro-, micro-, and nanomaterial-based tools and strategies for heavy-metal detection. Chem Rev 111(5):3433-3458

27. Nolan EM, Stephen J, Lippard (2008) Tools and tactics for the optical detection of mercuric ion. Chem Rev 108(9):3443-3480

28. Zhang Q et al (2017) A novel near-infrared chemosensor for mercury ion detection based on DA structure of triphenylamine and benzothiadiazole. Tetrahedron 73(19):2824-2830

29. Feng L, Deng Y, Wang X, Liu M (2017) Polymer fluorescent probe for $\mathrm{Hg}$ (II) with thiophene, benzothiazole and quinoline groups. Sens Actuators B 245:441-447

30. Kaewtong $\mathrm{C}$ et al (2014) Optical chemosensors for $\mathrm{Hg}^{2+}$ from terthiophene appended rhodamine derivatives: FRET based molecular and in situ hybrid gold nanoparticle sensors. New $\mathbf{J}$ Chem 38(8):3831-3839

31. Pal A, Bag B (2012) Hg (II) ion specific dual mode signalling in a thiophene derivatized rhodamine based probe and their complexation cooperativity. J Photochem Photobiol A Chem 240:42-49

32. Cho H, Chae JB, Kim C (2019) Cinnamaldehyde-Based Chemosensor for Colorimetric Detection of $\mathrm{Cu}^{2+}$ and $\mathrm{Hg}^{2+}$ in a NearPerfect Aqueous Solution. ChemistrySelect 4(9):2795-2801

33. Razi SS et al (2016) Phenyl-end-capped-thiophene (PT type) based ICT fluorescent probe (D- $\pi-\mathrm{A}$ ) for detection of $\mathrm{Hg}^{2+}$ and $\mathrm{Cu}^{2+}$ ions: Live cell imaging and logic operation at molecular level. J Photochem Photobiol A 324:106-116

34. Singhal D, Gupta N, Singh AK (2015) Chromogenic naked eye and fluorogenic turn on sensor for mercury metal ion using thiophene-based Schiff base. RSC Adv 5(81):65731-65738
35. Deo S, Godwin HA (2000) A selective, ratiometric fluorescent sensor for $\mathrm{Pb} 2+$. J Am Chem Soc 122(1):174-175

36. Rifai $\mathrm{N}$ et al (1993) Incidence of lead poisoning in young children from inner-city, suburban, and rural communities. Ther Drug Monit 15(2):71-74

37. Varnes AW, Barry R, Dodson, Wehry EL (1972) Interactions of transition-metal ions with photoexcited states of flavines. Fluorescence quenching studies. J Am Chem Soc 94(3):946-950

38. McClure, Donald S (1952) Spin-orbit interaction in aromatic molecules. J Chem Phys 20(4):682-686

39. Cao J et al (2011) A highly selective fluorescence chemosensor for $\mathrm{Pb}$ (II) in neutral buffer aqueous solution. Supramol Chem 23(11):777-781

40. Gomez V, Callao MP (2006) Chromium determination and speciation since 2000. TrAC Trends Anal Chem 25(10):1006-1015

41. KarakuS E (2020) An anthracene based fluorescent probe for the selective and sensitive detection of Chromium (III) ions in an aqueous medium and its practical application. Turk J Chem 44(4):941-949

42. Laurenti M et al (2013) Detection of heavy metal ions using a water-soluble conjugated polymer based on thiophene and meso-2, 3-dimercaptosuccinic acid. Polym Int 62(5):811-816

43. Kolcu F, Erdener D, Kaya İ (2020) A Schiff base based on triphenylamine and thiophene moieties as a fluorescent sensor for $\mathrm{Cr}$ (III) ions: Synthesis, characterization and fluorescent applications. Inorganica Chim Acta 509:119676

44. Vijay $\mathrm{N}$ et al (2017) A triple action chemosensor for $\mathrm{Cu}^{2+}$ by chromogenic, $\mathrm{Cr} 3+$ by fluorogenic and $\mathrm{CN}$ - by relay recognition methods with bio-imaging of HeLa cells. Photochem Photobiol Sci 16(9):1441-1448

45. Pradhan A, Bikash et al (2015) A highly selective fluorescent sensor for zinc ion based on quinoline platform with potential applications for cell imaging studies. Polyhedron 94:75-82

46. Frederickson CJ, Koh J-Y, Ashley I, Bush (2005) The neurobiology of zinc in health and disease. Nat Rev Neurosci 6(6):449-462

47. Dey $S$ et al (2019) An antipyrine based fluorescence turn-on dual sensor for $\mathrm{Zn} 2+$ and $\mathrm{Al}^{3+}$ and its selective fluorescence turn-off sensing towards 2, 4, 6-trinitrophenol (TNP) in the aggregated state. Photochem Photobiol Sci 18(11):2717-2729

48. Rotterdamseweg LB (2017) Chemical properties of zinc-Health. effects of zinc-Environmental effects of zinc.

49. Mazumdar $P$ et al (2017) Proton induced green emission from AIEE active 2, 2' biquinoline hydrosol and its selective fluorescence turn-on sensing property towards $\mathrm{Zn}^{2+}$ ion in water. Sens Actuators B 238:1266-1276

50. Yan X et al (2017) Low-affinity zinc sensor showing fluorescence responses with minimal artifacts. Inorg Chem 56(8):4332-4346

51. Li L, Liu F, Li HW (2011) Selective fluorescent probes based on $\mathrm{CN}$ isomerization and intramolecular charge transfer (ICT) for zinc ions in aqueous solution. Spectrochim Acta Part A Mol Biomol Spectrosc 79(5):1688-1692

52. Sun $F$ et al (2011) Aqueous fluorescence turn-on sensor for $\mathrm{Zn}^{2+}$ with a tetraphenylethylene compound. Org Lett 13(24):6378-6381

53. Mathew MM, Sreekanth A (2021) $\mathrm{Zn}^{2+}$ ion responsive fluorescent chemosensor probe of Thiophene-diocarbohydrazide derivatives. Inorg Chim Acta 516:120149

54. Mahapatra A, Kumar et al (2017) Carbazole-driven ratiometric fluorescence turn on for dual ion recognition of $\mathrm{Zn}^{2+}$ and $\mathrm{Hg}^{2+}$ by thiophene-pyridyl conjugate in HEPES buffer medium: spectroscopy, computational, microscopy and cellular studies. Supramol Chem 29(3):215-228

55. Zhang B et al (2012) Cell-Compatible Fluorescent Chemosensor for $\mathrm{Zn}^{2+}$ based on a 3, 8-Extended 1,10-Phenanthroline Derivative. Eur J Inorg Chem 2012(24):3844-3851 
56. Dai X et al (2014) Amino-functionalized mesoporous silica modified glassy carbon electrode for ultra-trace copper (II) determination. Anal Chim Acta 848:25-31

57. Suganya S, Velmathi S, Davoodbasha, MubarakAli (2014) Highly selective chemosensor for nano molar detection of $\mathrm{Cu} 2+$ ion by fluorescent turn-on response and its application in living cells. Dyes Pigm 104:116-122

58. He G et al (2018) Synthesis and application of a highly selective copper ions fluorescent probe based on the coumarin group. Spectrochim Acta Part A Mol Biomol Spectrosc 190:116-120

59. Barnham KJ, Masters CL, Ashley I, Bush A (2004) Neurodegenerative diseases and oxidative stress. Nat Rev Drug Discov $3(3): 205-214$

60. He G et al (2017) Design and synthesis of a fluorescent probe based on naphthalene anhydride and its detection of copper ions. Plos One 12(10):e0186994

61. Aysha TS et al (2019) Dual functional colorimetric and turnoff fluorescence probe based on pyrrolinone ester hydrazone dye derivative for $\mathrm{Cu}^{2+}$ monitoring and $\mathrm{pH}$ change. Dyes Pigm 170:107549

62. Tekuri V, Darshak R, Trivedi (2017) A new colorimetric chemosensors for $\mathrm{Cu}^{2+}$ and $\mathrm{Cd}^{2+}$ ions detection: application in environmental water samples and analytical method validation. Anal Chim Acta 972:81-93

63. Yin $\mathrm{P}$ et al (2020) A new thiophene-based dual functional chemosensor for ultrasensitive colorimetric detection of $\mathrm{Cu}^{2+}$ in aqueous solution and highly selective fluorimetric detection of $\mathrm{Al}^{3+}$ in living cells. J Photochem Photobiol A 389:112249

64. Nguyen T, Van Thi, and Young Jun Seo (2017) Highly sensitive fluorescent sensor targeting $\mathrm{CuCl}_{2}$ based on thiophene attached anthracene compound (TA). Tetrahedron Lett 58(10):941-944

65. Ratte HT (1999) Bioaccumulation and toxicity of silver compounds: a review. Environmental Toxicology Chemistry: An International Journal 18(1):89-108

66. Silver S (2003) Bacterial silver resistance: molecular biology and uses and misuses of silver compounds. FEMS MicroBiol Rev 27(2-3):341-353

67. Drake PL, Hazelwood KJ (2005) Exposure-related health effects of silver and silver compounds: a review. Ann Occup Hyg 49(7):575-585

68. Shelley WB, Shelley ED, Burmeister V (1987) Argyria: the intradermal photograph, a manifestation of passive photosensitivity. J Am Acad Dermatol 16(1):211-217

69. Bhuvanesh N et al (2018) Small molecule turn on fluorescent probe for silver ion and application to bioimaging. J Photochem Photobiol A 360:6-12

70. Shi H-X et al (2017) A novel self-assembled supramolecular sensor based on thiophene-functionalized imidazophenazine for dual-channel detection of $\mathrm{Ag}^{+}$in an aqueous solution. RSC Adv 7(84):53439-53444

71. Sahli R et al (2012) Thiophene-based electrochemically active probes for selective calcium detection. Electrochim Acta 63:228-231

72. Mahapatra A, Kumar et al (2013) First rhodamine-based off-on chemosensor with high selectivity and sensitivity for $\mathrm{Zr}^{4+}$ and its imaging in living cell. Sens Actuators B 183:350-355

73. Harsha K, Gavash et al (2020) Thiophene-phenylquinazoline probe for selective ratiometric fluorescence and visual detection of $\mathrm{Fe}(\mathrm{III})$ and turn-off fluorescence for $\mathrm{I}^{-}$and its applications. Photochem Photobiol Sci 19(12):1707-1716

74. Naik L et al (2012) A highly selective and sensitive thiophene substituted 1, 3, 4-oxadiazole based turn-off fluorescence chemosensor for $\mathrm{Fe}^{2+}$ and turn on fluorescence chemosensor for $\mathrm{Ni}^{2+}$ and $\mathrm{Cu}^{2+}$ detection. Mater Chem Phys 260:124063

75. Cao D et al (2019) Coumarin-based small-molecule fluorescent chemosensors. Chem Rev 119(18):10403-10519
76. Jang H, Jung et al (2017) A highly selective colorimetric chemosensor for sequential detection of $\mathrm{Fe}^{3+}$ and pyrophosphate in aqueous solution. Tetrahedron 73(47):6624-6631

77. Liu Y et al (2020) A selective N, N-dithenoyl-rhodamine based fluorescent probe for $\mathrm{Fe}^{3+}$ detection in aqueous and living cells. J Environ Sci 90:180-188

78. Sun T et al (2017) Novel oligothiophene-based dual-mode chemosensor: naked-eye colorimetric recognition of $\mathrm{Hg}^{2+}$ and sequential off-on fluorescence detection of $\mathrm{Fe}^{3+}$ and $\mathrm{Hg}^{2+}$ in aqueous media and its application in practical samples. Sens Actuators B 248:24-34

79. Li C-Y et al (2006) A fluorescent chemosensor for cobalt ions based on a multi-substituted phenol-ruthenium (II) tris (bipyridine) complex. Anal Chim Acta 580(2):143-148

80. Jang H, Jung TG, Jo, Kim C (2017) A single colorimetric sensor for multiple targets: the sequential detection of $\mathrm{Co}^{2+}$ and cyanide and the selective detection of $\mathrm{Cu}^{2+}$ in aqueous solution. RSC Adv 7(29):17650-17659

81. Rha C, Joo H, Lee, Kim C (2020) Simultaneous Detection of $\mathrm{Cu}^{2+}$ and $\mathrm{Co}^{2+}$ by a Water-Soluble Carboxamide-Based Colorimetric Chemosensor. ChemistrySelect 5(3):1103-1108

82. Kumar V et al (2020) Design and synthesis of new functionalized 8-(thiophen-2-yl)-1, 2, 3, 4-tetrahydroquinolines as turn-off chemosensors for selective recognition of $\mathrm{Pd}^{2+}$ ions. New J Chem 44(36):15559-15566

83. Esteves, Cátia IC et al (2016) Novel functionalised imidazobenzocrown ethers bearing a thiophene spacer as fluorimetric chemosensors for metal ion detection. Dyes Pigm 135:134-142

84. Batista, Rosa MF et al (2008) Synthesis and evaluation of bipendant-armed (oligo) thiophene crown ether derivatives as new chemical sensors. Tetrahedron Lett 49(46):6575-6578

85. Vennesland B et al (1981) Cyanide in Biology. Academic Press, London

86. Wen D, Deng X, Yu Y (2021) A novel indolium salt as a rapid colorimetric probe for cyanide detection in aqueous solution. Chem Pap 75(3): 1095-1102

87. Kim M, Seon et al (2019) A Novel Thiophene-Based Fluorescent Chemosensor for the Detection of $\mathrm{Zn}^{2+}$ and $\mathrm{CN}^{-}$: Imaging Applications in Live Cells and Zebrafish. Sensors 19(24):5458

88. Chemchem $\mathrm{M}$ et al (2018) A novel and synthetically facile coumarin-thiophene-derived Schiff base for selective fluorescent detection of cyanide anions in aqueous solution: Synthesis, anion interactions, theoretical study and DNA-binding properties. Tetrahedron 74(48):6897-6906

89. Mahapatra A, Kumar et al (2015) Ratiometric fluorescent and chromogenic chemodosimeter for cyanide detection in water and its application in bioimaging. RSC Adv 5(31):24274-24280

90. Zhao Y et al (2020) Triphenylamine-thiophene dyad as a Chemodosimeter for specific recognition of cyanide ions in aqueous solutions. Dyes Pigm 183:108713

91. Zheng Z-H et al (2017) A biocompatible colorimetric triphenylamine-dicyanovinyl conjugated fluorescent probe for selective and sensitive detection of cyanide ion in aqueous media and living cells. Sensors 17(2):405

92. Wang K et al (2016) Two fluorescence turn-on coumarin Schiff's base chemosensors for cyanide anions. Dyes Pigm 126:104-109

93. Wade CR et al (2010) Fluoride ion complexation and sensing using organoboron compounds. Chem Rev 110(7):3958-3984

94. Renuga D et al (2012) Novel thiophene based colorimetric and fluorescent receptor for selective recognition of fluoride ions. Tetrahedron Lett 53(38):5068-5070

95. Yanar U et al (2016) A fluorescent coumarin-thiophene hybrid as a ratiometric chemosensor for anions: Synthesis, photophysics, anion sensing and orbital interactions. J Mol Struct 1108:269-277 
96. Saini N et al (2019) Furan/thiophene-based fluorescent hydrazones as fluoride and cyanide sensors. J Photochem Photobiol A 385:112038

97. Vishwakarma $\mathrm{S}$ et al (2017) A multi writable thiophene-based selective and reversible chromogenic fluoride probe with dualNH functionality. Spectrochim Acta Part A Mol Biomol Spectrosc 170:191-197

98. Yadav P et al (2019) A pyrene-thiophene based probe for aggregation induced emission enhancement (AIEE) and nakedeye detection of fluoride ions. J Lumin 215:116704

99. Turkoglu, Gulsen ME, Cinar, Ozturk T (2017) Synthesis and Photophysical and Anion-Sensing Properties of TriarylboraneSubstituted Cross-Conjugated and Conjugated Thienothiophenes. Eur J Org Chem 2017(31):4552-4561

100. Turkoglu G, Cinar ME, Ozturk T (2017) Organoboron copolymers containing thienothiophene and selenophenothiophene analogues: optical, electrochemical and fluoride sensing properties. RSC Adv 7(37):23197-23207

101. Haque SA et al (2015) Colorimetric and optical discrimination of halides by a simple chemosensor. RSC Adv 5(48):38733-38741

102. Fonseca SM et al (2013) Selective Fluorescence Quenching in Cationic Fluorene-Thiophene Diblock Copolymers for Ratiometric Sensing of Anions. Macromol Rapid Commun 34(9):717-722

103. Chao J et al (2018) A pyrene-thiophene based fluorescent probe for ratiometric sensing of bisulfite and its application in vivo imaging. Sens Actuators B 272:195-202
104. Uchacz T et al (2019) Pyrazoline-based colorimetric and fluorescent probe for detection of sulphite. New J Chem 43(2):874-883

105. Kwan C-S et al (2020) Selective detection of sulfide in human lung cancer cells with a blue-fluorescent on-off-on benzimidazole-based chemosensor ensemble. Dalton Trans 49(17):5445-5453

106. Cheng X, He P, Zhong Z, Liang G (2016) Reaction-based probe for hydrogen sulfite: dual-channel and good ratiometric response. Luminescence 31(7):1372-1378

107. Xia Y et al (2018) A fluorometric and mitochondrion-targetable probe for rapid, naked-eye test of hypochlorite in real samples. Chin Chem Lett 29(10):1517-1520

108. Das $\mathrm{S}$ et al (2015) Visible light excitable $\mathrm{SCN}^{-}$selective fluorescence probe derived from thiophene. Chin J Chem 33(10):1173-1177

109. Suganya S, Park JS, Velmathi S (2014) Visual sensing of aqueous anions by $\mathrm{C} 2$-symmetric chemosensor and its application in real sample analysis. Sens Actuators B 190:679-684

110. Kim DS, Ahn KH (2008) Fluorescence turn-on sensing of carboxylate anions with oligothiophene-based o-(carboxamido) trifluoroacetophenones. J Org Chem 73(17):6831-6834

Publisher's Note Springer Nature remains neutral with regard to jurisdictional claims in published maps and institutional affiliations. 